\title{
Assessing the biometeorology of a newly established reclamation cover in Fort McMurray, Alberta
}

\author{
by \\ Sean Goodbrand
}

B.A. (Environmental Studies), Carleton University, Ottawa Ontario, Canada, 2009

\author{
A thesis submitted to \\ The Faculty of Graduate Studies and Research \\ In partial fulfillment of the requirements of the degree of \\ Master of Science \\ Department of Geography and Environmental Studies \\ Carleton University \\ Ottawa, Ontario
}

(C) Sean Christopher Goodbrand, 2009 


$\begin{array}{ll}\begin{array}{l}\text { Library and Archives } \\ \text { Canada }\end{array} & \begin{array}{l}\text { Bibliothèque et } \\ \text { Archives Canada }\end{array} \\ \begin{array}{l}\text { Published Heritage } \\ \text { Branch }\end{array} & \begin{array}{l}\text { Direction du } \\ \text { Patrimoine de l'édition }\end{array} \\ \begin{array}{l}\text { 395 Wellington Street } \\ \text { Ottawa ON K1A ON4 } \\ \text { Canada }\end{array} & \begin{array}{l}\text { 395, rue Wellington } \\ \text { Ottawa ON K1A ON4 } \\ \text { Canada }\end{array}\end{array}$

Your file Votre reférence

ISBN: 978-0-494-60203-4

Our file Notre référence

ISBN: 978-0-494-60203-4

NOTICE:

The author has granted a nonexclusive license allowing Library and Archives Canada to reproduce, publish, archive, preserve, conserve, communicate to the public by telecommunication or on the Internet, loan, distribute and sell theses worldwide, for commercial or noncommercial purposes, in microform, paper, electronic and/or any other formats.

The author retains copyright ownership and moral rights in this thesis. Neither the thesis nor substantial extracts from it may be printed or otherwise reproduced without the author's permission.
AVIS:

L'auteur a accordé une licence non exclusive permettant à la Bibliothèque et Archives Canada de reproduire, publier, archiver, sauvegarder, conserver, transmettre au public par télécommunication ou par l'Internet, prêter, distribuer et vendre des thèses partout dans le monde, à des fins commerciales ou autres, sur support microforme, papier, électronique et/ou autres formats.

L'auteur conserve la propriété du droit d'auteur et des droits moraux qui protège cette thèse. $\mathrm{Ni}$ la thèse ni des extraits substantiels de celle-ci ne doivent être imprimés ou autrement reproduits sans son autorisation.
In compliance with the Canadian Privacy Act some supporting forms may have been removed from this thesis.

While these forms may be included in the document page count, their removal does not represent any loss of content from the thesis.
Conformément à la loi canadienne sur la protection de la vie privée, quelques formulaires secondaires ont été enlevés de cette thèse.

Bien que ces formulaires aient inclus dans la pagination, il n'y aura aucun contenu manquant.

\section{Canadä}




\begin{abstract}
It is uncertain if the biophysical processes occurring in engineered reclamation covers mimic those of natural boreal ecosystems. To address this, micrometeorological fluxes of energy, water vapour and $\mathrm{CO}_{2}$ were measured using the eddy covariance technique atop an oilsands reclamation soil cover during its second year of regeneration.

Moist conditions during the 2008 growing season resulted in the majority of radiation being partitioned into latent heat, producing a mean Bowen ratio of $0.65 \pm 0.46$. The site exhibited a relatively low ratio of carbon gain to water loss, as the estimated water use efficiency of the reclamation site of $1.45 \mathrm{~g} \mathrm{C} \mathrm{kg}^{-1} \mathrm{H}_{2} \mathrm{O}$ was lower than other similar natural ecosystems.
\end{abstract}

A series of analyses pointed towards the atmospheric demand for water vapour being a primary driver of seasonal variations in evapotranspiration (ET), while evaporation from the soil is suggested to have contributed a significant portion of measured ET. 


\section{Acknowledgements}

I would like to express many thanks to my supervisor, Dr. Sean Carey, for first of all providing me with this opportunity and ensuring that it was an enjoyable experience, but most of all for being the most compatible supervisor I believe I could have found.

Funding from the Natural Sciences and Engineering Research Council of Canada and the Cumulative Environmental Management Association is gratefully acknowledged. A number of other people also deserve mention for their support throughout this process. I'd like to thank Dr. Elyn Humphreys for always making herself available and being more than happy to help with anything - be it Matlab or concept issues. Mike Treberg was not only responsible for all instrument calibration and setup, but also made himself available to provide timely technical support whenever needed. Special thanks are extended to Paul Moore, who went above and beyond all expectations in helping with the collection and processing of data. Supplementary data collection and management was provided by Sophie Kessler of O'Kane Consultants. Field support was provided by Dr. Carl Mendoza, Dan Heinrichs and Kristen Range of the University of Alberta. Christine Daly at Suncor was always quick to provide me with any information I needed regarding my site. It would be a shame to not mention my crew of peers at Carleton that were in for this ride with me. I always appreciated their timely beverage suggestions.

I'm deeply indebted to Mr. Ecko and Annie (my dogs), whose daily walks provided me with a chance to clear my head and get my thoughts in order for this thesis.

Lastly, and most importantly, I am ever grateful for my editor-in-chief, Elizabeth, who will be my loving wife before this is published, for without her support, patience and guidance I would never have found my way to this stage in the first place. 
Table of Contents:

Abstract ................................................. ii

Acknowledgements ..........................................

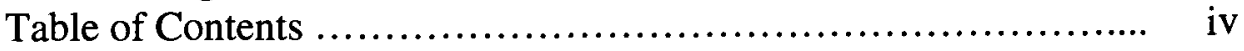

List of Tables ............................................... vi

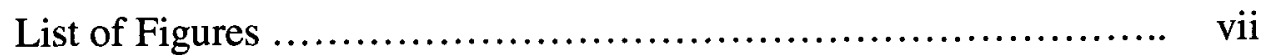

List of Symbols ........................................... xii

$\mathbf{1 . 0}$ Introduction $\ldots \ldots \ldots \ldots \ldots \ldots \ldots \ldots \ldots \ldots \ldots \ldots \ldots \ldots \ldots \ldots, 1$

2.0 Theoretical Framework $\ldots \ldots \ldots \ldots \ldots \ldots \ldots \ldots \ldots \ldots \ldots \ldots \ldots, 6$

2.1 Surface Energy Balance ................................ 6

2.2 Turbulent Transport ................................. 7

2.3 Eddy Covariance Principles .......................... 8

2.4 Big Leaf Concept $\ldots \ldots \ldots \ldots \ldots \ldots \ldots \ldots \ldots \ldots \ldots \ldots \ldots, 10$

3.0 Literature Review ....................................... 13

3.1 Geographical Context ................................. 13

3.2 Boreal Water Budget ................................ 14

3.3 Boreal Energy Balances .............................. 15

4.0 Methods ................................................. 20

4.1 Site Description ...................................... 20

4.2 Field Measurements .................................... 23

4.3 Supplementary Measurements ......................... 25

4.4 Data Quality Control .................................. 26

4.5 Flux Covariance Computations ........................ 30

4.6 Penman-Monteith Equation ............................. 31

4.7 Gap Filling ........................................ 32

4.8 Quality Assurance of Turbulence Measurements .......... 35

4.8.1 Adequate Sampling Period ....................... 35

4.8.2 Steady-State Test ................................. 37

4.8.3 Flux Variance Similarity Test .................... 39

4.8.4 Flux Footprint .................................... 41

4.9 Energy Balance Closure $\ldots \ldots \ldots \ldots \ldots \ldots \ldots \ldots \ldots \ldots \ldots \ldots . \quad 42$

5.0 Results and Discussion $\ldots \ldots \ldots \ldots \ldots \ldots \ldots \ldots \ldots \ldots \ldots \ldots, 47$

5.1 Climatic Conditions ................................. 47

5.1.1 Temperature ..................................... 47

5.1 .2 Precipitation .................................. 48

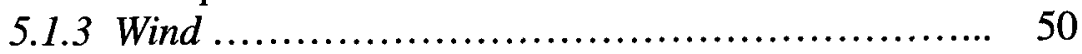

5.2 Surface Conditions .................................. 52

5.2 .1 Leaf Area Index ............................... 52

5.2 .2 Soil Moisture ...................................... 53

5.3 Water Balance ..................................... 57

5.4 Surface Energy Balance ................................ 60

5.4 .1 Albedo .......................................... 60

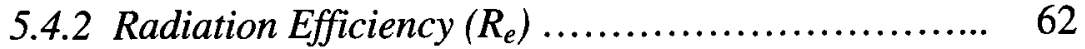

5.4 .3 Net Radiation $\left(R_{n}\right) \ldots \ldots \ldots \ldots \ldots \ldots \ldots \ldots \ldots \ldots \ldots . . . \ldots \ldots$ 
5.4 .4 Latent Heat Flux (LE) .......................... 65

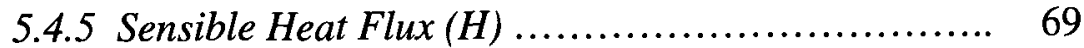

5.4.6 Ground Heat Flux $(G)$........................... 70

5.4.7 Seasonal and Diurnal Energy Partitioning .......... 72

5.5 Controls on ET ........................................ 77

5.5.1 Aerodynamic vs. Surface Conductance ............. 77

5.5 .2 Equilibrium Evaporation ....................... 78

5.5.3 Jarvis-McNaughton Decoupling Coefficient $(\Omega) \ldots \ldots \quad 82$

5.5 .4 ET Sensitivity Analysis ........................... 85

5.6 Controls on Surface Conductance ..................... 89

5.7 Carbon Balance ...................................... 93

5.7.1 Seasonal $\mathrm{CO}_{2}$ Flux ............................... 93

5.7.2 Diurnal $\mathrm{CO}_{2}$ Flux ................................. 95

5.8 Water Use Efficiency ................................ 97

6.0 Summary ................................................ 99

7.0 Concluding Remarks $\ldots \ldots \ldots \ldots \ldots \ldots \ldots \ldots \ldots \ldots \ldots \ldots \ldots \ldots, 101$

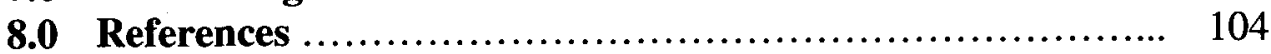




\section{List of Tables:}

\begin{tabular}{|c|c|}
\hline ble & \\
\hline 4.4 .1 & $\begin{array}{l}\text { Threshold values that potential spikes must exceed in each respective } \\
\text { variable's difference distributions before being identified as spikes and } \\
\text { removed. }\end{array}$ \\
\hline 4.4 .2 & $\begin{array}{l}\text { Summary of spike occurrence in half hourly time series data. Results are } \\
\text { displayed as percentage of all half hours }(n=6901) \text {, half hours with } \\
\text { precipitation (P) }(n=283) \text {, and periods with high relative humidity (RH) } \\
(n=608)\end{array}$ \\
\hline
\end{tabular}

4.4.3 The percentage of soft and hard flagged data based on skewness and kurtosis of all data $(n=6887)$, data during periods of instability $(n=3496)$ and during stable periods $(n=3301)$

Results of the steady-state test (Foken and Wichura, 1996) showing the percentage of total data $(n=6887)$ and from measurements taken during rain events $(n=283)$ both before and after rotation. Measurements were considered to be stationary if the difference between the means of $30 \mathrm{~min}$ and $6 * 5$ min covariances was less than $30 \%$

4.8.4 Summary of Dyke 11A South flux footprint results calculated online using the footprint model created by Kljun et al. (2004).

Parameterizations are derived from the measured mean standard deviation of vertical velocity fluctuations $\left(\sigma_{\mathrm{w}}\right)$ and surface friction velocity $\left(\mathrm{u}_{*}\right) \pm$

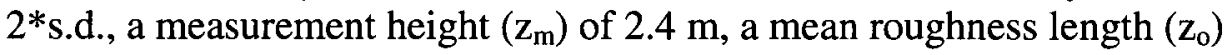
of $0.04 \mathrm{~m}$, and estimated values of typical planetary boundary layer heights $\left(\mathrm{h}_{\mathrm{PBL}}\right)$ for each stability regime. Results show the range of distance of maximum flux contribution $\left(\mathrm{X}_{\max }\right)$ and the estimated distance that contributes $80 \%$ to the flux

$\left(\mathbf{R}_{80}\right)$

5.1 Comparison of mean monthly temperatures and total precipitation during the 2008 field season with Environment Canada's 1971 - 2000 climate normals (CN.)

5.4 Monthly changes in daily $(0900-1700)$ mean atmospheric conditions and site characteristics throughout the growing season and their influence on energy partitioning at Dyke 11A South. Soil suction $\left(\Psi_{m}\right)$ represents the mean $\Psi_{\mathrm{m}}$ in the $0.25 \mathrm{~m}$ soil cover. Bowen ratio $(\beta)$ was calculated from daily averages of $H / L E$ for each month. The partitioning of $R_{n}$ into $\mathrm{H}, \mathrm{LE}$, and $\mathrm{G}$ was calculated from the ratio of the sums of gapfilled flux data within respective month. Shaded brackets denote \pm 1

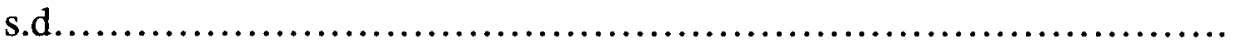




\section{List of Figures:}

4.1 Overhead view of Dyke 11A South (outlined in yellow in bottom photo) at the Suncor Millennium mine. The location of the EC tower is indicated by the star in the bottom photograph

4.7.1 Ecosystem respiration curve generated with Eq. 4.7.2 (Drewitt et al., 2002) using half-hour measurements of dry canopy nighttime values of $\mathrm{R}(n=374)$ after excluding periods with insufficient friction velocity $\left(\mathrm{u}_{*}<0.25 \mathrm{~m} \mathrm{~s}^{-1}\right)$. The model indicates that the fractional change in the rate of $\mathrm{R}$ at Dyke 11A South has a $\mathrm{Q}_{10}$ of 2.01

4.7.2 Mean daily GEP light response curve generated with Equation 4.7.2 (Amiro et al., 2006) $\left(\mathrm{r}^{2}=0.41\right)$. GEP values used in the model $(n=$ 972) were taken from half-hour measurements of dry canopy daytime $(0900-1700)$ conditions after excluding periods with insufficient friction velocity $\left(\mathrm{u} *<0.25 \mathrm{~m} \mathrm{~s}^{-1}\right)$.

4.8.1 Ogive plot generated from a series of ' $\mathrm{w}^{\prime} \mathrm{T}$ ' cospectra measured on June 10 (DOY 162). Each curve represents 6 hrs of high frequency measurements and are centered on the hours running from 1100 to 1700 , thus covering the period from $0800-2000$. Negligible increases in the cumulative cospectrum of each ogive occurs at $0.003 \mathrm{~Hz}$, indicating that 30 min was a suitable sampling period for EC measurements

4.8.3 Integral turbulence characteristic (ITC) $\left(\varphi_{\mathrm{w}}=\sigma_{\mathrm{w}} / \mathrm{u} *\right)$ versus stability $(\zeta$ ) using the modeled parameters of Foken and Wichura (1996). Mean \pm 1 s.d. of ITC are indicated by circles and error bars, while the modeled similarity function and 30\% cutoff range are shown as solid and dashed lines, respectively....

4.9.1 Energy balance closure calculated as the slope of all half hour measurements of $(\mathrm{H}+\mathrm{LE}) /(\mathrm{Rn}-\mathrm{G})$ forced through zero during similar periods of surface friction velocity ( $u *-$ top panel) and stability $(\zeta=(\mathrm{z}-\mathrm{d}) / \mathrm{L}-$ bottom panel). The grey vertical bars represent the proportion of half hour measurements that occur within each bin of $u_{*}$ and $\zeta$ ranges, using a minimum of twenty values in each bin. The dotted line in each panel represents a closure error of $-20 \%$

4.9.2 Relation of mean surface friction velocity $(\mathrm{u} *)$ and energy budget closure calculated from the linear regression of $(\mathrm{H}+\mathrm{LE}) /(\mathrm{Rn}-\mathrm{G})$ forced through zero for half hour measurements between May $10-$ October 8 (DOY 131 - 282). Results correspond to wind directions binned into $18^{\circ}$ sectors, with vertical bars representing the proportion of half hour wind direction measurements that occur within each bin. Error bars in the top panel show \pm 1 s.d. of the mean $u_{*}$ for each wind direction sector. The dotted line in the bottom panel represents a closure error of $-20 \%$ 
5.1.1 Time series showing (A) the diurnal variation in mean air temperature $\left(\mathrm{T}_{\mathrm{a}}\right)$ and $(\mathrm{B})$ soil temperature $\left(\mathrm{T}_{\mathrm{s}}\right)$ measured at a depth of $0.05 \mathrm{~m}$, as well as (C) the difference between them $\left(T_{a}-T_{s}\right)$ during the 2008 growing season at Dyke 11A South. The seasonal trend of $T_{a}$ and $T_{s}$ is highlighted (solid line) using a $2^{\text {nd }}$ order polynomial regression $\left(\mathrm{r}^{2}=\right.$ 0.40 for $T_{a} ; r^{2}=0.71$ for $T_{s}$ ) with $95 \%$ confidence intervals (dotted lines) in panels A and B. The shaded area in panel C indicates differences with respect to zero.

5.1.2 Percentage of rainfall events $(n=59)$ corresponding to half-hourly binned durations (Panel A) and $0.5 \mathrm{~mm} \mathrm{hr}^{-1}$ bins of rainfall intensity (Panel B)

5.1.3 Wind roses indicating (A) the seasonal patterns of wind direction and (B) mean wind direction associated with storm events. The values on the right of each of the inner and outer axes represent the number of recorded half-hour measurements within each $18^{\circ}$ bin interval (A) and in (B) represent the number of storm events that originated from each corresponding bin direction.

5.1.4 Seasonal variation in mean daily wind speed measured at Dyke 11A South...............................................................

5.2.1 Time series of mean leaf area index (LAI) measured at Dyke $11 \mathrm{~A}$ South during the 2009 field season. Measurements occurred approximately bi-weekly from May 10 - August 21 (DOY 131 - 234). Error bars indicate \pm 1 standard error

5.2.2 Seasonal variability of mean daily soil moisture content $\left(\theta_{\mathrm{s}}\right)$ during the 2008 growing season at Dyke $11 \mathrm{~A}$ South. $\theta_{\mathrm{s}}$ in the soil cover is separated into two separate panels to show the difference between the peat-mineral mix and the underlying sand. Total daily precipitation is also included to show the soil cover's response to rain events.

5.2.3 Seasonal variability of mean daily soil suction $\left(\Psi_{\mathrm{m}}\right)$ during the 2008 growing season at Dyke 11A South. $\Psi_{\mathrm{m}}$ in the soil cover is separated into two separate panels to show the difference between the peatmineral mix and the underlying sand. Total daily precipitation is also included to show the soil cover's response to rain events...

5.3 (A) Cumulative sum of precipitation (P) and evapotranspiration (ET) from May 10 - October 8 (DOY 131 - 282). (B) Cumulative inventory of all water balance components, including the cumulative change in soil moisture storage $(\Delta S)$ of the entire soil cover (measured to a depth of $0.8 \mathrm{~m}$ ). The shaded bars represent the difference between $\Delta \mathrm{S}$ and $\mathrm{P}-\mathrm{ET}$, indicating a net surplus of $40 \mathrm{~mm}$ of water by the end of the field study.

5.4.1 Seasonal variation of albedo, calculated as the mean $\mathrm{K} \uparrow / \mathrm{K} \downarrow$ between $1100-1500$ from DOY $131-282$ 
5.4.2 Seasonal variation of mean radiation efficiency $\left(R_{e}=R_{n} / K \downarrow\right)$, calculated between $1100-1500$ under clear sky conditions $\left(\mathrm{K} \downarrow \geq 0.8 * \mathrm{~K} \downarrow_{\max }, n=\right.$ 63) for Dyke 11A South during the 2008 growing season.

5.4.3 Seasonal variation of mean daily net radiation $\left(R_{n}\right)$ for Dyke 11A South during the 2008 growing season. Positive values of $R_{n}$ represent net flux towards the surface. The seasonal trend is highlighted (solid line) using a $2^{\text {nd }}$ order polynomial regression $\left(\mathrm{r}^{2}=0.43\right)$ with $95 \%$ confidence intervals (dotted lines).

5.4.4.1 Seasonal variation of daily mean $24 \mathrm{hr}$ latent heat flux (LE) for Dyke 11A South during the 2008 growing season. Positive values of LE represent heat flux directed away from the surface. The seasonal trend is highlighted (solid line) using a $2^{\text {nd }}$ order polynomial regression $\left(\mathrm{r}^{2}=\right.$ 0.35 ) with $95 \%$ confidence intervals (dotted lines)

5.4.4.2 Seasonal variation in the Bowen ratio $(\beta)$, calculated as the ratio of daytime (0900 - 1700) sums of $\mathrm{H}$ and LE. The dotted line represents

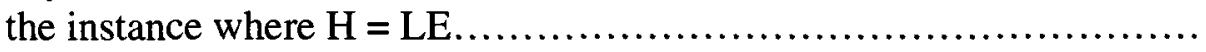

5.4.4.3 Advection effects of dry air shown by the variations in mean latent heat flux (LE) and vapour pressure deficit (D) with the associated changes in wind direction. Wind direction has been separated into 24 separate $15^{\circ}$ bins. The percentage of total half-hour measurements $(n=7337)$ is represented by shaded bars on the secondary y-axis in the bottom panel.

5.3.5 Time series of mean $24 \mathrm{hr}$ sensible heat flux $(\mathrm{H})$ for Dyke 11A South during the 2008 growing season. Positive values of $\mathrm{H}$ represent heat flux directed away from the surface. The seasonal trend is highlighted (solid line) using a $2^{\text {nd }}$ order polynomial regression $\left(r^{2}=0.12\right)$ with 95\% confidence intervals (dotted lines).

5.4.6 Seasonal variability of mean $24 \mathrm{hr}$ daily ground heat flux (G) for Dyke 11A South during the 2008 growing season. Positive values of $G$ represent heat flux into the ground (heat sink), while negative values represent $G$ as a heat source of energy into the atmosphere. $G$ is calculated as the heat flux measured at $0.05 \mathrm{~m}$ plus the heat storage in the soil above (Eq. 4.2.1). The seasonal trend is highlighted (solid line) using a $2^{\text {nd }}$ order polynomial regression $\left(\mathrm{r}^{2}=0.27\right)$ with $95 \%$ confidence intervals (dotted lines).

5.4.7 Mean daily variation of the partitioning of $R_{n}$ into the energy components H, LE and G from May 10 - September 30 (DOY 131 282). A summary of climatic and site conditions during each month is included in Table 6 
5.5.1 Comparison of variations in (A) aerodynamic conductance $\left(\mathrm{g}_{\mathrm{a}}\right)$ and (B) bulk surface conductance $\left(\mathrm{g}_{\mathrm{s}}\right)$ measured at Dyke 11A South during the 2008 growing season. Both panels represent mean daytime ( $0900-$ 1700 ) values, with $g_{a}$ being calculated using Eq. 4.8 .1 and $g_{s}$ found by inverting the $\mathrm{P}-\mathrm{M}$ equation

5.5.2.1 Time series of the mean daytime $(0900-1700 \mathrm{hrs})$ Priestley-Taylor $\alpha$ coefficient $\left(\alpha=\mathrm{LE} / \mathrm{LE} \mathrm{eq}_{\mathrm{eq}}\right)$ during wet (closed circles; $\left.n=59\right)$ and dry (open circles; $n=83$ ) canopy conditions from DOY $131-282$. The straight solid line represents $\alpha$ at unity, while the dotted line represents the empirically derived Priestley and Taylor (1972) coefficient $(\alpha=$ 1.26)

5.5.2.2 (A) Relationship between bulk surface conductance $\left(\mathrm{g}_{\mathrm{s}}\right)$ and the Priestley-Taylor $\alpha$ coefficient measured during dry canopy daytime (0900 - 1700) conditions from June 1 - August 31 (DOY 153 - 244) $(n$ $=37$ ) at Dyke 11A South. The best fit line represents the exponential form taken from Blanken et al., (1997). (B) Comparison of the mean response of $\alpha$ measured at Dyke 11A South with others found in the literature. The exponential line representing the boreal aspen forest (Blanken et al., 1997) is in the same form as this study, while that of the northern temperate grassland (Wever et al., 2002) is in the logarithmic

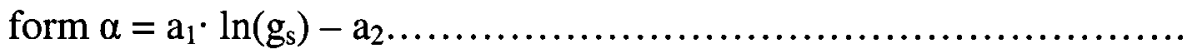

5.5.3.1 Variation of the dimensionless Jarvis-McNaughton decoupling coefficient $(\Omega)$ at Dyke 11A South during the 2008 growing season. Values of $\Omega$ were calculated during dry canopy daytime (0900 - 1700) conditions.....

5.5.3.2 Monthly changes in half-hourly mean daily variation of the decoupling coefficient $(\Omega)$ during dry canopy daytime $(0900-1700)$ conditions. Vertical bars indicate \pm 1 s.d.........................................

5.5.4.1 Seasonal variation of latent heat flux $(\mathrm{LE})$, available radiation $\left(\mathrm{R}_{\mathrm{a}}\right)$, vapour pressure deficit (D), bulk surface conductance $\left(g_{s}\right)$, volumetric soil water content $\left(\theta_{\mathrm{s}}\right)$ and leaf area index (LAI). Plotted values represent two week means calculated from dry canopy, daytime (0900 1700 ) conditions. Error bars represent \pm 1 standard error

5.5.4.2 Results from the ET sensitivity analysis showing total change in dry canopy daytime (0900 - 1700) ET rates in succeeding months as well as the portion of that change derived analytically from Eq. 5.2 due to changes in available energy $\left(R_{a}\right)$, vapour pressure deficit (D), surface conductance $\left(\mathrm{g}_{\mathrm{s}}\right)$. An imbalance term (lb) is also included to account for the assumption that $\gamma, \rho, s$ and $\mathrm{g}_{\mathrm{a}}$ remained constant................. 
5.6.1 Relationships between mean daily values of surface conductance $\left(\mathrm{g}_{\mathrm{s}}\right)$ with (A) vapour pressure deficit (D), (B) volumetric soil moisture $\left(\theta_{\mathrm{s}}\right)$ and (C) soil matric suction $\left(\Psi_{\mathrm{m}}\right)$. The results displayed in Panels B and $\mathrm{C}$ have been binned using measurements that correspond to being above and below the median $\mathrm{D}$ of $2.6 \mathrm{kPa}$. All values represent daily means from measurements taken during dry canopy daytime $(0900-1700)$ conditions from June 1 - August 31 (DOY 153 - 244) $(n=38) \ldots \ldots \ldots \ldots .90$

5.6.2 Example of half-hour measurements showing the response of (Panel D) surface conductance $\left(\mathrm{g}_{\mathrm{s}}\right)$ to (Panel $\mathrm{A}$ ) incident photosynthetic active radiation $(\mathrm{Q})$, (Panel $\mathrm{B})$ air temperature $\left(\mathrm{T}_{\mathrm{a}}\right)$ and $($ Panel $\mathrm{C})$ atmospheric vapour pressure deficit (D) from August 5-8 (DOY $218-221$ ). The time series corresponds with the progression towards the maximum seasonal $\mathrm{T}_{\mathrm{a}}\left(32.3^{\circ} \mathrm{C}\right)$ and $\mathrm{D}(4.8 \mathrm{kPa})$ on DOY 221 , as well as a period with a full soil moisture profile that was provided from $42 \mathrm{~mm}$ of rain that fell on August 2-3 (DOY 215-216)...

5.7.1 Seasonal variation of the mean daily carbon flux at Dyke 11A South during the 2008 growing season, encapsulating the contributions of respiration (R) and gross ecosystem productivity (GEP) to net ecosystem exchange (NEE). The conventional sign of GEP has been switched to a negative to illustrate uptake of $\mathrm{CO}_{2}$ during photosynthesis. The NEE trace has been shaded to elucidate the gain/loss of $\mathrm{CO}_{2}$ from the atmosphere, with positive/negative values indicating the surface $(0)$ as being a $\mathrm{CO}_{2}$ source/sink

5.7.2 Mean diurnal variation of half-hour measurements of net ecosystem exchange $(\mathrm{NEE}=-\mathrm{NEP})$ for the months May through September at Dyke 11A South during the 2008 growing season......................

5.8 Growing season gross ecosystem productivity (GEP) versus evapotranspiration (ET) (weekly averages) observed at Dyke 11A South. a denotes the intercept $\left(\mathrm{g} \mathrm{C} \mathrm{m}^{-2} \mathrm{~d}^{-1}\right)$ and b denotes the slope ( $\mathrm{g} \mathrm{C}$ $\mathrm{m}^{-2} \mathrm{~d}^{-1} \mathrm{~mm}^{-1} \mathrm{H}_{2} \mathrm{O} \mathrm{d}^{-1}$ or $\left.\mathrm{g} \mathrm{C} \mathrm{kg}{ }^{-1} \mathrm{H}_{2} \mathrm{O}\right)$, which describes the water use efficiency (WUE) of the canopy (Kljun et al., 2006).................. 98 


\section{List of Symbols}

\begin{tabular}{|c|c|c|}
\hline Symbols & Units & Description \\
\hline \multicolumn{3}{|l|}{ Greek } \\
\hline$\Delta_{\mathrm{x}}$ & units of $x$ & total change in an entity \\
\hline$\sum x$ & units of $x$ & sum of $x$ \\
\hline$\Psi_{\mathrm{m}}$ & $\mathrm{kPa}$ & soil matric suction \\
\hline$\Omega$ & & Jarvis-McNaughton decoupling coefficient \\
\hline$\alpha$ & & Priestly-Taylor coefficient, $\alpha=\mathrm{LE} / \mathrm{LE}_{\mathrm{eq}}$ \\
\hline$\beta$ & & Bowen ratio, $\beta=\mathrm{H} / \mathrm{LE}$ \\
\hline$\gamma$ & $\mathrm{g} \mathrm{m}^{-3}{ }^{\circ} \mathrm{C}^{-1}$ & psychrometric constant \\
\hline$\delta$ & & partial derivative change of an entity \\
\hline$\varepsilon$ & $\mathrm{W} \mathrm{m} \mathrm{m}^{-2}$ & residual flux density \\
\hline$\zeta$ & & stability parameter, $\zeta=(\mathrm{z}-\mathrm{d}) / \mathrm{L}$ \\
\hline$\theta_{\mathrm{fc}}$ & $\mathrm{m}^{3} \mathrm{~m}^{-3}$ & volumetric water content at field capacity \\
\hline$\theta_{\mathrm{s}}$ & $\mathrm{m}^{3} \mathrm{~m}^{-3}$ & volumetric water content \\
\hline$\theta_{v}$ & ${ }^{\circ} \mathrm{C}$ & virtual potential temperature \\
\hline$\theta_{\mathrm{wp}}$ & $\mathrm{m}^{3} \mathrm{~m}^{-3}$ & volumetric water content at wilting point \\
\hline$\lambda$ & $\mathrm{J} \mathrm{kg}^{-1}$ & latent heat of vaporization \\
\hline$\rho$ & $\mathrm{g} \mathrm{m}^{-3}$ & density \\
\hline$\sigma_{\mathrm{x}}$ & units of $x$ & standard deviation of variable $\mathrm{x}$ \\
\hline$\sigma_{x}^{2}$ & units of $x^{2}$ & variance of variable $x$ \\
\hline$\varphi_{w}$ & & integral turbulence characteristic, $\varphi_{\mathrm{w}}=\sigma_{\mathrm{w}} / \mathrm{u}_{*}$ \\
\hline$x_{c}$ & $\mu$ mol CO${ }_{2}$ mol $^{-1}$ moist air & $\mathrm{CO}_{2}$ mole fraction \\
\hline$\chi_{\mathrm{v}}$ & $\mathrm{mmol} \mathrm{H}_{2} \mathrm{O} \mathrm{mol}{ }^{-1}$ dry air & water vapour mole fraction \\
\hline$\chi_{w v}$ & $\mathrm{mmol} \mathrm{H}_{2} \mathrm{O}$ mol $^{-1}$ moist air & water vapour mole fraction \\
\hline$\psi_{\mathrm{h}}$ & & stability correction function for heat \\
\hline$\psi_{\mathrm{h}}$ & & stability correction function for momentum \\
\hline$\psi_{\mathrm{wp}}$ & $\mathrm{kPa}$ & matric suction at wilting point \\
\hline
\end{tabular}




\section{Roman}

\begin{tabular}{|c|c|c|}
\hline $\mathrm{A}_{\max }$ & & photosynthetic capacity at light saturation \\
\hline $\mathrm{C}$ & $\mathrm{g}$ & carbon \\
\hline $\mathrm{C}$ & $\mathrm{J} \mathrm{m}^{-3} \mathrm{~K}^{-1}$ & volumetric heat capacity of soil \\
\hline$C_{p}$ & $\mathrm{~J} \mathrm{~m}^{-3} \mathrm{~K}^{-1}$ & heat capacity of dry air \\
\hline $\mathrm{D}$ & $\mathrm{kPa}$ & vapour pressure deficit \\
\hline ET & $\mathrm{mm}$ & evapotranspiration \\
\hline $\mathrm{F}$ & $\mathrm{W} \mathrm{m} \mathrm{m}^{-2}$ & vertical flux \\
\hline $\mathrm{F}_{\mathrm{c}}$ & $\mu \mathrm{mol} \mathrm{m} \mathrm{m}^{-2}$ & $\mathrm{CO}_{2}$ flux density \\
\hline $\mathrm{G}$ & $\mathrm{W} \mathrm{m} \mathrm{m}^{-2}$ & ground heat flux density \\
\hline $\mathrm{H}$ & $\mathrm{W} \mathrm{m} \mathrm{m}^{-2}$ & sensible heat flux density \\
\hline $\mathrm{K} \downarrow$ & $\mathrm{W} \mathrm{m} \mathrm{m}^{-2}$ & incoming solar radiation flux density \\
\hline $\mathrm{K} \uparrow$ & $\mathrm{W} \mathrm{m} \mathrm{m}^{-2}$ & outgoing solar radiation flux density \\
\hline $\mathrm{K} \downarrow_{\max }$ & $\mathrm{W} \mathrm{m} \mathrm{m}^{-2}$ & maximum possible $\mathrm{K} \downarrow$ \\
\hline $\mathrm{L}$ & $\mathrm{m}$ & Monin-Obukhov scaling length \\
\hline $\mathrm{L} \downarrow$ & $\mathrm{W} \mathrm{m} \mathrm{m}^{-2}$ & incoming long-wave radiation flux density \\
\hline $\mathrm{L} \uparrow$ & $\mathrm{W} \mathrm{m}{ }^{-2}$ & outgoing long-wave radiation flux density \\
\hline LE & $\mathrm{W} \mathrm{m} \mathrm{m}^{-2}$ & latent heat flux density \\
\hline $\mathrm{LE}_{\mathrm{eq}}$ & $\mathrm{W} \mathrm{m}^{-2}$ & equilibrium latent heat flux density \\
\hline $\mathrm{LE}_{\mathrm{PM}}$ & $\mathrm{W} \mathrm{m} \mathrm{m}^{-2}$ & Penman-Monteith model estimate of LE \\
\hline M & $\mathrm{W} \mathrm{m} \mathrm{m}^{-2}$ & rate of change in soil heat storage in top $5 \mathrm{~cm}$ \\
\hline$M$ & & 5 minute covariance interval \\
\hline$N$ & & 3000 measurements at $10 \mathrm{~Hz}$ \\
\hline $\operatorname{Og}_{w t}\left(f_{0}\right)$ & & ogive curve \\
\hline $\mathrm{P}$ & $\mathrm{mm}$ & precipitation \\
\hline Q & $\mu \mathrm{mol} \mathrm{m} \mathrm{s}^{-1}$ & photosynthetic active radiation \\
\hline $\mathrm{Q}_{10}$ & & fractional change in $\mathrm{R}$ with a $10^{\circ} \mathrm{C}$ increase in $\mathrm{T}_{\mathrm{s}}$ \\
\hline $\mathrm{R}$ & $\mu \mathrm{mol} \mathrm{m} \mathrm{s}^{-1}$ & respiration \\
\hline $\mathrm{R}_{\mathrm{a}}$ & $\mathrm{W} \mathrm{m}^{-2}$ & available radiation flux density, $R_{a}=R_{n}-G$ \\
\hline $\mathrm{R}_{\mathrm{e}}$ & & radiation efficiency, $R_{e}=R_{n} / K \downarrow$ \\
\hline
\end{tabular}




\begin{tabular}{|c|c|c|}
\hline $\begin{array}{l}R_{n} \\
R_{\text {ref }}\end{array}$ & $\begin{array}{l}\mathrm{W} \mathrm{m}{ }^{-2} \\
\mu \mathrm{mol} \mathrm{m} \mathrm{m}^{-2} \mathrm{~s}^{-1}\end{array}$ & $\begin{array}{l}\text { net radiation flux density, } R_{n}=K \downarrow-K \uparrow+L \downarrow-L \uparrow \\
\text { reference respiration rate }\end{array}$ \\
\hline $\mathrm{R}_{80}$ & $\mathrm{~m}$ & distance that contributes $80 \%$ of flux footprint \\
\hline $\mathrm{RN}_{\mathrm{cov}}$ & & difference between $5 \& 30$ min covariance sets \\
\hline$S$ & $\mathrm{~mm}$ & soil moisture storage \\
\hline $\mathrm{T}_{\mathrm{a}}$ & ${ }^{\circ} \mathrm{C}$ & air temperature \\
\hline $\mathrm{T}_{\text {ref }}$ & ${ }^{\circ} \mathrm{C}$ & reference temperature in $Q_{10}$ relationship \\
\hline $\mathrm{T}_{\mathrm{s}}$ & ${ }^{\circ} \mathrm{C}$ & soil temperature \\
\hline$U$ & $\mathrm{~m} \mathrm{~s}^{-1}$ & mean wind speed \\
\hline $\mathrm{V}$ & $\mathrm{mm}$ & vertical drainage \\
\hline$X_{\max }$ & $\mathrm{m}$ & area of greatest contribution to flux footprint \\
\hline $\mathrm{X}^{*}$ & $\mathrm{~m} \mathrm{~s}^{-1}$ & test statistic for $\sigma_{w}$ \\
\hline$c_{1}, c_{2}$ & & coefficients of turbulence in ITC test \\
\hline$d$ & $\mathrm{~m}$ & zero-plane displacement \\
\hline $\mathrm{dT}$ & ${ }^{\circ} \mathrm{C}$ & raw change in measured $229-\mathrm{L}$ temperature \\
\hline$e_{a}$ & $\mathrm{kPa}$ & vapour pressure of air \\
\hline$e_{s}$ & $\mathrm{kPa}$ & vapour pressure at surface \\
\hline$f$ & $\mathrm{~Hz}$ & frequency \\
\hline$f_{0}$ & $\mathrm{~Hz}$ & highest frequency \\
\hline$g$ & $\mathrm{~m}^{2} \mathrm{~s}^{1}$ & acceleration due to gravity \\
\hline $\mathrm{g}_{\mathrm{a}}$ & $\mathrm{m} \mathrm{s}^{-1}$ & aerodynamic conductance \\
\hline$g_{s}$ & $\mathrm{~m} \mathrm{~s}^{-1}$ & surface conductance \\
\hline$h$ & $\mathrm{~m}$ & canopy height \\
\hline $\mathrm{h}_{\mathrm{PBL}}$ & $\mathrm{m}$ & height of planetary boundary layer \\
\hline $\mathrm{k}$ & & von Karman constant \\
\hline $\mathrm{lb}$ & & error term in ET sensitivity analysis \\
\hline$n$ & & sample number \\
\hline$r_{a}$ & $\mathrm{~s} \mathrm{~m}^{-1}$ & aerodynamic resistance \\
\hline$r_{s}$ & $\mathrm{~s} \mathrm{~m}^{1}$ & surface resistance \\
\hline $\mathrm{s}$ & $\mathrm{g} \mathrm{m}^{-3}$ & scalar concentration \\
\hline$s$ & $\mathrm{kPa} \mathrm{K}^{-1}$ & slope of the saturation vapour pressure curve \\
\hline
\end{tabular}




$\begin{array}{lll}\mathrm{t} & \mathrm{s}, \mathrm{min}, \mathrm{hr}, \text { day } & \text { time } \\ \mathrm{u} & \mathrm{m} \mathrm{s}^{-1} & \text { streamwise wind speed } \\ \mathrm{u} * & \mathrm{~m} \mathrm{~s}^{-1} & \text { friction velocity } \\ \mathrm{v} & \mathrm{m} \mathrm{s}^{-1} & \text { cross-stream wind speed } \\ \mathrm{w} & \mathrm{m} \mathrm{s}^{-1} & \text { vertical wind speed } \\ \mathrm{Z} & \mathrm{m} & \text { reference measurement height } \\ \mathrm{z}_{\mathrm{m}} & \mathrm{m} & \text { receptor heights } \\ \mathrm{z}_{\mathrm{O}} & \mathrm{m} & \text { roughness length } \\ \mathrm{z}_{\mathrm{o}, \mathrm{h}} & & \text { momentum roughness parameter for heat } \\ \mathrm{z}_{\mathrm{o}, \mathrm{m}} & & \text { momentum roughness length }\end{array}$

Abbreviations

CS

Campbell Scientific

$\mathrm{EC}$

Eddy covariance

GEP $\quad \mu \mathrm{mol} \mathrm{m} \mathrm{s}^{-2}$

Gross ecosystem productivity

IRGA

Infrared gas analyzer

ITC

Integral turbulence characteristic

LAI $\quad \mathrm{m}^{2} \mathrm{~m}^{-2}$

Leaf area index

M-O

Monin-Obukhov

$\mathrm{NaN}$

not a number

$\mathrm{NEE} \quad \mu \mathrm{mol} \mathrm{m} \mathrm{s}^{-2}$

Net ecosystem exchange

NEP $\quad \mu \mathrm{mol} \mathrm{m} \mathrm{m}^{-2}$

Net ecosystem productivity

P-M

Penman-Monteith

PET $\mathrm{mm}$

Potential evapotranspiration

RH $\% \quad$ Relative humidity

WUE $\mathrm{g} \mathrm{C} \mathrm{kg}^{-1} \mathrm{H}_{2} \mathrm{O}$ Water use efficiency

a.s.1. $\mathrm{m}$ above sea level

s.d.

standard deviation

s.e.

standard error

Subscripts

a

air / aerodynamic

c

carbon dioxide / canopy 
eq

h

$\mathrm{m}$

S

EC Operators

6 equilibrium

heat

momentum

surface / soil

overbar = mean used in eddy covariance flux computation

prime $=$ instantaneous deviation from the 30 min mean 


\subsection{Introduction}

Mining of the oil sands in Fort McMurray, Alberta has caused large-scale land disturbance and triggered significant ecosystem change, resulting in dramatic alterations in the energy and water balance of the boreal region. Alberta's Environmental Protection and Enhancement Act (2000) states that mining operators must return oil production sites to pre-disturbance land capability (Canadian Legal Information Institute, 2008) so that it may support a given land use (such as providing timber to the logging industry or habitat

for boreal species). Concerns arise because the soil in which the regenerating ecosystems grow, which is engineered from waste-rock and salvage material, may not sustain suitable reservoirs of moisture to promote rapid plant development and allow the regenerating ecosystem to follow a natural path of succession.

Following the process of strip-mining, which involves the removal of a salinesodic overburden in order to access the oil-bearing formation, waste material is placed back into the mined-out pits and capped with a soil cover. The finished constructed landforms are composed of uplands topography that is significantly different than the original boreal landscape, which consisted of a relatively flat mosaic of black sprucedominated forests and wetlands. Currently, the expansion of oil sands operations has already disturbed approximately $1200 \mathrm{~km}^{2}$, and it is projected that over $2000 \mathrm{~km}^{2}$ will have been mined by 2020 (Carey, 2008).

In an attempt to meet operational requirements and prepare for future expansion, several experimental watersheds have been established in the Fort McMurray region as part of a risk-based assessment of various reclamation strategies. These trials are set up to assess the ability of a range of soil covers, each composed of varying ratios of 
peat/mineral mixtures deposited with varying thicknesses, to sustain regeneration. Adequate soil depth and the associated water holding capacity of each cover is central to successfully providing sufficient moisture for rapid plant development and also for minimizing the upward diffusion of harmful salts from the underlying saline waste material (Hauser et al., 2001; Albright et al., 2004; Elshorbagy et al., 2005).

Due to the strong influence of the boreal forest on global climate (Baldocchi, 2003), many studies have examined the biophysical processes that occur in natural ecosystems in the region, including areas regenerating following fire and harvesting disturbances (Chambers and Chapin, 2003; Litvak and Miller, 2003; Amiro et al., 2006). However, few studies have investigated the ability of engineered soil covers to support regenerating ecosystems, or how these systems will respond to natural climate forcings (Swanson et al., 2003; Elshorbagy et al., 2005; Carey, 2008; Moore, 2008). As a result, it is uncertain whether or not the biophysical processes occurring in the early stages at reclamation sites mirror those of natural boreal ecosystems.

The following study has been undertaken in conjunction with Suncor Energy Inc. as part of a greater mission to identify the most feasible and effective means of rehabilitation. Of a series of experimental watersheds established in the Fort McMurray area, this study site, with a $0.25 \mathrm{~m}$ soil cover, represents the thinnest cover on trial and is thus a critical test for reclamation success. Therefore, this site may exemplify the lowest acceptable limits of reclamation measures needed to promote successful regeneration of disturbed areas. As the cost of soil covers increases with volume (Hauser et al., 2001), this site represents the most cost-effective reclamation option (minimal soil depth) for 
mining companies in the oil sands region. However, this soil cover also represents the system with the least available water holding capacity to provide for plant use.

With evapotranspiration (ET) being the largest consumer of summer precipitation in the sub-humid climate of Fort McMurray (Devito et al., 2005), the probability of cover failure at this site is thought to be elevated due to the possibility of high ET rates limiting soil moisture availability. As such, an understanding of the biophysical processes controlling ET will have a determining impact on the impending success/failure of this site and may even help regulators to identify what a 'reclaimed site' initially requires, as there is currently no such definition in Alberta's Environmental Protection and Enhancement Act (Canadian Legal Information Institute, 2008).

The 2008 growing season represents this site's second year of regeneration. As the abiotic and biotic parameters that control ET have been shown to differ within ecosystems of varying stand age and type (Baldocchi et al., 2000; Amiro et al., 2006), particular attention is paid to ET in this study to establish an understanding of the main water balance component of newly constructed reclamation sites. A detailed investigation of the temporal variations in ET rates and its governing factors provides insight into the regional climatic controls on ET, as well as other ecosystem components such as vegetation productivity and stand water dynamics (Humphreys et al., 2003).

Examining the efficiency at which this site is able to assimilate carbon at the expense of water use provides a means of gauging the productivity and overall health of the system. The original tree seedlings and shrubs that were planted, which included such $\mathrm{C}_{3}$ species as jack pine (Pinus banksiana), trembling aspen (Populus tremuloides), white birch (Betula papyrifera), rose (Rosa sp.) and raspberry (Rubus idaeus), among 
others, are competing against grasses and other weedy ruderal species that commonly colonize the nearby surrounding reclamation efforts. Successional vegetation structure at this site will ultimately be determined by how each plant species responds to the climatic and soil conditions, and may also be influenced by competition-driven water depletion (Tsialtas et al., 2001).

To evaluate the current state of the ecosystem, the eddy covariance technique has been employed in this study with the purpose of quantifying the turbulent exchange of energy and mass scalars $\left(\mathrm{H}_{2} \mathrm{O}\right.$ and $\left.\mathrm{CO}_{2}\right)$ between the atmosphere and surface. To facilitate an understanding of the processes controlling these exchanges and to assess the probability of a successful rehabilitation at this site, the primary objectives of this thesis are to:

i.) report on the magnitude and seasonal variability of mass and energy fluxes

ii.) monitor the drying rate and moisture availability in the soil

iii.) understand the environmental and biological controls on ET

iv.) compare the ecosystem-scale fluxes of energy, water and $\mathrm{CO}_{2}$ at this reclamation site with other natural ecosystems identified in the literature to determine if this system is functioning in a similar manner

Furthermore, this research helps to fill the gap in the literature pertaining to the unique biometeorology (the exchanges of heat, mass and momentum between the biosphere and atmosphere) of the initial stages of ecosystem establishment on engineered soil covers. An increased understanding of these regenerating ecosystems will allow for earlier detection of specific environmental indicators that may help to forecast the impending success or failure of reclamation efforts. Therefore, any mitigation strategies 
needed to prevent ecosystem collapse can be implemented earlier due to a greater awareness of the system ecohydrology (plant-water interactions). Early detection of problems is critical, as decades are needed to re-establish a mature forest at disturbed sites. It is therefore important for industry to create the most optimal conditions for ecosystem recovery, as oil sands development projects may be faced with increased opposition from regulators and the public if reclamation efforts are found to be unsustainable (Elshorbagy et al., 2005) 


\subsection{Theoretical Framework}

\subsection{Surface Energy Balance}

In an attempt to understand surface-atmospheric interactions, the two fundamental cycles of importance pertain to solar energy (heat) and water (mass). The classical approach when investigating any earth-atmosphere system is to conceptualize it as a process-response system, where the input of mass or energy is balanced by the sum of an output plus a change in storage (Eq. 2.1) (Oke, 1987), so that:

Input - Output - Storage Change $=0$

When the sun rises, the net radiation $\left(R_{n}\right)$ at the surface is either consumed by plants in the process of photosynthesis, is stored $(\Delta \mathrm{S})$ or is transferred away by either convection or conduction. Heat accumulated at the surface is removed and lifted by convection into the air through a sensible heat flux $(\mathrm{H})$. If the surface is moist however, latent heat flux (LE) will remove heat via either evaporation or transpiration (which combine as the components of ET). Heat can also be conducted by way of molecular diffusion into the ground, creating a ground heat flux (G) (Oke, 1987; Stull, 1997). The surface, therefore, responds by partitioning $R_{n}$ into the principal components of the surface energy balance (Eq. 2.2 - with all variables in $\mathrm{W} \mathrm{m}^{-2}$ ):

$$
\mathrm{K} \downarrow-\mathrm{K} \uparrow+\mathrm{L} \downarrow-\mathrm{L} \uparrow=\mathrm{Rn}=\mathrm{H}+\mathrm{LE}+\mathrm{G}+\Delta \mathrm{S}
$$

where $\mathrm{K}$ and $\mathrm{L}$ respectively refer to incoming and outgoing shortwave and long-wave radiation. When viewing the system in the aforementioned process-response framework, radiation serves as the external forcing (left side of equation) that produces $R_{n}$, and all the terms on the right side of the equation are responses. Conventionally, $R_{n}$ is positive when directed towards the surface, and the terms $\mathrm{H}, \mathrm{LE}$ and $\mathrm{G}$ are positive when directed away 
from the surface. Accumulation of energy within the system causes the storage term to be positive, while depletion of the energy store creates a negative sign. With regards to biometeorological measurements, $\Delta \mathrm{S}$ refers to the change in storage of energy between the measurement height and the surface.

The two convective forms of energy, $\mathrm{H}$ and LE, provide the principal means of transporting the energy surplus away from the surface (Oke, 1987). H is a function of the temperature gradient between the surface $\left(T_{s}\right)$ and the atmosphere $\left(T_{a}\right)$, while LE is a function of the vapour pressure difference between the surface $\left(e_{s}\right)$ and the atmosphere $\left(e_{a}\right)$. The ratio of these two flux terms is called the Bowen ratio ( $\beta$ ) (Eq. 2.3), a useful meteorological parameter that is written as:

$$
\beta=H / L E=\gamma\left(T_{s}-T_{a}\right) /\left(e_{s}-e_{a}\right) \quad(P e n m a n, 1948)
$$

where $\gamma$ is the psychrometric constant $\left(\mathrm{kPa} \mathrm{K}^{-1}\right)$. The Bowen ratio, which is governed by the temperature and the dryness of the surface, gives an indication of whether more energy is going into evaporation or into sensible heating (Priestley and Taylor, 1972). Typical values range from 5 (over deserts) to 0.5 (over grasslands) to 0.2 (over wellwatered grass) (Stull, 1997).

\subsection{Turbulent Transport}

Biometeorological measurements are conducted within the boundary layer, which is the bottom portion of the troposphere where depth fluctuates due to the diurnal changes in solar radiation. As the ground warms, rising thermals are set into turbulent motion due to the combined effects of flowing wind and frictional drag at the surface, producing turbulent eddies. Eddies are responsible for the transfer of energy (H and LE) and mass (water vapour and trace gases) within the boundary layer. The process of entropy 
produces a cascade of turbulent energy from large scale eddies, which can range from 100 to $3000 \mathrm{~m}$ in diameter (depending on the depth of the boundary layer), to smaller

scale eddies (on the order of a few $\mathrm{mm}$ ), until the energy dissipates to molecular viscosity at the laminar boundary layer of the surface-atmosphere interface. This study focuses on the micro-scale eddies with durations of approximately 10 seconds to 10 minutes, as these are responsible for the bulk of surface-atmosphere interactions that allow insight into the daily response of the surface to environmental changes within the boundary layer (Stull, 1997).

\subsection{Eddy Covariance Principles}

The EC technique employed in this research is an in situ, micrometeorological method of statistically measuring the exchange of scalars (mass and energy) between the biosphere and atmosphere. The exchange of these scalars is described as a vertical flux (F), where the mass and energy of an air parcel is transported vertically through a horizontal plane via turbulent eddies in the atmosphere. The EC technique implies the concepts of stationarity (statistically not changing over time) and ergodicity (where temporal ensemble statistics can be used to make inferences about spatial variability) to give a statistical description of the state of an ecosystem at any point in time (Baldocchi et al., 1988; Stull, 1997; Baldocchi 2003; Lee et al., 2004).

The theory behind EC is that the amount of a scalar being transported within a parcel of air co-varies at the same frequency and at proportional magnitudes with the vertical wind component of turbulent eddies. The EC equation is based on continuous, direct measurements, where the flux $(F)$ is calculated as the product of the average density of air $\left(\rho_{a}\right)$ and the covariance of instantaneous deviations (') from a 30 minute 
mean ( $)$ of the vertical velocity component of wind fluctuations (w') and scalar concentration fluctuations (s'), assuming the mean vertical velocity $(\bar{w})$ is negligible (Baldocchi et al., 1988; Baldocchi 2003). After applying the rules of Reynolds averaging to the mean and fluctuating parts of turbulence (Webb et al., 1980; Stull, 1997), the equation to determine the flux (Eq. 2.4) is written as:

$$
F=\overline{\rho_{a}} \cdot \overline{w^{\prime} s^{\prime}} \quad \text { (Eq. 2.4) }
$$

Three major assumptions are made in order for the theory of EC to hold true (Baldocchi, 2003):

i.) the surface beneath the EC tower consists of horizontally homogeneous terrain; ii.) there are no sources/sinks in the surface boundary layer for the flux of the measured entity;

iii.) there is no advection

The full aerial extent to which the EC flux measurements allegedly represent is known as the flux footprint, which is further determined by the mean horizontal wind speed, wind direction, and atmospheric stability (Baldocchi, 2003; Lee et al., 2004;). When air flows from rough to smooth surfaces, flux divergence will occur as the air in the boundary layer subsides and accelerates; similarly, the boundary layer will rise when a transition from a smooth to rough surface causes airflow to decelerate and converge. Horizontally homogeneous terrain prevents horizontal flux divergences/convergences and thus advection from occurring. In order to meet this criterion, flat, homogeneous land cover is required within the fetch or flux footprint of the upwind area. This ensures that the depth of the boundary layer is fully developed and will be greater than the height of the EC mast such that only the ecosystem of interest will have contributed to the energy 
and mass exchanges measured with the EC instrumentation (Stull, 1997; Baldocchi, 2003). The general rule when setting up the flux measurement tower is that $100 \mathrm{~m}$ of flat, homogeneous fetch is required for every $1 \mathrm{~m}$ that the instrumentation is situated above the effective surface (Baldocchi et al., 1988).

\subsection{Big Leaf Concept}

The stomata of leaves provide the pathway through which water contained within plants is released into the atmosphere during photosynthesis. When the stomata open in response to sunlight during the day, the degree of their openness is reduced when there is a limited supply of moisture in the soil and when the temperature of the plant is too high or too low (Monteith, 1981). Stomatal conductance, which refers to the ease with which water vapour diffuses through the stomata of transpiring plants, plays a primary role in governing the rates of ET (Monteith and Unsworth, 1990). In order to account for such a major control in the field, this study will employ the 'big leaf' concept, which scales up from the leaf to the canopy to treat the vegetated surface as a single, extensive isothermal leaf (Jarvis and McNaughton, 1986).

The Penman-Monteith (P-M) equation (Penman, 1948; Monteith, 1981) will be applied in this study in conjunction with the 'big leaf' concept in order to determine the role of surface conductance in partitioning the available energy $\left(R_{n}-G-\Delta S\right)$ in the system into $\mathrm{H}$ and LE. Monteith (1995) writes the P-M equation (Eq. 2.5) as:

$$
L E=\frac{s\left(R_{n}-G-\Delta S\right)+\rho C_{p} D g_{a}}{s+\gamma\left(1+\frac{g_{a}}{g_{s}}\right)}
$$

where $s$ is the slope of the saturation water vapour versus temperature curve $\left(\mathrm{kPa} \mathrm{K}^{-1}\right)$, $\rho c_{p}$ is the volumetric specific heat of air $\left(\mathrm{J} \mathrm{m}^{-3} \mathrm{~K}^{-1}\right), \mathrm{D}$ is the vapour pressure deficit 
$(\mathrm{kPa})$, and $\mathrm{g}_{\mathrm{a}}$ and $\mathrm{g}_{\mathrm{s}}$ are the aerodynamic and surface conductance to water vapor, respectively. As the EC technique provides direct measurements of LE (and hence ET) in the field, the P-M equation can be solved for $\mathrm{g}_{\mathrm{s}}$ such that diurnal and seasonal variations in $\mathrm{g}_{\mathrm{s}}$ can be analyzed (Monteith, 1995).

Equilibrium evaporation ( $\mathrm{LE}_{\text {eq }}$ ) (Eq. 2.6) is one limit to the P-M evaporation theory (Baldocchi et al., 2000). LE $E_{\text {eq }}$ occurs when a freely evaporating wet surface ( $\mathrm{g}_{\mathrm{s}} \rightarrow$ infinity) has completely saturated the atmosphere $(\mathrm{D} \rightarrow 0)$. Baldocchi et al. (2000) write this as:

$$
L E_{e q}=\frac{s}{s+\gamma}\left(R_{n}-G-\Delta S\right)
$$

Priestley and Taylor (1972) found that this value of ET - which only accounts for the effects of surface temperature, available energy and saturation vapour pressure - was often less than what was measured because it assumes winds are calm $\left(\mathrm{g}_{\mathrm{a}}=0\right)$. After acknowledging that advection of heat will further increase the rate of ET, they developed an empirically derived constant $(\alpha)$ of 1.26 to include in the equation to increase the potential magnitude of $\mathrm{LE}_{\text {eq. }}$. However, as the $\alpha$ of 1.26 usually only applies to wellwatered surfaces, it can be useful to calculate $\alpha$ (where $\alpha=\mathrm{LE} / \mathrm{LE}_{\mathrm{eq}}$ ) to indicate the role of $g_{s}$ in limiting LE during dry periods (Wilson and Baldocchi, 2000).

Lastly, in order to evaluate the coupling between the meteorological conditions at the surface of the 'big leaf' with those within the boundary layer, Jarvis and McNaughton (1986) developed the dimensionless decoupling coefficient $(\Omega)$ :

$$
\Omega=\frac{s / \gamma+1}{s / \gamma+1+g_{a} / g_{s}}
$$


Eq. 2.7 indicates that the assessment of $\Omega$ depends on the ratio between $\mathrm{g}_{s}$ and $\mathrm{g}_{\mathrm{a}}$, rather than their absolute values. Values of $\Omega$ range between 0 (for perfect coupling) and 1 (for complete isolation), indicating that the control of LE by surface resistance $\left(r_{s}=\right.$ $1 / \mathrm{g}_{\mathrm{s}}$ ) increases as $\Omega$ approaches zero (Wever et al., 2002). Typically, tall forest canopies result in large $g_{\mathrm{a}}$ that drives $\Omega$ to small values, while the shorter, aerodynamically smooth canopies of grasslands produce small $\mathrm{g}_{\mathrm{a}}$ that result in large $\Omega$ values. If soil conditions at the reclamation site were dry and D was large, a decrease in $g_{s}$ due to water-stressed vegetation would result in $\Omega$ also decreasing (Wilson and Baldocchi, 2000). 


\subsection{Literature Review}

\subsection{Geographical Context}

The boreal forest is the world's second largest biome, located in the latitudinal band of $50-70$ degrees north, covering an area of $12.0-14.7$ million $\mathrm{km}^{2}$. It is delineated by the $10-13^{\circ} \mathrm{C}$ July isotherm in the north, and by precipitation in the south, where it is bounded by temperate forests and grasslands. The landscape of the Canadian boreal region is very diverse, consisting of a mixture of deciduous broad-leaved forests, deciduous and evergreen conifer forests, wetlands and lakes. Precipitation is relatively low, ranging between $200-600 \mathrm{~mm}$ per year, of which approximately $30 \%$ falls as snow. The boreal region experiences extremely cold winters, warm summers and a short growing season (less than 120 days). Cold temperatures inhibit decomposition rates and nutrient cycling, resulting in what is typically a very young, thin and nutrient-poor soil (Baldocchi et al., 1997; Blanken et al., 1997; Baldocchi et al., 2000; Amiro et al., 2006).

The boreal growing season is dominated by extended hours of sunlight (up to 18 hours) with low sun angles which, when coupled with the low albedo (0.08) of the dark evergreen forest canopy, results in most of the incoming solar radiation being absorbed at the surface and becoming available for $\mathrm{H}$ and LE (Baldocchi et al., 2000). $\mathrm{H}$ and LE vary during the boreal growing season due to temporal variations in solar energy, soil and air temperature, soil moisture, leaf area and vegetation type. At deciduous sites after leaf emergence, substantially more energy typically goes into LE than $\mathrm{H}$, whereas in conifer sites the magnitude of $\mathrm{H}$ is generally greater than LE throughout the growing season (Baldocchi et al., 1997; Amiro et al., 2006). 
An increase in the magnitude of LE occurs early in the growing season, despite the deep soil profile being nearly frozen after the long, cold winter. Soil temperature is generally cooler than air temperature, as it is governed by the amount of radiation that is able to penetrate through the canopy to the ground. Throughout most of the growing season, the mean daily difference between the air and shallow soil temperature ranges between $0-5^{\circ} \mathrm{C}$. Heat lost from the soil late in the growing season is an additional energy source for heating the air and evaporating water, which partially offsets the effect of decreasing net radiation with shorter hours of sunlight (Baldocchi et al., 1997; Amiro et al., 2006).

\subsection{Boreal Water Budget}

The boreal water balance (Eq. 3.1) is written by Blanken et al. (2001) as:

$$
\mathrm{P}=\mathrm{ET}+\mathrm{V}+\Delta \mathrm{S}+\mathrm{R}_{\mathrm{s}}
$$

where $\mathrm{P}$ is precipitation, $\mathrm{V}$ is vertical drainage, $\Delta \mathrm{S}$ is the change in the amount of water stored in the soil and $\mathrm{R}_{\mathrm{s}}$ is surface runoff (often assumed to be zero at most boreal sites). Snowmelt recharge in the spring provides a relatively full profile of soil moisture at the start of the growing season. Thereafter, soil moisture is redistributed within the profile, being recharged from precipitation and depleted via ET and V. In the sub-humid climate of the boreal region, ET dominates the water balance, as PET (potential ET) is greater than or equal to $\mathrm{P}$ (Devito et al., 2005). The magnitudes of the water balance components vary widely among sites depending on soil drainage conditions and vegetation type. As low leaf area indexes (LAI, the ratio of the total leaf area of vegetation divided by the ground surface area) are typical of boreal conifer stands, ample radiation may penetrate through the sparse canopy to the ground, resulting in large amounts of ET and energy 
exchange at the soil surface. This results in the top $0.15 \mathrm{~m}$ of the soil profile holding varying amounts of soil moisture, both spatially and temporally (Baldocchi et al., 1997). Despite low average annual precipitation, the boreal ecosystem is able to maintain a favorable water balance for vegetation growth, as the cool soils at depth $(>1 \mathrm{~m})$ retain sufficient soil moisture to provide for deep rooting trees (Baldocchi et al., 1997; Baldocchi et al., 2000; Amiro et al., 2006). Considering that constructed soils are rarely this deep, it is uncertain if reclaimed sites will be able to support boreal tree species, particularly during periods of drought when trees require access to deeper sources of moisture.

\subsection{Boreal Energy Balances}

The EC technique has been applied in many studies in the various ecosystems of the boreal forest in order to provide an improved understanding of the exchange of mass and energy typical of the boreal region (Baldocchi et al., 2000; Amiro et al., 2006). However, only a minimal knowledge base of the same information exists pertaining to that of engineered soil covers. Due to the forecasted expansion of the oil sands industry, it is necessary to perform a detailed investigation of how alterations in the biometeorology of regenerating ecosystems differs from that in natural boreal ecosystems so that reclamation efforts can be proactively directed towards an optimal path of recovery. Understanding the photosynthetic pathways that provide connections between the water and energy budgets (LE) and the assimilation of carbon help to gauge how the ecosystem is functioning and whether it can be viewed as being productive or not. Comparing reclamation sites with natural boreal ecosystems is difficult however, due to the considerable variability in vegetation and microclimates in the vast expanse of the 
boreal forest. Variations in tree species and stand age produce substantially different microclimates (Baldocchi et al., 2000; Litvak et al., 2003; Amiro et al., 2006), and so it is important to design each reclamation cover so that it can cope with the natural variability of climatic and hydrologic processes that can be expected to occur with the establishment of each regenerating site.

ET in coniferous dominated stands generally begins early in spring and continues late into autumn (Baldocchi et al., 1997). Seasonal and diurnal patterns of $\mathrm{H}$ and LE exhibit greater responses to humidity and soil moisture deficits than to changes in $R_{n}$ (Baldocchi et al., 2000). Conifer stands in the boreal forest are dominated by black spruce and jack pine. A major determining factor governing which evergreen species establishes a mature forest is the presence of a suitable soil type (Amiro et al., 2006). Black spruce stands will grow in organic soils that maintain moisture near the surface. ET rates at these sites are inhibited by cold, waterlogged soils in the spring and atmospheric humidity deficits in the summertime (Baldocchi et al., 2000). Jack pine, however, which are able to tap deeper sources of moisture, can grow in well-drained, sandy soils. The combination of atmospheric humidity deficits and dry sandy soils result in typically low transpiration rates in jack pine stands compared with other boreal forest species (Baldocchi et al., 1997; Baldocchi et al., 2000).

When compared to the enclosed canopy of deciduous sites after leaf-out, the low leaf area of jack pines allows a relatively large amount of energy to be exchanged at the soil surface, resulting in $\mathrm{G}$ consuming between $4-8 \%$ of $R_{n}$. Consequently, surface evaporation can account for up to $45 \%$ of what is already a low rate of canopy ET (Baldocchi et al., 2000). As the volumetric soil moisture content drops below a certain 
threshold and $r_{s}$ increases, the ratio between LE and available energy diminishes significantly. As a result, Bowen ratios are usually greater than $1, \alpha$ values are on average only 0.5 in dry conditions (Baldocchi et al., 1997), and forest productivity rates are relatively low (Amiro et al, 2006).

Broad-leaved aspen stands tend to exist in regions where $\mathrm{P}$ and PET are in balance (Baldocchi et al., 1997). The water and energy balance of deciduous stands exhibit a large response to phenology and weather. During the winter when the canopy is bare and the surface is covered in snow, $\mathrm{H}$ exceeds LE. The magnitude of $\mathrm{H}$ will steadily increase as temperature increases in spring and the snow cover diminishes. However, as the frozen soil begins to thaw, LE will increase with soil moisture availability and increased radiation penetrating through the bare canopy. The period of leaf emergence produces small ratios of $G / R_{n}(0.03)$ and high levels of transpiration, which subsequently results in low Bowen ratios $(\beta \leq 0.5)$ and high levels of productivity (Baldocchi et al., 2000). Surface conductance at deciduous sites is typically limited by photosynthetic active radiation (Q) and the ambient D. By mid-summer the Priestley-Taylor $\alpha$ approaches (and can exceed) unity (Blanken et al., 1997).

Deciduous sites also differ from their coniferous counterparts in that LE and $\mathrm{H}$ are more sensitive to $\mathrm{R}_{\mathrm{n}}$, as the turbulent fluxes typically mirror the parabolic rise and fall of diurnal $\mathrm{R}_{\mathrm{n}}$ (Amiro et al., 2006). The large leaf area of aspen sites absorbs most of the incoming radiation $(\sim 70 \%)$, resulting in minimal $(<5 \%)$ canopy ET sourced from the soil, which in turn allows for more moisture to be available to the vegetation (Baldocchi et al., 2000). Blanken et al (2001) reported that ET during the growing season amounted 
to $5-6 \mathrm{~mm} \mathrm{~d}^{-1}$ at a mature aspen site, which is higher than peak growing season ET rates at conifer forests that are typically on the order of $2.5-3 \mathrm{~mm} \mathrm{~d}^{-1}$ (Baldocchi et al., 2000).

The vegetation that develops during the first few years of reclamation efforts is similar to grasslands, and thus it can be expected that before the tree seedlings begin to create an overstory canopy that the two ecosystems will share similar biometeorological characteristics. Grasslands exhibit strong resistances to drought and are largely responsive to increases in $\mathrm{P}$, which result in increased productivity and ET (Knapp and Smith, 2001). In a northern temperate grassland, Wever et al. (2002) found that peak rates of ET ( $\left.3 \mathrm{~mm} \mathrm{~d}^{-1}\right)$ were similar during a drought year and when $\mathrm{P}$ was near the climate normal, but increased to $4.5 \mathrm{~mm} \mathrm{~d}^{-1}$ with above normal P. Throughout all three years of their study LE only ever exceeded $\mathrm{H}$ during the year with high $\mathrm{P}$. The lack of a closed canopy in the short vegetation resulted in $\mathrm{G}$ reaching levels as high as $100 \mathrm{~W} \mathrm{~m}^{-2}$, which approached and sometimes even matched the portion of $R_{n}$ consumed by LE.

Energy balance studies of post-disturbance (fire and harvest) sites at different stages of regeneration (Litvak et al., 2003; Amiro et al., 2006) found that energy balances are primarily altered due to changes in albedo. The albedo that results from post-fire disturbances will initially decrease due to the black mats of charred organic material, and then increase beyond the original value after grass and other leafy vegetation replace what were previously darker, mature conifers. These changes in albedo will subsequently alter the site's radiation efficiency $\left(R_{e}=R_{n} / K \downarrow\right)$ (Chambers and Chapin, 2003) and consequently change the magnitude of the partitioning of energy into $\mathrm{G}, \mathrm{H}$ and $\mathrm{LE}$. Because the partitioning of energy is also largely dependent on water availability, a newly regenerating site with sufficient soil moisture will usually exhibit greater LE than 
$\mathrm{H}$ during the first stages of regeneration, resulting in low Bowen ratios and ET rates that match - or even exceed - those of mature deciduous stands (Baldocchi et al., 1997; Amiro et al., 2006).

The productivity of disturbed areas is initially much lower than the preceding forest but will increase steadily during the first few decades of regeneration.

Regeneration following natural disturbances often results in a competition among the mix of species that may have previously inhabited the forest (Amiro et al., 2006). In the case of post-mining reclamation efforts, this process of natural succession is complicated by what is planted on site. Consequently, the success of reclamation efforts relies on the appropriate selection of vegetation that is most suitable to the cover soil type and the in situ environmental conditions. If seasonal growing conditions are favorable for vegetation, rapid changes in succession, and hence the surface energy and water balances, will occur (Carey, 2008).

One concern at the study site in question is that due to the lack of any kind of surface debris from fire or harvesting, the penetration of radiation into the exposed surface may cause soil moisture to evaporate at a high rate. As evaporation in short vegetation has been found to be largely a radiation-controlled process (Shuttleworth and Calder, 1979) this could potentially reduce soil moisture to the wilting point for plants and prove to be detrimental to the health of the vegetation (Monteith, 1981). If the soil cover results in a dry soil profile, it might be beneficial for all reclamation efforts to consider planting species that are naturally adapted to thrive in dry conditions, such as jack pine, which grow relatively quickly after the first few years of planting (Amiro et al., 2006). 


\subsection{Methods}

\subsection{Site Description}

The study site (Dyke $11 \mathrm{~A}$ South $-56^{\circ} 53.7^{\prime} \mathrm{N}, 111^{\circ} 21.8^{\prime} \mathrm{W}, \sim 345 \mathrm{~m}$ a.s.1.) is located at the Suncor Energy Inc. Millennium mine site, approximately $20 \mathrm{~km}$ north of Fort McMurray, Alberta. Thirty-year Environment Canada climate normals (1971-2000) for Fort McMurray indicate mean daily temperatures for January and July are -18.8 and $+16.8^{\circ} \mathrm{C}$, respectively. Mean annual precipitation is $456 \mathrm{~mm}$, of which roughly threequarters occurs as rainfall during the summer months (June - August), delivered in storms of high intensity and short duration.

Entering into its second growing season after reclamation, Dyke 11A South covers a rectangular area of 27 ha and is situated on a 15 degree south-facing slope with a profile that is stepped with three benches. The soil cover being tested at the site is referred to as an ET soil cover, which has eliminated the geosynthetic soil membrane that is used in conventional soil covers to control percolation rates into the underlying wasterock material. The ET cover at this site relies instead on natural water storage principles to control percolation rates. The cover consists of a $0.25 \mathrm{~m}$ peat/mineral mixture layer overlying a coarser layer of tailings sand material (known as a capillary break) to prevent the upward diffusion of salts from the saline-sodic overburden below. The cover is designed to control percolation by storing water during periods of high precipitation and by promoting sufficient ET to prevent percolation during periods of low precipitation. The soil used in the ET cover was salvaged from a stockpile of natural earth material that was extracted from the area during the strip-mining process. The cover soil has a loam 
texture with a mean bulk density of $1.19 \mathrm{Mg} \mathrm{m}^{-3}$, while the underlying tailings sand has a mean bulk density of $1.49 \mathrm{Mg} \mathrm{m}^{-3}$.

The EC tower was placed in the approximate center of Dyke 11A South, providing uniform fetch for approximately $350 \mathrm{~m}$ in the ENE and WSW directions, and 100 meters to both the NNW and SSE directions (Figure 4.1). As a result of land disturbances caused by mining activities, the region surrounding Dyke $11 \mathrm{~A}$ South is largely a heterogeneous landscape, with Suncor's central mining facility located approximately $13 \mathrm{~km}$ to the northwest of the site. There are two small tailings ponds within a few hundred meters downslope to the south and southeast, a significantly large tailings sand basin $\left(\sim 4 \mathrm{~km}^{2}\right)$ upslope to the immediate north, and the Athabasca River flows $2 \mathrm{~km}$ to the west. The area surrounding the mine site is composed of a mosaic of muskeg and black spruce-dominated forests interspersed with white spruce and trembling aspen.

Dyke 11A South was originally planted in August 2006 with a mixture of native species to provide protection during periods when limiting natural factors might cause individual species to grow poorly. Seedlings that were planted included jack pine, trembling aspen, white birch, American willow (Salix discolor), buffaloberry (Shepherdia canadensis), blueberry (Vaccinium sp.), rose, raspberry and green alder (Alnus viridus). A surveying report provided by Suncor Energy Inc. showed that the major species that persisted into the 2008 season were jack pine (1130 stems ha $\left.{ }^{-1}\right)$, willow (1000 stems ha $\left.{ }^{-1}\right)$, aspen (430 stems ha $\left.{ }^{-1}\right)$ and raspberry (178 stems ha $\left.{ }^{-1}\right)$. 


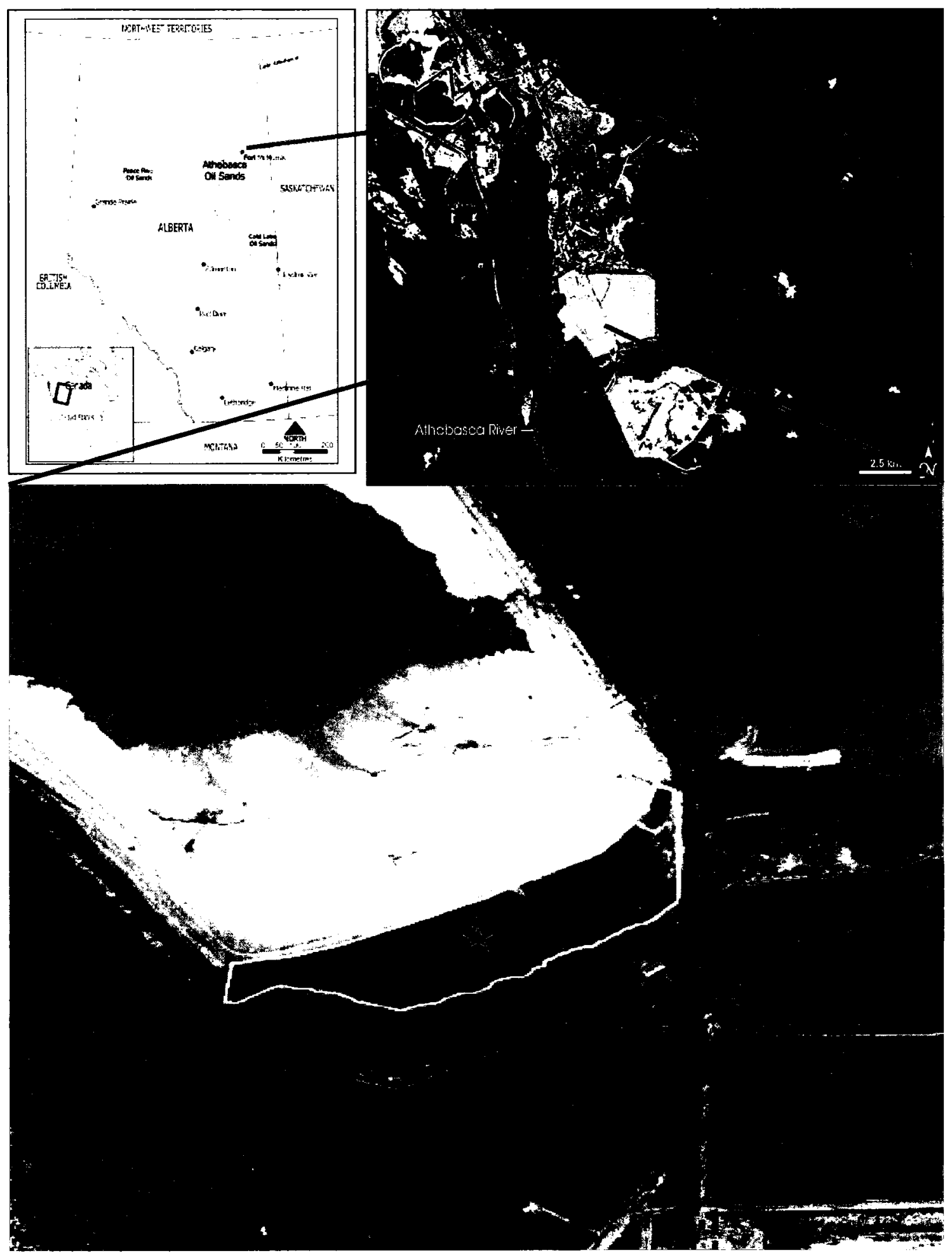

Figure 4.1: Overhead view of Dyke 11A South (outlined in bottom photo) at the Suncor Millennium mine. The location of the EC tower is indicated by the star in the bottom photograph. 
The Braun-Blanquet cover-abundance method (Wikum and Shanholtzer, 1978)

was used to obtain a visual estimate of vegetation cover from ten separate $1 \mathrm{~m}^{2}$ plots, and helped to identify other grass and weedy species that are found to commonly invade recently disturbed areas. The major species that were found to have encroached upon this site by June included Canada goldenrod (Solidago canadensis), tansy mustard (Descurainia sophia), sow thistle (Sonchus arvensis), rough cinquefoil (Potentilla norvegica), fireweed (Epilobium angustilfolium), horsetail (Equisetum sp.), and a variety of grasses (barley foxtail (Hordeum jubatum), fowl meadow grass (Poa palustris) and purple smallreed (Calamagrostis canescens). Vegetation height was measured within three separate $0.5 \mathrm{~m}^{2}$ plots at the beginning of three LAI surveying transects. The mean height changed throughout the growing season, starting at only a few centimeters tall in May and increasing to about $0.5 \mathrm{~m}$ at the peak of the growing season in July, when sow thistles up to about $1 \mathrm{~m}$ tall became prominent in the area. Vegetation did not completely cover the ground during the second growing season, as the cover abundance survey near the end of the season found that nearly $20 \%$ of the surface was exposed bare soil.

\subsection{Field Measurements}

Micrometeorological measurements began in 2008 on May 10 (DOY 131) and ran until October 8 (DOY 282). Site instruments were mounted on a $3 \mathrm{~m}$ triangular tower that was powered with four $12-\mathrm{V}$ batteries charged by solar panels. The EC system was mounted $2.4 \mathrm{~m}$ above the surface and consisted of a CSAT3 sonic anemometerthermometer (Campbell Scientific Inc. (CS), Edmonton, AB, Canada) to measure three dimensional wind speed and temperature (derived from the speed of sound) and a LI- 
7500 open-path infrared gas analyzer (IRGA) (LI-COR Inc., Lincoln, NE, USA) to measure the mass density of water vapour $\left(\rho_{\mathrm{v}}\right)$ and $\mathrm{CO}_{2}\left(\rho_{\mathrm{c}}\right)$.

Supporting meteorological measurements included cup wind speed (MET-ONE cup anemometer (CS)), air temperature and relative humidity (HMP-45 probe, Vaisala Inc., Helsinki, Finland) that were installed on the tower at heights of $2.75 \mathrm{~m}$ and $2.6 \mathrm{~m}$, respectively. Radiation observations were measured at a height of $2.58 \mathrm{~m}$ using an NRlite net radiometer (Kipp \& Zonen, Delft, The Netherlands) and two LI-200 pyranometers

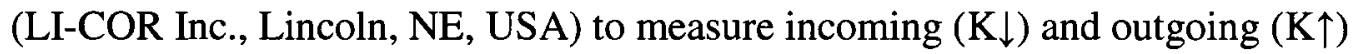
shortwave radiation.

Ground heat flux (G) was measured using a single CM3 heat flux plate (CS), buried $1 \mathrm{~m}$ south of the tower at a depth of $0.05 \mathrm{~m}$. Heat storage in the top $0.05 \mathrm{~m}$ of the soil above the heat flux plate was included to calculate (Eq. 4.2.1) G at the surface:

$$
\mathrm{G}=\mathrm{G}_{0.05 \mathrm{~m}}+\mathrm{M}
$$

where $\mathrm{M}$ (Eq. 4.2.2) is the rate of change of heat stored in the top $0.05 \mathrm{~m}$ of soil and is defined as:

$$
M=z C \frac{\Delta T}{\Delta t} \quad \text { Eq. } 4.2 .2
$$

where $\mathrm{z}$ is the thickness of soil above the heat flux plate $(\mathrm{m}), \mathrm{C}$ is the volumetric heat capacity of the soil $\left(\mathrm{J} \mathrm{m}^{-3} \mathrm{~K}^{-1}\right)$, and $\Delta \mathrm{T}$ is the change in temperature $(\mathrm{K})$ over the time interval $\Delta \mathrm{t}(\mathrm{s})$.

EC flux measurements were sampled at a frequency of $10 \mathrm{~Hz}$ and stored on a CR3000 data logger (CS). All other tower data was stored on the same data logger every half hour from averages taken every $10 \mathrm{~s}$. 
LAI was measured along three randomly selected $15 \mathrm{~m}$ transects around the tower using an LAI-2000 plant canopy analyzer (LI-COR Inc., Lincoln, NE, USA). Each area was sampled bi-weekly from May 10 (DOY 131) to August 21 (DOY 265). In an attempt to only sample during low solar zenith angles, measurements using a $270^{\circ}$ view cap were generally taken before $10 \mathrm{am}$. All measurements were made with a shadow cast over the lens in order to avoid direct solar radiation on the sensor. Mean vegetation height measurements $(h)$ and digital photographs were also taken within three $0.5 \mathrm{~m}^{2}$ plots at the beginning of each transect to provide visual documentation of the growth of vegetation at the study site throughout the growing season.

\subsection{Supplementary Measurements}

A soil monitoring station located approximately $100 \mathrm{~m}$ to the west of the EC tower (operated by O'Kane Consultants Inc.) provided continuous measurements that were available for the entire 2008 year. The station established a profile of soil moisture, matric suction and soil temperature from measurements taken at depths of $0.05,0.15$, $0.25,0.4$ and $0.8 \mathrm{~m}$ beneath the surface. The top three levels were chosen to be representative of the centre of the surrounding $0.1 \mathrm{~m}$ depth, while the 0.4 and $0.8 \mathrm{~m}$ levels are said to represent depths of 0.3 and $0.2 \mathrm{~m}$, respectively. Volumetric water content $\left(\theta_{\mathrm{s}}\right)$ was measured with a CS-616 water content reflectometer (CS), soil temperature $\left(\mathrm{T}_{\mathrm{s}}\right)$ using thermistors (CS) and matric suction $\left(\Psi_{\mathrm{m}}\right)$ using a 229-L electronic tensiometer (CS), with each instrument being calibrated individually to their respective soil layer.

The 229-L electronic tensiometer measured the change in thermal conductivity (dT) that was associated with changes in water potential and water content in the soil. Raw dT values measured by the $229-\mathrm{L}$ were converted into $\Psi_{\mathrm{m}}(\mathrm{kPa})$ using a best-fit polynomial 
equation $\Psi_{\mathrm{m}}=242.5(\mathrm{dT})^{2}-527.36(\mathrm{dT})+283.99$. Soil measurements were recorded every minute and averaged over four hours using a CR10X data-logger (CS). Halfhourly soil measurements were interpolated with a cubic spline in order to provide values to compare with the 30 minute EC and climate data.

Additionally, a TI-525 tipping bucket rainfall gauge (Texas Instruments Inc., Dallas, Texas, USA), located within $0.5 \mathrm{~km}$ of the site, was used to record precipitation. This rain gauge is calibrated to tip for each $0.254 \mathrm{~mm}$ of precipitation that collects in the bucket. All tips that were recorded within each half hour were summed in order to provide total precipitation amounts that could be compared with other half-hourly data.

\subsection{Data Quality Control}

Data quality control was performed by examining the statistical characteristics of all measured EC variables after the identification and removal of spikes. Spikes, which are characterized as short duration, large amplitude fluctuations in the time series, are known to arise in EC flux measurements due to random noise in the electronic signals or water collecting on the sensors (Lee et al., 2004). The despiking of the high frequency time series began with the removal of error values such as $-9999, \mathrm{NaN}$, and extreme values that didn't fall into a realistic range for any of the EC variables (eg. $-10 \mathrm{~m} \mathrm{~s}^{-1}>\mathrm{w}$

$>10 \mathrm{~m} \mathrm{~s}^{-1}$ or $0 \mathrm{~g} \mathrm{~m}^{-3}>\rho_{v}>65 \mathrm{~g} \mathrm{~m}^{-3}$ ). Subsequent spike identification involved flagging individual measurements $(0.1 \mathrm{~s})$ in the time series that exceeded five times the standard deviation of a moving $60 \mathrm{~s}$ mean (Vickers and Mahrt, 1997; Humphreys et al., 2003).

Due to the low variability in the time series that occurred during stable nighttime conditions when turbulence was suppressed, potential spikes were only removed if they exceeded adjacent measurements by a predefined threshold. Threshold values (Table 
4.4.1) were identified by differencing the time series of each respective variable every other day from June 1 (DOY 153) to June 19 (DOY 171) with the purpose of producing normal distributions. Potential spikes were identified as true spikes if they exceeded adjacent points by three times the standard deviation (s.d.) of each respective difference distribution. Single gaps produced during the spike identification and removal process in each high frequency time series were filled by linear interpolation between adjacent points. If spiking rates ever exceeded five spikes in any thirty minute period the entire half hour was removed from the time series (Humphreys et al., 2003).

Table 4.4.1: Threshold values that potential spikes must exceed in each respective variable's difference distributions before being identified as spikes and removed.

\begin{tabular}{cc}
\hline Variable & Threshold (3*s.d.) \\
\hline $\mathrm{u}$ & $1.11 \mathrm{~m} \mathrm{~s}^{-1}$ \\
$\mathrm{v}$ & $1.04 \mathrm{~m} \mathrm{~s}^{-1}$ \\
$\mathrm{w}$ & $0.86 \mathrm{~m} \mathrm{~s}^{-1}$ \\
$\rho_{\mathrm{c}}$ & $2.45 \mathrm{mg} \mathrm{m}^{-3}$ \\
$\rho_{\mathrm{v}}$ & $0.21 \mathrm{~g} \mathrm{~m}^{-3}$ \\
$\mathrm{~T}$ & $0.40{ }^{\circ} \mathrm{C}$ \\
\hline
\end{tabular}

There were not a significant portion of half-hours detected during the despiking process that contained more than five spikes per sampling period. Only 5.6 and $2.7 \%$ of the $\rho_{\mathrm{v}}$ and $\rho_{\mathrm{c}}$ measurements were removed, and less than $1 \%$ of each variable measured with the sonic. There were generally more spikes corresponding to IRGA measurements as opposed to those made with the sonic anemometer (Table 4.4.2), particularly during rain events and periods of high humidity. Vertical wind speed produced the greatest number of spikes with regards to the sonic anemometer, with $15.8 \%$ of the total time series containing at least one spike per half hour. 
Table 4.4.2: Summary of spike occurrence in half hourly time series data. Results are displayed as percentage of all half hours $(n=6901)$, half hours with precipitation (P) $(n=$ $283)$, and periods with high relative humidity (RH) $(n=608)$.

\begin{tabular}{ccccccc}
\hline & \multicolumn{3}{c}{ \% with $\geq \mathbf{1}$ spike } & \multicolumn{3}{c}{ \% with $\geq 5$ spikes } \\
Variable & Total & $\mathbf{P}$ & $\mathbf{R H} \geq \mathbf{0 . 9}$ & Total & $\mathbf{P}$ & $\mathbf{R H} \geq \mathbf{0 . 9}$ \\
\hline $\mathbf{u}$ & 9.6 & 15.9 & 10.9 & 0.5 & 4.2 & 3.1 \\
$\mathbf{v}$ & 5.7 & 17.7 & 11.4 & 0.5 & 4.2 & 3.8 \\
$\mathbf{w}$ & 15.8 & 19.4 & 9.5 & 0.7 & 3.5 & 2.5 \\
$\mathbf{T}$ & 7.62 & 26.2 & 16.6 & 0.7 & 4.6 & 3.5 \\
$\mathbf{\rho}_{\mathbf{c}}$ & 21.4 & 71.0 & 34.1 & 5.6 & 38.5 & 18.1 \\
$\mathbf{\rho}_{\mathbf{v}}$ & 11.3 & 56.2 & 26.5 & 2.7 & 19.4 & 11.2 \\
\hline
\end{tabular}

Following the initial despiking procedure, the remaining data was subject to a 'hard' and 'soft' flagging system that examined higher order moment statistics such as skewness and kurtosis. Lower and upper limits of hard and soft flags corresponded to a skewness that exceeded $(-2,2)$ and $(-1,1)$, and kurtosis that exceeded $(1,8)$ and $(2,5)$, respectively (Vickers and Mahrt, 1997). Values that fell outside of this range represented substantial deviations from the mean that were indicative of instrument or recording problems and physically uncharacteristic behaviour. Hard flags were removed from the data set outright as they were believed to not represent any physically normal phenomenon, and soft flags were evaluated further using visual inspection.

The frequency of hard and soft flags found in the high frequency variables' time series and the influence of stability $(\zeta)$ on their occurrence are shown in Table 4.4.3. Stability was calculated as $\zeta=\frac{z-d}{L}$, where $z$ is the reference measurement height $(2.4$ $\mathrm{m}), d$ is the zero-plane displacement approximated as $\frac{2}{3} h$ where $h$ is the height of the 
canopy, and $L$ is the Monin-Obhukov (M-O) scaling length (m). The M-O scaling length represents the approximate height where shear production is equal to the buoyant energy production term, calculated as $L=-\frac{\theta_{v} u_{*}^{3}}{k g \overline{w^{\prime} \theta_{v}{ }^{\prime}}}$ where $\theta_{v}$ is the potential virtual temperature $(\mathrm{K}), \mathrm{u} *$ is the surface friction velocity $\left(\mathrm{m} \mathrm{s}^{-1}\right)$, calculated as $\left(\overline{w^{\prime} u^{\prime}}+\overline{w^{\prime} v^{\prime}}\right)^{0.25}($ Stull, 1997), $g$ is the acceleration due to gravity $\left(9.81 \mathrm{~m} \mathrm{~s}^{-2}\right)$, and $\overline{w^{\prime} \theta_{v}{ }^{\prime}}$ is the mean surface kinematic heat flux $\left(\mathrm{K} \mathrm{s}^{-1} \mathrm{~m}^{-2}\right)$ (Irwin and Binkowski, 1981). Unless otherwise indicated, stable conditions correspond to $\zeta$ values $>0.02$, neutral to $-0.02 \leq \zeta \leq 0.02$, and unstable was $\zeta<$ -0.02 .

There was a greater percentage of soft flags compared to hard flags for all variables, with a tendency for more of each type of flag to have occurred during stable conditions when turbulence was suppressed (Table 4.4.3). One case where this trend did not persist was for flags identified for T. A possible explanation for a larger percentage of unusually skewed and kurtotic $\mathrm{T}$ values is due to strong surface heating during the day that can intensify convection of sensible heat (Lee et al., 2004). 
Table 4.4.3: The percentage of soft and hard flagged data based on skewness and kurtosis of all data $(n=6887)$, data during periods of instability $(n=3496)$ and during stable periods $(n=3301)$.

\begin{tabular}{|c|c|c|c|c|c|c|c|c|}
\hline \multicolumn{3}{|c|}{ Flagging Criteria } & $\mathbf{u}$ & $\mathbf{v}$ & $\mathbf{w}$ & $\mathbf{T}$ & $\rho_{\mathbf{v}}$ & $\rho_{c}$ \\
\hline \multirow{6}{*}{$\frac{\mathscr{d}}{\frac{d}{2}}$} & \multirow{3}{*}{ है: } & Total & 2.0 & 2.1 & 0.3 & 5.1 & 9.3 & 13.8 \\
\hline & & $\zeta<0$ & 1.1 & 0.9 & 0.2 & 7.0 & 6.4 & 12.9 \\
\hline & & $\zeta>0$ & 2.7 & 3.1 & 0.2 & 2.7 & 12.0 & 14.6 \\
\hline & \multirow{3}{*}{ 总 } & Total & 0.2 & 0.1 & 0.1 & 0.4 & 3.3 & 4.9 \\
\hline & & $\zeta<0$ & 0.0 & 0.0 & 0.0 & 0.3 & 1.8 & 4.1 \\
\hline & & $\zeta>0$ & 0.1 & 0.1 & 0.0 & 0.3 & 4.7 & 5.6 \\
\hline \multirow{6}{*}{ 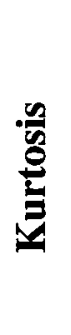 } & \multirow{3}{*}{ 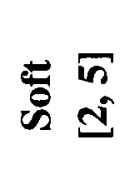 } & Total & 2.8 & 5.5 & 13.2 & 6.0 & 12.4 & 17.3 \\
\hline & & $\zeta<0$ & 1.3 & 2.9 & 4.5 & 6.6 & 7.5 & 15.0 \\
\hline & & $\zeta>0$ & 3.5 & 7.6 & 21.8 & 4.8 & 17.1 & 19.4 \\
\hline & \multirow{3}{*}{$\begin{array}{l}\infty \\
\Xi\end{array}$} & Total & 0.4 & 0.8 & 1.6 & 1.0 & 4.9 & 8.5 \\
\hline & & $\zeta<0$ & 0.1 & 0.4 & 0.6 & 0.9 & 2.9 & 7.5 \\
\hline & & $\zeta>0$ & 0.2 & 0.8 & 2.2 & 0.7 & 6.8 & 9.5 \\
\hline
\end{tabular}

\subsection{Flux covariance computations}

High frequency turbulent fluxes of sensible heat $(\mathrm{H})$, latent heat (LE), and carbon dioxide $\left(\mathrm{F}_{\mathrm{c}}\right)$ were measured continuously and calculated as:

$$
\begin{aligned}
& H=\rho_{a} C_{p} \overline{w^{\prime} T^{\prime}} \\
& L E=\lambda \rho_{a} \overline{w^{\prime} \chi_{v}{ }^{\prime}} \\
& F_{c}=\rho_{a} \overline{w^{\prime} \chi_{c}{ }^{\prime}}
\end{aligned}
$$

where overbars ( $\overline{)}$ and primes (') denote the covariance of the fluctuations from the mean for $w$ and the scalar concentration for half-hour measurement intervals, $\rho_{a}$ is the density of dry air $\left(\mathrm{g} \mathrm{m}^{-3}\right), \mathrm{C}_{\rho}$ is the heat capacity of air $\left(\mathrm{J} \mathrm{m}^{-3} \mathrm{~K}^{-1}\right)$, T is temperature $(\mathrm{K}), \lambda$ is the latent heat of vaporization $\left(\mathrm{J} \mathrm{g}^{-1}\right), \chi_{\mathrm{v}}$ is the water vapour mixing ratio ( $\mathrm{mmol} \mathrm{mol}{ }^{-1}$ dry air) calculated as $\left(\chi_{v}=\chi_{w v} /\left(1-\chi_{w v} / 1000\right)\right.$, where $\chi_{w v}$ is the mole fraction of water vapour (mmol mol ${ }^{-1}$ moist air) and $\chi_{\mathrm{c}}$ is the $\mathrm{CO}_{2}$ mixing ratio ( $\mu \mathrm{mol} \mathrm{CO}_{2} \mathrm{~mol}^{-1}$ dry air). calculated as $\rho_{\mathrm{d}} / \rho_{\mathrm{a}}$, where $\rho_{\mathrm{c}}$ is the mole density of $\mathrm{CO}_{2}$. The mass densities of $\mathrm{H}_{2} \mathrm{O}$ and 
$\mathrm{CO}_{2}$ that were measured by the IRGA were converted to mole mixing ratios when calculating the high frequency fluxes in order to account for the density corrections that need to be applied due to variations in the transfer of heat and water vapor (Webb et al., 1980).

Turbulence used in the flux computations was mathematically rotated using the planar fit method described by Wilczak et al. (2001). Being as the position of the sonic anemometer was never adjusted, a best-fit horizontal plane was acquired from multiple linear regressions of the velocity data from May 29 - August 7 (DOY 150 - 220), providing a single set of anemometer tilt angles for the entire field season. The z-axis was rotated to be perpendicular to the mean streamlines so that the mean vertical velocity over the entire sampling period was zero. This method of coordinate rotation was chosen over other traditional methods that force $\bar{w}$ to zero for every averaging period, because it has been noted that the latter can result in flux bias errors and high-pass filtering of lower frequencies due to over-rotation (Lee et al., 2004).

\subsection{Penman-Monteith Equation}

Before the P-M equation could be employed to analyze the relative influences of the various controls on ET, it was first necessary to calculate the aerodynamic resistance $\left(r_{a}=1 / g_{a}\right)$ to heat and water vapour. The term $r_{a}$ refers to the limiting effect that eddy and molecular diffusion have on the transfer of water vapour in the turbulent boundary layer. It is a function of wind speed, surface roughness and atmospheric stability, and was calculated in this study using the method (Eq. 4.6.1) proposed by Gash et al. (1999):

$$
r_{a}=\frac{\left(\frac{U}{u_{*}}+\frac{2}{k}+\frac{\psi_{h}-\psi_{m}}{k}\right)}{u_{*}}
$$


where $k$ is the Von Karman constant (0.4), and $\Psi_{h}$ and $\Psi_{m}$ represent integrated stability correction functions for the exchange of heat and momentum, respectively, applied during non-neutral conditions (Campbell and Norman, 1998). If gaps in the calculation of $r_{a}$ arose due to missing values of $u_{*}$ they were filled using (Eq. 4.6.2) a modified version of the log wind profile (Gash et al., 1999):

$$
r_{a}=\frac{\ln \left\lfloor(z-d) / z_{0, m}\right\rfloor \ln \left\lfloor(z-d) / z_{0, h}\right\rfloor}{k^{2} u}
$$

where $\mathrm{z}_{0, \mathrm{~m}}(=0.1 h)$ is the momentum roughness length and $\mathrm{z}_{0, \mathrm{~h}}\left(=0.2 * \mathrm{z}_{0, \mathrm{~m}}\right)$ is the roughness parameter for heat. Lastly, the calculation of canopy/surface resistance $\left(r_{s}=\right.$ $1 / g_{s}$ ) was calculated by inverting the P-M equation. It should be noted that $r_{a}$ and $r_{s}$ are sometimes used interchangeably with $\mathrm{g}_{\mathrm{a}}$ and $\mathrm{g}_{\mathrm{s}}$, respectively.

\subsection{Gap Filling}

Gap filling of flux measurements was necessary to enable the calculation of total ET and net ecosystem exchange (NEE) over the full growing season. Following all of the above quality control and filtering procedures the remaining flux data set consisted of $62 \%$ of $\mathrm{F}_{\mathrm{c}}, 64 \%$ of $\mathrm{H}$ and $66 \%$ of LE from the original EC measurements. A large portion (15\%) of the omitted data occurred between May 16 - 26 (DOY $137-147$ ), beginning with a complete five day gap from May $16-21$ (DOY $137-142$ ). This corresponded to a period when the IRGA lens was obscured possibly due to the collection of dust from the exposed bare soil at the time (pre leaf-out).

Small gaps in each half hour time series of two hours or less were filled using cubic spline interpolation. Larger gaps of LE were filled using the P-M equation after filling $r_{s}$ measurements using the mean diurnal variation of a five day moving window 
(and a 15 day moving window for the larger gaps mentioned above). Gaps in $\mathrm{H}$ were filled by assuming it as the residual of the energy balance.

NEE, which represents the exchange of $\mathrm{CO}_{2}$ between the ecosystem and atmosphere, was calculated as (Eq. 4.7.1) the sum of $F_{c}$ measured using the EC technique plus the change in rate of $\mathrm{CO}_{2}$ stored below the height of the $\mathrm{EC}$ instruments:

$$
N E E=F_{c}+\overline{\rho_{a}} \int_{0}^{h} \frac{\partial \overline{s_{c}}}{\partial t} d z
$$

where $d z=2.4 \mathrm{~m}$ and $\partial t=1800 \mathrm{~s}$. NEE is positive if there is a net loss of $\mathrm{CO}_{2}$ from the ecosystem via surface respiration (R), and negative if there is a net uptake of $\mathrm{CO}_{2}$ via photosynthesis. The amount of $\mathrm{CO}_{2}$ that is assimilated via photosynthesis is described as net ecosystem production (NEP), which is the equivalent of -NEE. Gross ecosystem production (GEP) describes the amount of carbon fixation at the surface, and is equal to NEP + R (Amiro et al., 2006).

As the EC tower could only measure NEE, a series of steps were taken to derive values of R, NEP and GEP. The fact that plants require daylight to photosynthesize meant that nighttime values of $\mathrm{NEE}=\mathrm{R}$. In order to estimate $\mathrm{R}$ during the day and to fill nighttime gaps in NEE, an empirical $\mathrm{R}=f\left(\mathrm{~T}_{\mathrm{s}}\right)$ model was applied using the $\mathrm{Q}_{10}$ relationship (Eq. 4.7.2) described by Drewitt et al. (2002):

$$
R=R_{r e f} Q_{10}\left(\frac{T_{s}-T_{r e f}}{10}\right)
$$

where $Q_{10}$ represents the fractional change in the rate of $\mathrm{R}$ with a $10^{\circ} \mathrm{C}$ increase in soil temperature ( $T_{s}$ at $0.05 \mathrm{~m}$ depth), and $R_{\text {ref }}$ is the respiration rate at $T_{\text {ref }}=10^{\circ} \mathrm{C}$. The model used dry canopy (assumed to occur 24 hrs after rainfall) nighttime values of $\mathrm{R}(n=374)$ after excluding data that corresponded to $\mathrm{u}_{*}<0.25 \mathrm{~m} \mathrm{~s}^{-1}$. A more constrained surface 
friction velocity than the threshold used to reject $F_{c}$ at night $\left(\mathrm{u}_{*}<0.1 \mathrm{~m} \mathrm{~s}^{-1}\right)$ was used to ensure that only strong turbulent conditions were used to model R. The model, which fit reasonably well $\left(r^{2}=0.62\right)$, was consistent with other studies as it showed this system to have an average $\mathrm{Q}_{10}$ of 2.01 (Tjoelker et al., 2001).

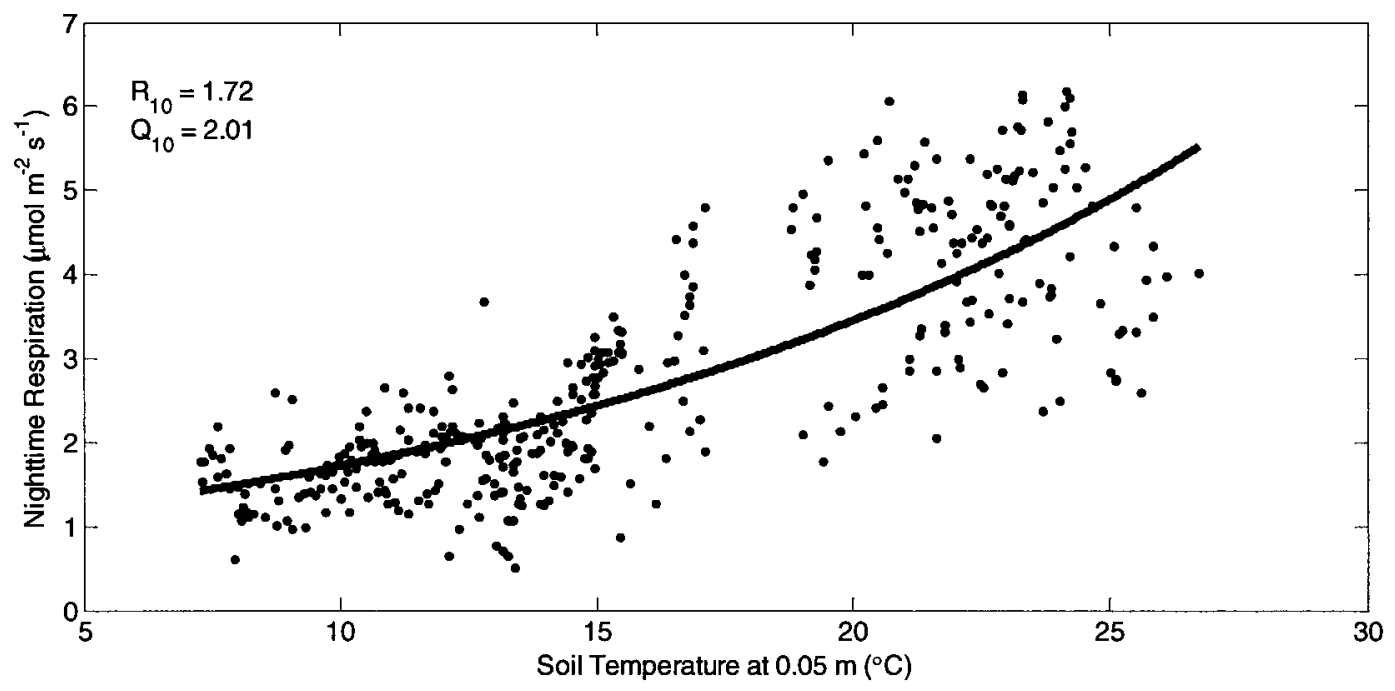

Figure 4.7.1: Ecosystem respiration curve generated with Eq. 4.7.2 (Drewitt et al., 2002) using half-hour measurements of dry canopy nighttime values of $\mathrm{R}(n=374)$ after excluding periods with insufficient friction velocity $\left(\mathrm{u}_{*}<0.25 \mathrm{~m} \mathrm{~s}^{-1}\right)$. The model indicates that the fractional change in the rate of $R$ at Dyke 11A South has a $Q_{10}$ of 2.01 .

GEP was estimated as NEP $+\mathrm{R}$ during the day and set to zero at night. An empirical GEP $=f(\mathrm{Q})$ model (Eq. 4.7.2) (Amiro et al., 2006) was fit to the mean dry canopy daytime (0900 - 1700) GEP data after excluding $\mathrm{u} *<0.25 \mathrm{~m} \mathrm{~s}^{-1}$ (Figure 4.7.2) as:

$$
G E P=\frac{\alpha Q A_{\max }}{\alpha Q+A_{\max }} \quad \text { (Eq. 4.7.3) }
$$

where $\alpha$ represents the quantum yield (taken as a constant), $\mathrm{Q}$ is downwelling photosynthetic active radiation (calculated as $2 * \mathrm{~K} \downarrow$ (Humphreys, personal communication, 2009)) and $A_{\max }$ is the photosynthetic capacity (GEP at light saturation). 
Eq. 4.7.2 was used to fill daytime gaps in GEP, and the remaining NEP gaps were filled using the modeled GEP $-\mathrm{R}$ (and corresponding gaps in NEE $=-\mathrm{NEP}$ ).

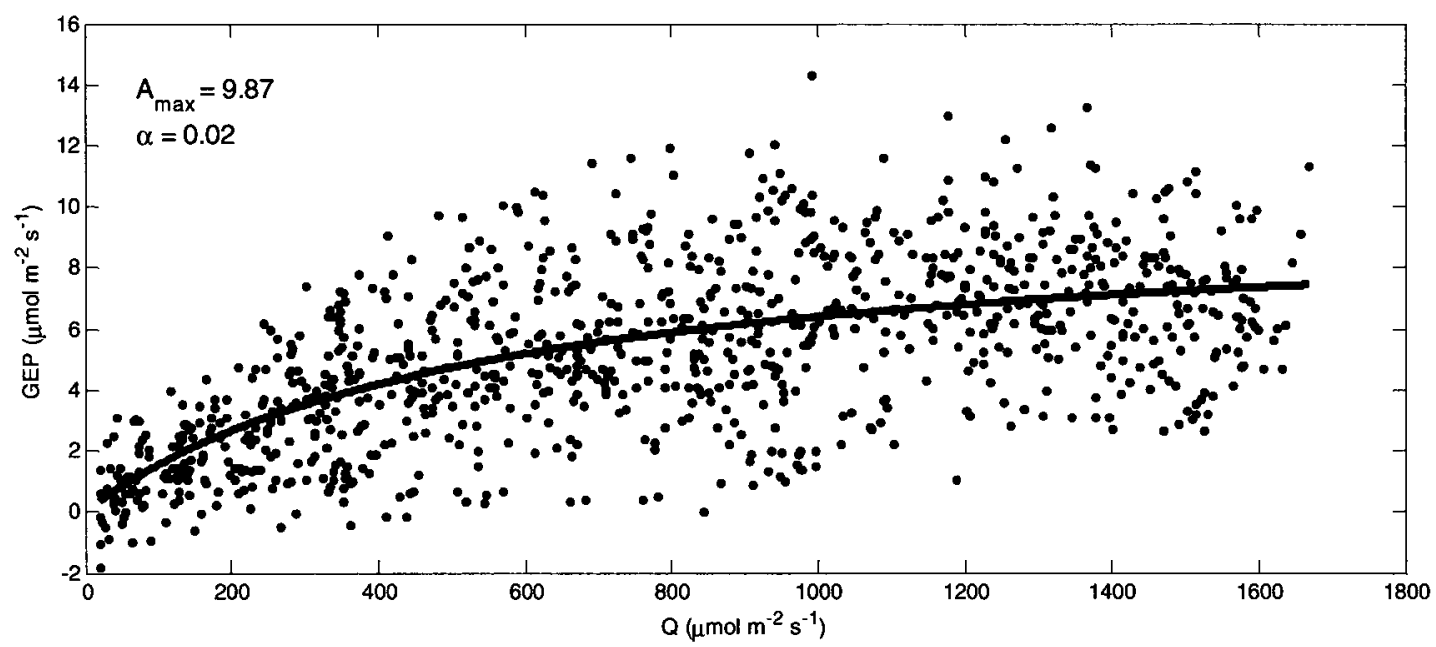

Figure 4.7.2: Mean daily GEP light response curve generated with Equation 4.7.2 (Amiro et al., 2006) $\left(\mathrm{r}^{2}=0.41\right)$. GEP values used in the model $(n=972)$ were taken from half-hour measurements of dry canopy daytime $(0900-1700)$ conditions after excluding periods with insufficient friction velocity $\left(\mathrm{u} *<0.25 \mathrm{~m} \mathrm{~s}^{-1}\right)$.

\subsection{Quality Assurance of Turbulence Measurements}

\subsubsection{Adequate sampling period}

Linear detrending of 30 min measurement periods was used to separate turbulent fluxes from the mean wind component of atmospheric transport. To determine if this method was sufficient in capturing all contributing components of the flux a series of ogive curves (Eq. 4.8.1) were constructed by integrating the area under the $\overline{w^{\prime} T}$ cospectral density plots of measurements taken on June 10 (DOY 162):

$$
O g_{w t}\left(f_{0}\right)=\int_{f_{0}}^{f_{\max }} C o_{w t}(f) d f
$$

where $C o_{w t}$ is the co-spectrum of the turbulent heat flux and $f$ is frequency. Ogive curves $\left(O g_{w t}\left(f_{0}\right)\right)$ show the cumulative contribution of eddies beginning with the highest 
frequencies $\left(f_{\mathrm{o}}\right)$. The frequency at which the ogive converges to a more or less constant plateau represents a reliable sampling rate (Lee et al, 2004). All ogives in Figure 4.8.1 reach an initial asymptote at $15 \mathrm{~min}$, however three are slight increases in ogives that begin from 0800 - 1000 hours, which can be attributed to the morning transition in stability. The general trend in all the ogives is that there is no significant increase in the cumulative co-spectrum beyond 30 minutes, indicating that this averaging period was sufficient in collecting all relevant eddies in the measured flux and that any flux contributions at longer wavelengths may be considered negligible.

One aspect that the ogive curves are not able to show is if linear detrending affected the higher frequency signals, for although it does primarily run the risk of altering the low frequency signals, it actually has the potential to affect all frequencies (Lee et al., 2004). One method of checking that neither frequency was affected is to perform the steady-state test in section 4.6.3, which compares shorter averaging periods to each half hour measurement. 


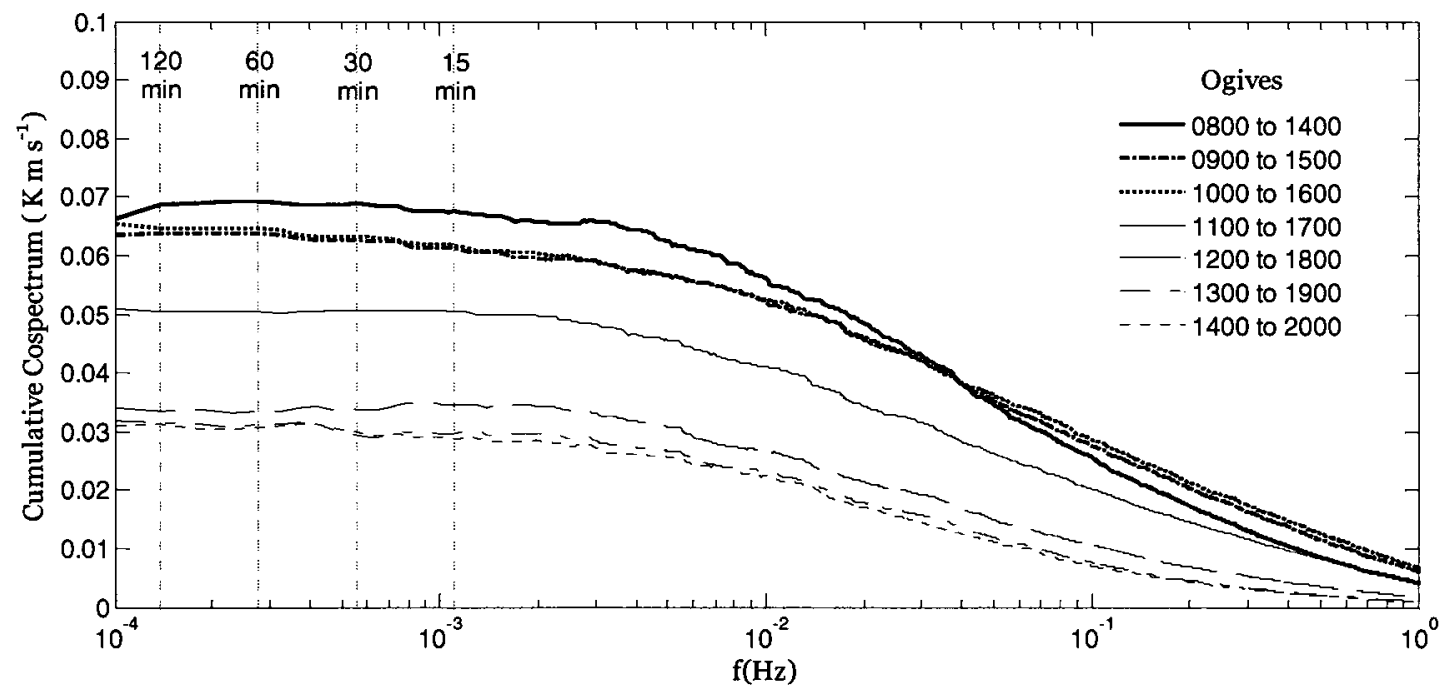

Figure 4.8.1: Ogive plot generated from a series of w' $T$ ' cospectra measured on June 10 (DOY 162). Each curve represents $6 \mathrm{hrs}$ of high frequency measurements and are centered on the hours running from 1100 to 1700 , thus covering the period from $0800-$ 2000. Negligible increases in the cumulative cospectrum of each ogive occurs at 0.003 $\mathrm{Hz}$, indicating that 30 min was a suitable sampling period for $\mathrm{EC}$ measurements.

\subsubsection{Steady-State Test}

The choice of an averaging period that is too long can run the risk of including non steady-state conditions. These conditions can result from mesoscale variability in the meteorological conditions, due to such things as changing footprint areas, changing internal boundary layers, or by gravity waves (Lee et al., 2004). In order to ensure that measurements met the EC theoretical requirements of stationarity, the steady state test proposed by Foken and Wichura (1996) was performed on all EC data in the study. This test divided each half hourly averaged covariance $\left(\overline{w^{\prime} x^{\prime}}\right)_{\mathrm{i}}$ into $M=6$ intervals of 5 minutes with $N=3000$ measurements at $10 \mathrm{~Hz}$, and compared it to the covariance determined over the half hour from each 5 minute period $\left(\overline{w^{\prime} x^{\prime}}\right)_{o}$ : 


$$
\begin{aligned}
& 30 \min =\overline{w^{\prime} x^{\prime}}=\frac{1}{M} \sum_{i}\left(\overline{w^{\prime} x^{\prime}}\right)_{i} \\
& 5 \min =\left(\overline{w^{\prime} x^{\prime}}\right)_{0}=\frac{1}{M(N-1)}\left[\sum_{i}\left(\sum_{j} w_{j} x_{j}\right)-\frac{1}{M N} \sum_{i}\left(\sum_{j} w_{j} \sum_{j} x_{j}\right)_{i}\right]
\end{aligned}
$$

The difference between each set of covariances $\left(\mathrm{RN}_{\text {cov }}\right)$ was then compared by:

$$
R N_{\mathrm{cov}}=\left|\frac{\left(\overline{w^{\prime} x^{\prime}}\right)-\left(\overline{w^{\prime} x^{\prime}}\right)_{0}}{\left(\overline{w^{\prime} x^{\prime}}\right)_{0}}\right|
$$

Ensemble statistics are shown to be independent of time (stationary) if the difference between both covariances is less than a threshold of $30 \%\left(\mathrm{RN}_{\mathrm{cov}}<0.3\right)$.

The steady-state test was performed on $u, w, T_{s}, \rho_{v}$ and $\rho_{c}$ for the entire data set and repeated to examine measurements made during precipitation events, both before and after applying the planar fit method of coordinate rotation to each length of averaging period (Table 4.8.2). Results show that the $15^{\circ}$ slope had an effect on the raw measurements, as coordinate rotation improved stationary conditions significantly for all variables during the study period. Stationarity was particularly improved for $u, \rho_{v}$ and $\rho_{c}$, which all previously consisted of a large percentage $(30-40 \%)$ that fell below the steady-state threshold. Precipitation was shown to only affect the steady-state conditions of measurements made by the IRGA, as the sonic was found to have performed well during rain events. Coordinate rotation during rainfall events ensured that at least $85 \%$ of all sonic measurements met the steady-state requirements. 
Table 4.8.2: Results of the steady-state test (Foken and Wichura, 1996) showing the percentage of total data $(n=6887)$ and from measurements taken during rain events $(n=$ 283) both before and after rotation. Measurements were considered to be stationary if the difference between the means of $30 \mathrm{~min}$ and $6 * 5$ min covariances was less than $30 \%$.

\begin{tabular}{ccccc}
\hline & \multicolumn{2}{c}{ Total Data Stationary } & \multicolumn{2}{c}{ Rain Data Stationary } \\
& Raw & Rotated & Raw & Rotated \\
\hline$\overline{w^{\prime} u^{\prime}}$ & 59.8 & 75.5 & 74.4 & 85.2 \\
$\overline{w^{\prime} w^{\prime}}$ & 99.8 & 99.8 & 98.9 & 99.2 \\
$\overline{w^{\prime} T^{\prime}}$ & 75.6 & 89.3 & 75.2 & 86.5 \\
$\overline{w^{\prime} \rho_{v}{ }^{\prime}}$ & 67.9 & 81.2 & 50.4 & 62.3 \\
$\overline{w^{\prime} \rho_{c}{ }^{\prime}}$ & 65.2 & 80.0 & 46.9 & 57.1 \\
\hline
\end{tabular}

\subsubsection{Flux Variance Similarity Test}

To check for fully developed turbulent conditions, Foken and Wichura's (1996) flux variance similarity test was applied to the $\mathrm{w}$ and $\mathrm{T}$ values that remained after despiking of the 30 minute time series. This test involved comparing the ratio of each turbulent parameter's standard deviation $(\sigma)$ with its turbulent flux $\left(\mathrm{X}^{*}=\mathrm{u}^{*}\right.$ for $\sigma_{\mathrm{w}}$ and $\mathrm{T}^{*}=-\overline{w^{\prime} T^{\prime}} / u^{*}$ for $\sigma_{\mathrm{T}}$ ) to values predicted by the Businger-Dyer formulations (Kaimal and Finnigan, 1994):

$$
\frac{\sigma_{x}}{X^{*}}=c_{1}\left(\frac{z}{L}\right)^{c_{2}}
$$

where $c_{1}$ and $c_{2}$ are coefficients of integral turbulence characteristics (ITC) that are dependent on stability (Lee et al., 2004). The test is only applied to measures of stability when $-2<\zeta<1$ and was not performed on sonic measurements of the horizontal wind components because $u$ and $v$ do not follow M-O scaling (Kaimal and Finnigan, 1994). 
Similar to the test for stationarity, measurements are said to derive from fully turbulent conditions if they fall within $30 \%$ of the modelled range.

Results of the flux variance similarity test showed that $89 \%(n=3120)$ of $w$ fell within the ITC modelled range both before and after coordinate rotation. Figure 4.8.3 shows that the test for w performed well during all conditions, although there is more variance in the results during moderately unstable conditions $(\zeta<-1)$ and during stable conditions $(\zeta>0)$ when turbulence was suppressed. The ITC test performed much more poorly for temperature (not shown), as only $56.4 \%(n=1607)$ fell within $30 \%$ of the modeled range, all of which occurred during unstable conditions. Although it is suggested by Foken and Wichura (1996) that data that fails the steady-state and flux variance similarity test is of poor quality, it was not removed from the data set outright.

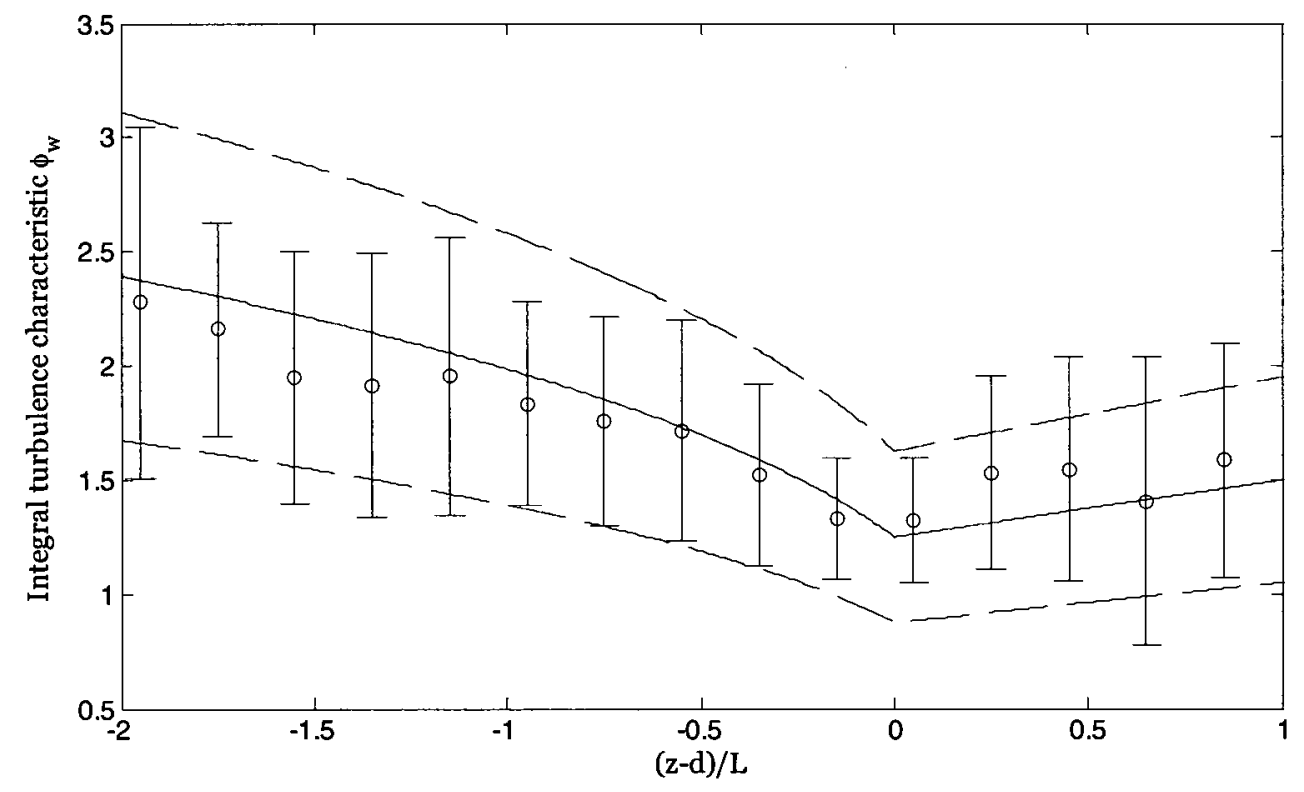

Figure 4.8.3: Integral turbulence characteristic (ITC) $\left(\varphi_{\mathrm{w}}=\sigma_{\mathrm{w}} / \mathrm{u} *\right)$ versus stability $(\zeta)$ using the modeled parameters of Foken and Wichura (1996). Mean \pm 1 s.d. of ITC are indicated by circles and error bars, while the modeled similarity function and 30\% cutoff range are shown as solid and dashed lines, respectively. 


\subsubsection{Flux Footprint}

Flux footprint estimations were calculated using the footprint model of Kljun $e t$ al. (2004). Footprint estimates are primarily controlled by the study area's roughness length $\left(z_{0}\right)$, the height of the EC instrumentation $\left(z_{m}\right)$, the height of the planetary boundary layer $\left(\mathrm{h}_{\mathrm{PBL}}\right)$, and on the turbulence regime in which the scalar is transported. The turbulence regime depends on the ratio of advection to thermal and mechanical turbulent transport. In the model, $\mathrm{u} *$ is used to describe the extent of horizontal advection, while the standard deviation of vertical velocity fluctuations $\left(\sigma_{\mathrm{w}}\right)$ is used to characterize the vertical dispersion strength.

The $\mathrm{u} *$ and $\sigma_{\mathrm{w}}$ input values in Table 4.8 .4 were calculated as the mean $\pm 2 *$ s.d. at times when each stability regime experienced a mean wind speed of $2 \pm 0.3 \mathrm{~m} \mathrm{~s}^{-1}$. The model indicated that the maximum distance to contribute $80 \%$ of the flux $\left(\mathrm{R}_{80}\right)$ corresponded to distances of 93,145 and $186 \mathrm{~m}$ during unstable, neutral and stable conditions, respectively. The area of greatest contribution to the flux $\left(\mathrm{X}_{\max }\right)$ in the same stability regimes was identified to extend out to 42,66 and $85 \mathrm{~m}$ of the tower. These distances became smaller as the ratio of $\sigma_{\mathrm{w}} / \mathrm{u}_{*}$ increased. The $\mathrm{h}_{\mathrm{PBL}}$ that were input into the model were only estimates of typical stability conditions, however the model did not appear to be very sensitive to different values after several tests. Results from the footprint model indicated that although there was adequate fetch in all directions at this site for $\mathrm{X}_{\mathrm{max}}$, there was only adequate fetch for $\mathrm{R}_{80}$ in all directions during unstable periods. During periods of neutral and stable conditions the $\mathrm{R}_{80}$ of the flux footprint extended beyond the site limits in the NNW and SSE directions, providing an opportunity 
for dry air from the upslope tailings sand and moist air originating from the small ponds below to advect past the IRGA and influence the measurements of the turbulent fluxes.

Table 4.8.4: Summary of Dyke 11A South flux footprint results calculated online using the footprint model created by Kljun et al. (2004). Parameterizations are derived from the measured mean standard deviation of vertical velocity fluctuations $\left(\sigma_{\mathrm{w}}\right)$ and surface friction velocity $\left(u_{*}\right) \pm 2 *$ s.d., a measurement height $\left(\mathrm{z}_{\mathrm{m}}\right)$ of $2.4 \mathrm{~m}$, a mean roughness length $\left(z_{0}\right)$ of $0.04 \mathrm{~m}$, and estimated values of typical planetary boundary layer heights $\left(h_{\mathrm{PBL}}\right)$ for each stability regime. Results show the range of distance of maximum flux contribution $\left(\mathrm{X}_{\max }\right)$ and the estimated distance that contributes $80 \%$ to the flux $\left(\mathrm{R}_{80}\right)$.

\begin{tabular}{cccc}
\hline Parameters & Unstable & Neutral & Stable \\
\hline $\boldsymbol{\sigma}_{\mathbf{w}}\left(\mathbf{m ~ s}^{-1}\right)$ & $0.33 \pm 0.11$ & $0.33 \pm 0.12$ & $0.26 \pm 0.13$ \\
$\mathbf{u}^{*}\left(\mathbf{m ~ s}^{-1}\right)$ & $0.23 \pm 0.11$ & $0.26 \pm 0.12$ & $0.19 \pm 0.13$ \\
$\mathbf{h}_{\mathbf{P B L}}(\mathbf{m})$ & 1500 & 800 & 200 \\
$\mathbf{X}_{\max }(\mathbf{m})$ & $22-42$ & $22-66$ & $24-85$ \\
$\mathbf{R}_{\mathbf{8 0}}(\mathbf{m})$ & $48-93$ & $47-145$ & $53-186$ \\
\hline
\end{tabular}

\subsection{Energy Balance Closure}

Energy balance closure was assessed during different periods of the study to ensure that the quality of eddy covariance measurements was consistent with the conservation of energy. Most EC studies report a residual error $(\varepsilon)$ term on the order of $10-30 \%$ (Twine et al., 2000), where the sum of the turbulent fluxes (H and LE) do not equal the difference between net radiation and the ground heat flux. Heat storage is also usually included in the energy balance equation, however it was not calculated in this study as it was assumed to be negligible due to the lack of canopy storage available, and the fact that it is often much less than $\mathrm{G}$. The main reasons for the $\varepsilon$ problem have been attributed to violation of the EC assumptions such as insufficient fetch or non-stationarity arising from missing low frequency flux contributions, or errors of the sensors, which 
may be caused by sensor separation and alignment problems, or interference with the sensor readings caused by dust, water, or bugs (Moncreif et al., 1996; Twine et al., 2000; Lee et al., 2004).

It is commonly assumed that poor energy balance closure is due to an underestimation of the turbulent fluxes rather than any errors incurred in the measurement of $R_{n}$ or $G$, particularly during nighttime stable periods when turbulent mixing is suppressed. In order to examine the effects of stability and turbulence on energy balance closure, closure was assessed in relation to $\zeta$ and $u_{*}$. To allow for comparison, closure was calculated as the slope of the regression of $(\mathrm{H}+\mathrm{LE}) /(\mathrm{Rn}-\mathrm{G})$ forced through zero for the complete field season after despiking and filtering. Results in the top panel of Figure 4.9.1 show that poor closure was a result of weak turbulent mixing, supporting the decision to remove $F_{c}$ fluxes that coincided with $\mathrm{u}_{*}<0.1 \mathrm{~m} \mathrm{~s}^{-1}$. The bottom panel of Figure 4.9.1 shows closure measurements near unity during unstable and neutral periods, however these values become increasingly inadequate with increasing stability $(\zeta>0)$, which are usually associated with nighttime periods. Lack of closure in these conditions was a result of $\mathrm{H}$ and LE measurement errors by the EC system due to turbulent conditions not being fully developed. 

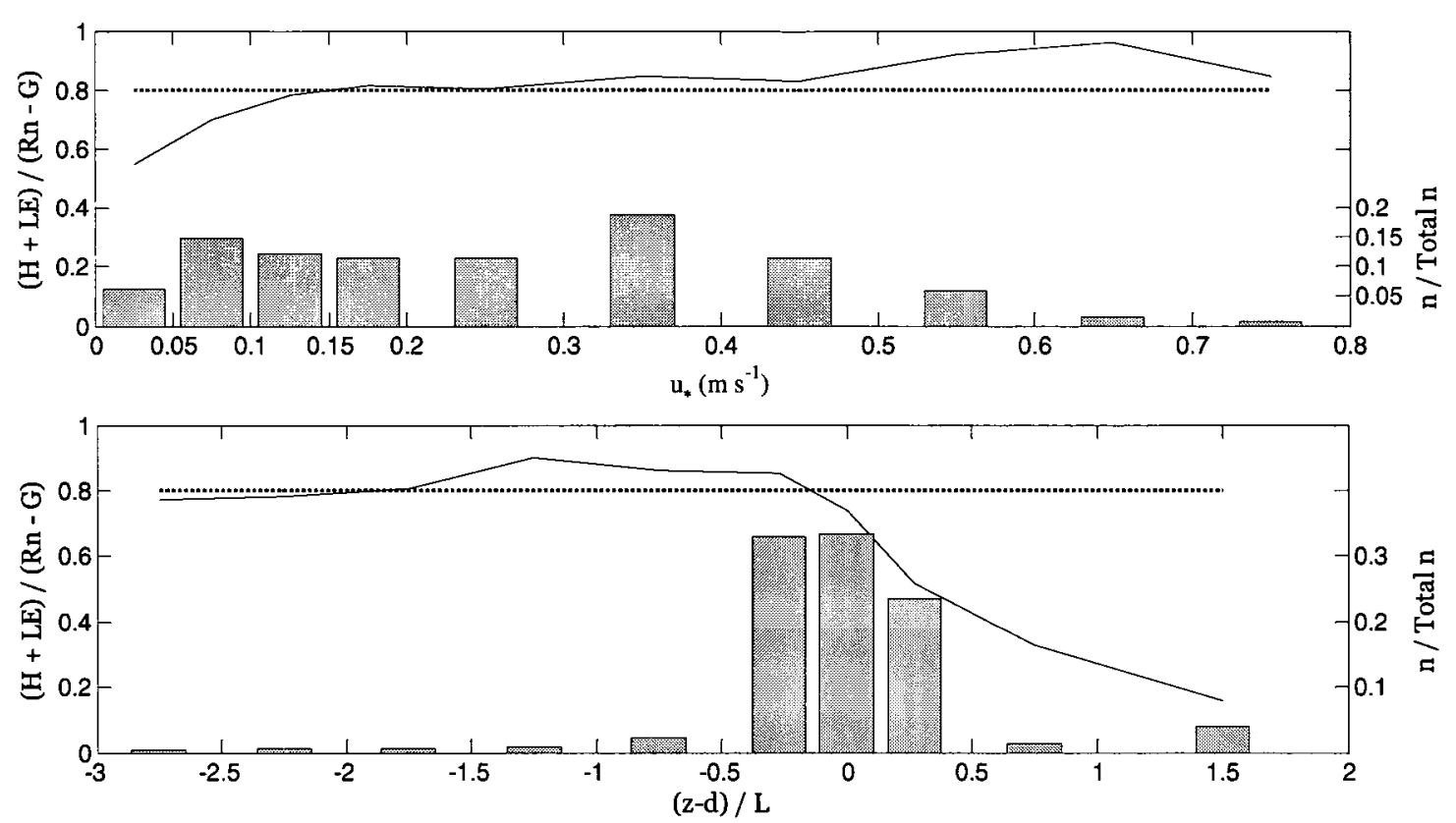

Figure 4.9.1: Energy balance closure calculated as the slope of all half hour measurements of $(\mathrm{H}+\mathrm{LE}) /(\mathrm{Rn}-\mathrm{G})$ forced through zero during similar periods of surface friction velocity ( $\mathrm{u}_{*-}$ top panel) and stability $(\zeta=(\mathrm{z}-\mathrm{d}) / \mathrm{L}-$ bottom panel). The grey vertical bars represent the proportion of half hour measurements that occur within each bin of $u_{*}$ and $\zeta$ ranges, using a minimum of twenty values in each bin. The dotted line in each panel represents a closure error of $-20 \%$.

Energy balance closure for the entire field campaign was relatively good in comparison with most studies $\left((\mathrm{H}+\mathrm{LE}) /(\mathrm{Rn}-\mathrm{G})=87 \%, \mathrm{r}^{2}=0.87\right)$. Midday closure (0900 - 1700) was very similar, increasing to $88 \%\left(r^{2}=0.76\right)$. Closure decreased at night to $55 \%$ and exhibited much more scatter $\left(r^{2}=0.26\right)$.

In order to check if changes in wind direction affected these results, closure was also assessed with regard to the upwind source area, with wind direction binned into $18^{\circ}$ sectors. Figure 4.9.2 shows that the poorest closure corresponded with the predominant easterly winds, which were consistent with the low values of $u_{*}\left(<0.2 \mathrm{~m} \mathrm{~s}^{-1}\right)$ that resulted from wind blowing across the aerodynamically smooth north-easterly sector of Dyke 11A South. Low values of $\mathrm{u} *$, approaching $0.1 \mathrm{~m} \mathrm{~s}^{-1}$, resulted in a closure error that coincided 
with winds from the southwest, as turbulent fluxes exceeded available energy by approximately $20 \%$. Due to winds being sourced from this direction very infrequently $(<$ $2 \%$ of all measurements), these flux values did not have a significant effect on the results and thus were not removed from the data set. Despite the short fetch in the north and south directions, winds sourced from these areas were associated with closure approaching unity, which could be attributed to increased wind blowing across the terraced slope of the surface that caused $u *$ values to increase up to $0.2-0.4 \mathrm{~m} \mathrm{~s}^{-1}$.

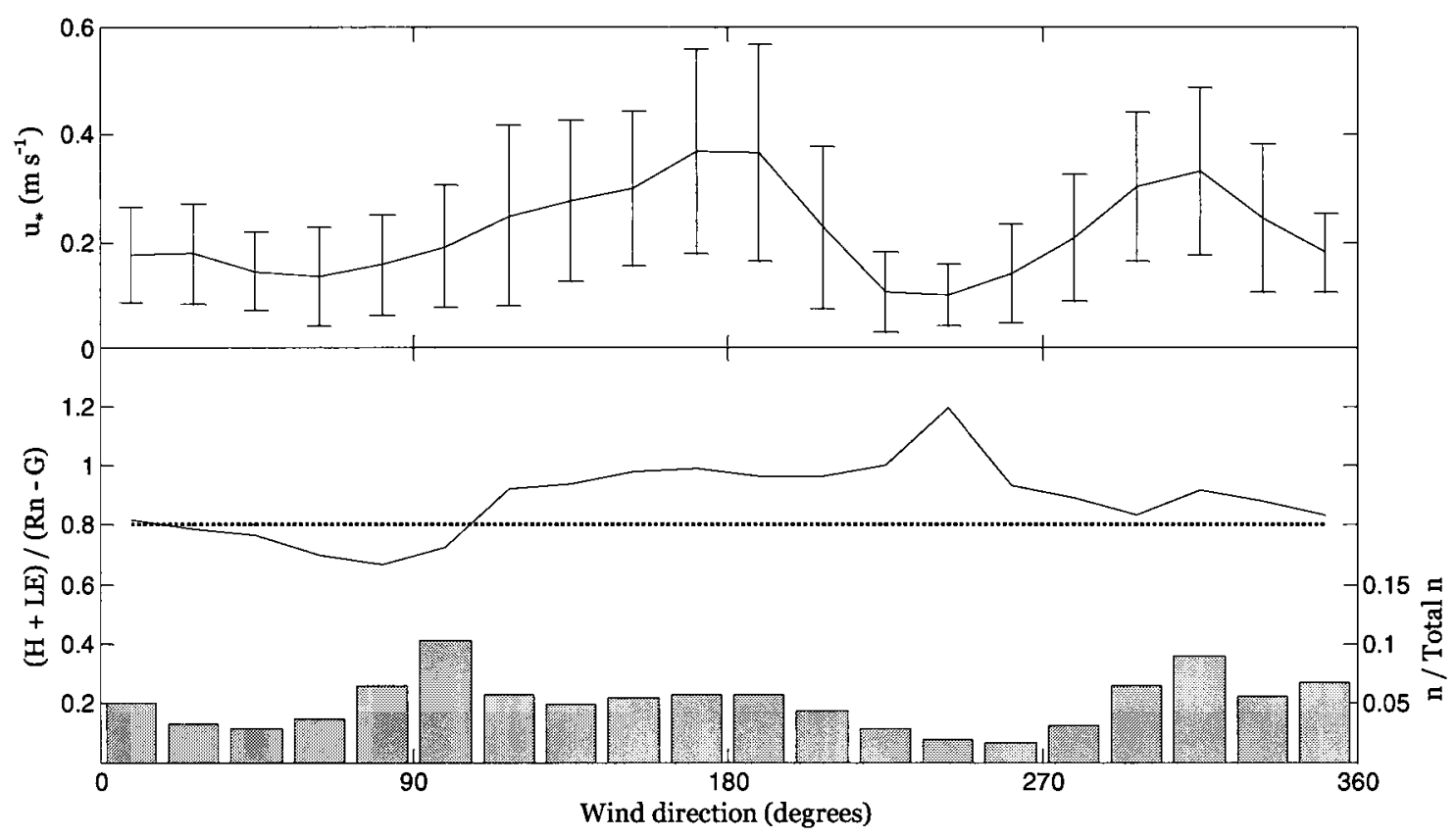

Figure 4.9.2: Relation of mean surface friction velocity $\left(\mathrm{u}_{*}\right)$ and energy budget closure calculated from the linear regression of $(\mathrm{H}+\mathrm{LE}) /(\mathrm{Rn}-\mathrm{G})$ forced through zero for half hour measurements between May 10 - October 8 (DOY 131 -282). Results correspond to wind directions binned into $18^{\circ}$ sectors, with vertical bars representing the proportion of half hour wind direction measurements that occur within each bin. Error bars in the top panel show \pm 1 s.d. of the mean $\mathrm{u} *$ for each wind direction sector. The dotted line in the bottom panel represents a closure error of $-20 \%$. 
Due to the many reasons identified in the literature that may account for lack of closure, various methods have been proposed to correct for $\varepsilon$ (Lee et al., 2004; Twine et al., 2000). However, no measures were taken to adjust any of the fluxes in this study due to the current uncertainty of what actually causes the $\varepsilon$ term. Falge (2008) recently advised that the lack of energy balance closure is actually more of a scale issue, as the larger surrounding heterogeneous landscape can have a significant influence on sensible fluxes of heat. It is suggested that rather than the high frequency eddies, it is more likely large scale eddies that contribute more to $\varepsilon$, and thus increasingly longer measurement times (up to $24 \mathrm{hrs)}$ may be needed to completely close the energy balance. Furthermore, the errors associated with the measurement of $\mathrm{G}-$ heat storage issues and the questionable representation of using only one soil heat flux plate within the entire flux footprint - may also be an important factor in the lack of energy balance closure (Cava et al., 2008). 


\subsection{Results and Discussion}

\subsection{Climatic Conditions}

2008 was distinct as there was record snow accumulation, a relatively dry spring, and a growing season with both temperature and precipitation higher than average (Table 5.1). While temperatures were higher than normal for each month from May to June, the increase in precipitation was due to a wet August, which had more than double the normal precipitation $(150.6 \mathrm{~mm})$. Precipitation in June and July was near average, while May and September were drier.

Table 5.1: Comparison of mean monthly temperatures and total precipitation during the 2008 field season (May 10 - Sept 30 (DOY 131 - 274)) with Environment Canada's $1971-2000$ climate normals (CN.).

\begin{tabular}{ccccccc}
\hline Month & May & June & July & Aug & Sept & Season \\
\hline Temp & 13.1 & 16.7 & 17.8 & 16.9 & 9.6 & 14.9 \\
CN. $\left({ }^{\circ} \mathrm{C}\right)$ & 10.4 & 14.7 & 16.8 & 15.3 & 9.4 & 13.3 \\
Precip & 7.1 & 74.7 & 70.6 & 150.6 & 24.6 & 327.7 \\
CN. $(\mathrm{mm})$ & 36.9 & 74.8 & 81.3 & 72.7 & 46.8 & 312.5 \\
\hline
\end{tabular}

\subsubsection{Temperature}

The seasonal trends of mean 24 hour temperatures of air $\left(\mathrm{T}_{\mathrm{a}}\right.$ - measured at EC height) and soil $\left(\mathrm{T}_{\mathrm{s}}-\right.$ measured at a depth of $\left.0.05 \mathrm{~m}\right)$ are shown in Figure 5.1.1. The trend of $\mathrm{T}_{\mathrm{s}}$ (Figure 5.1.1, Panel B) followed that of $\mathrm{T}_{\mathrm{a}}$ (Figure 5.1.1, Panel A) closely, yet exhibited less variability. Maximum $\mathrm{T}_{\mathrm{s}}\left(19^{\circ} \mathrm{C}\right.$ on July 12 (DOY 194)) occurred earlier than maximum $\mathrm{T}_{\mathrm{a}}\left(24.7^{\circ} \mathrm{C}\right.$ on August 18 (DOY 231)) and remained predominantly warmer than $T_{a}$ throughout the entire growing season (Figure 5.1.1, Panel C). Higher $T_{s}$ was a result of the lack of shade provided by the incomplete vegetation cover, as well as the thermal properties of the soil. Other studies conducted within more mature and 
developed tree canopies in the boreal forest have shown above-canopy $\mathrm{T}_{\mathrm{a}}$ to be generally greater than $\mathrm{T}_{\mathrm{s}}$ (Baldocchi et al., 1997; Moore, 2008). Exceptions where $\mathrm{T}_{\mathrm{a}}$ was greater than $T_{s}$ at Dyke 11A South occurred on extremely hot and sunny days, during the period when LAI had reached a plateau (Figure 5.2.1). Greater $T_{s}$ was a result of more energy being exchanged at the surface and enabled more ET to be contributed from the soil.

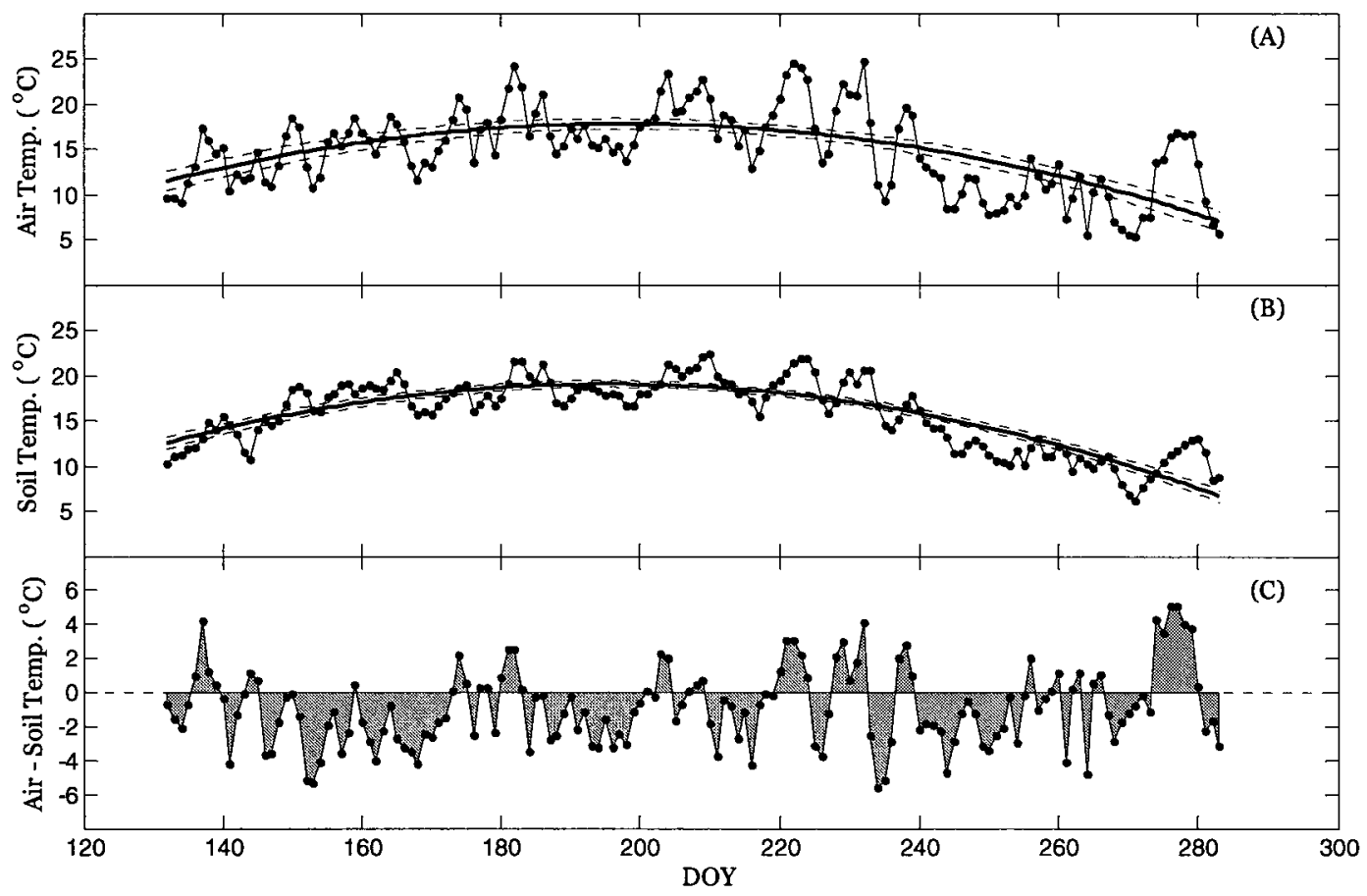

Figure 5.1.1: Time series showing (A) the diurnal variation in mean air temperature $\left(\mathrm{T}_{\mathrm{a}}\right)$ and (B) soil temperature $\left(\mathrm{T}_{\mathrm{s}}\right)$ measured at a depth of $0.05 \mathrm{~m}$, as well as (C) the difference between them $\left(\mathrm{T}_{\mathrm{a}}-\mathrm{T}_{\mathrm{s}}\right)$ during the 2008 growing season at Dyke 11A South. The seasonal trend of $T_{a}$ and $T_{s}$ is highlighted (solid line) using a $2^{\text {nd }}$ order polynomial regression $\left(r^{2}=0.40\right.$ for $T_{a} ; r^{2}=0.71$ for $\left.T_{s}\right)$ with $95 \%$ confidence intervals (dotted lines) in panels $\mathrm{A}$ and $\mathrm{B}$. The shaded area in panel $\mathrm{C}$ indicates differences with respect to zero.

\subsubsection{Precipitation}

As the tipping bucket rain gauge was calibrated to tip for every $0.254 \mathrm{~mm}$ of rain that collected in the bucket, it was possible that light precipitation could have occurred 
and not have been recorded in successive half hour measurements. To account for this, individual rain events in the following analysis were recognized and grouped together when $P>0$ in a span of six hours. Palynchuk and Guoy (2008) indicated that this is a sufficient length of time to minimize any serial correlation between storm events and allows each event to be characterized by the depth, duration and intensity of rainfall.

A total of $340.9 \mathrm{~mm}$ of precipitation fell during 59 individual rainfall events. Initial conditions at Dyke 11A South were dry, with no large rainfall events occurring until June 5-6 (DOY $157-158$ ) with $13 \mathrm{~mm}$. As shown in Table 5.1, June and July experienced average precipitation, while the climate normal of August (72.7 mm) was doubled, being surpassed in three days when $79.2 \mathrm{~mm}$ of rain fell between August $11-$ 13 (DOY 224 - 226). A season-high $31 \mathrm{~mm} \mathrm{hr}^{-1}$ was observed to fall during one halfhour period on August 11 (DOY 224), and was followed by relatively constant $24 \mathrm{hr}$ precipitation on August 12 (DOY 225). The largest single-day precipitation event was October 6 (DOY 280) when $54.6 \mathrm{~mm}$ fell following the dry month of September.

The majority of precipitation measured during the season was delivered in intense bursts, with $65.8 \%$ of the total half-hourly measured precipitation falling at rates greater than $2 \mathrm{~mm} \mathrm{hr}^{-1}$. Although $46 \%$ of all precipitation was delivered in short $(<2 \mathrm{hr})$ bursts, there was also a relatively large amount (30\%) that spanned intervals over $5 \mathrm{hrs,}$ with one particularly long-duration event lasting $15.5 \mathrm{hrs}$ (Figure 5.1.2, Panel A). When averaged over their durations, $78 \%$ of all rain events contained a mean rainfall intensity of $<2 \mathrm{~mm}$ $\mathrm{hr}^{-1}$. (Figure 5.1.2, Panel B). 

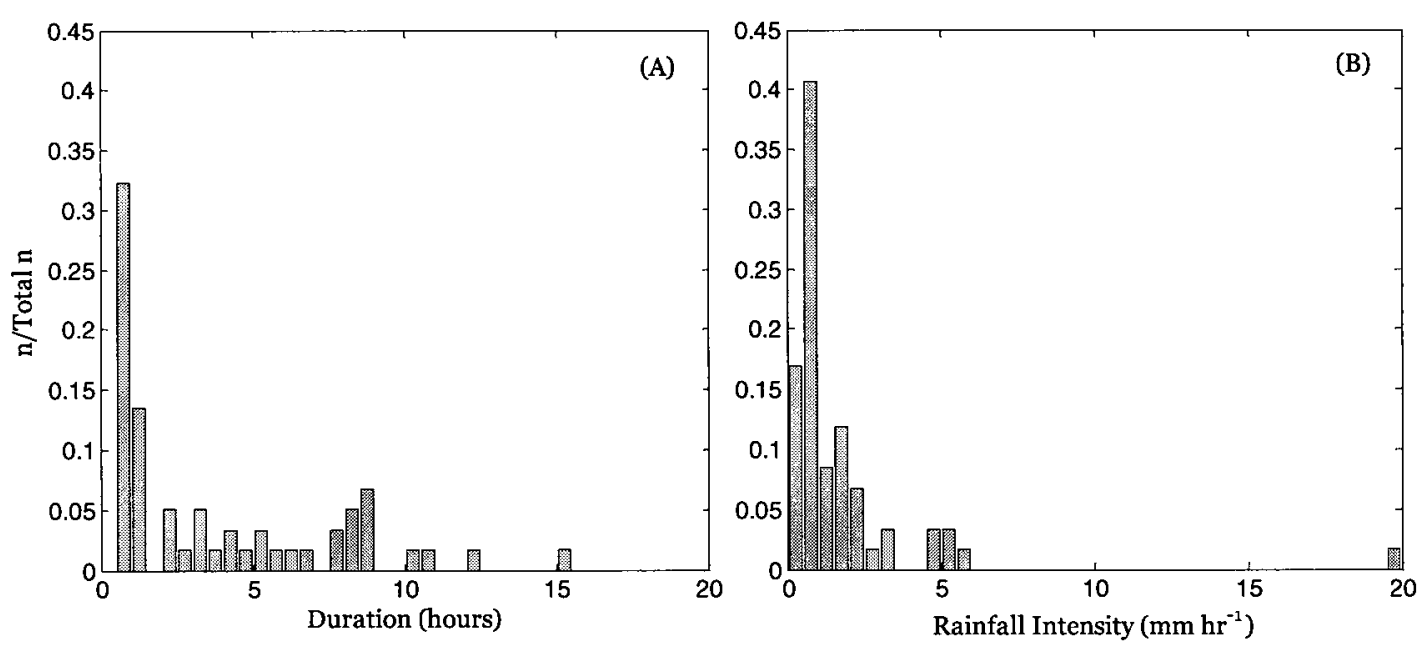

Figure 5.1.2: Percentage of rainfall events $(n=59)$ corresponding to half-hourly binned durations (Panel A) and $0.5 \mathrm{~mm} \mathrm{hr}^{-1}$ bins of rainfall intensity (Panel B).

\subsubsection{Wind}

Winds originating from the south-east direction were found to be responsible for the majority of precipitation (Figure 5.1.3, Panel B), giving evidence that the unseasonal rainfall was attributed to the cyclonic rotation of low pressure systems traveling through the area. The predominant winds at Dyke 11A South originated from the east and northwest directions (Figure 5.1.3, Panel A), with no discernible difference occurring between the day and night (not shown). 
(A) Seasonal Wind Direction

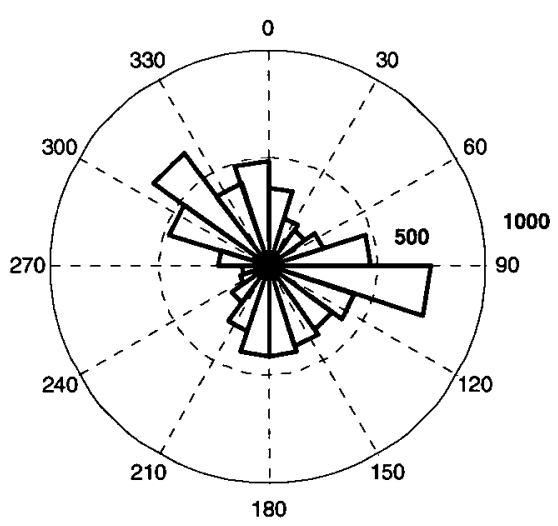

(B) Winds Associated with Storms

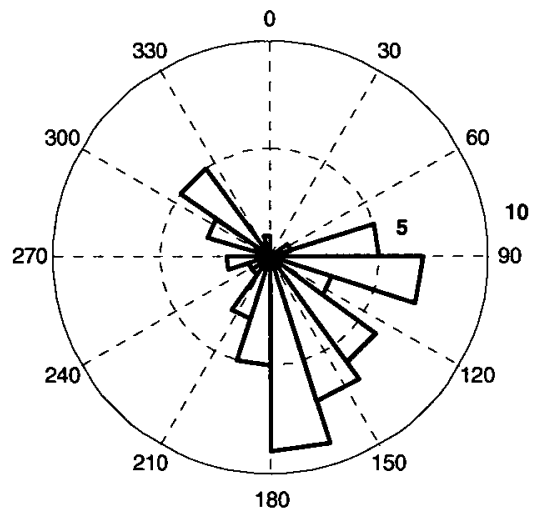

Figure 5.1.3: Wind roses indicating (A) the seasonal patterns of wind direction and (B) mean wind direction associated with storm events. The values on the right of each of the inner and outer axes represent the number of recorded half-hour measurements within each $18^{\circ}$ bin interval (A) and in (B) represent the number of storm events that originated from each corresponding bin direction.

The influence of wind speed on LE had the potential to be an important factor in causing evaporation from the large portion of exposed bare soil at Dyke 11A South.

There was a high degree of seasonal variability in the measured mean daily wind speeds, with a mean ( \pm s.d.) daily wind speed of $2.15 \pm 0.91 \mathrm{~m} \mathrm{~s}^{-1}$ (Figure 5.1.4). Mean wind speeds decreased steadily throughout the summer, with the exception of increased wind speeds that were associated with the stormy conditions in August. 


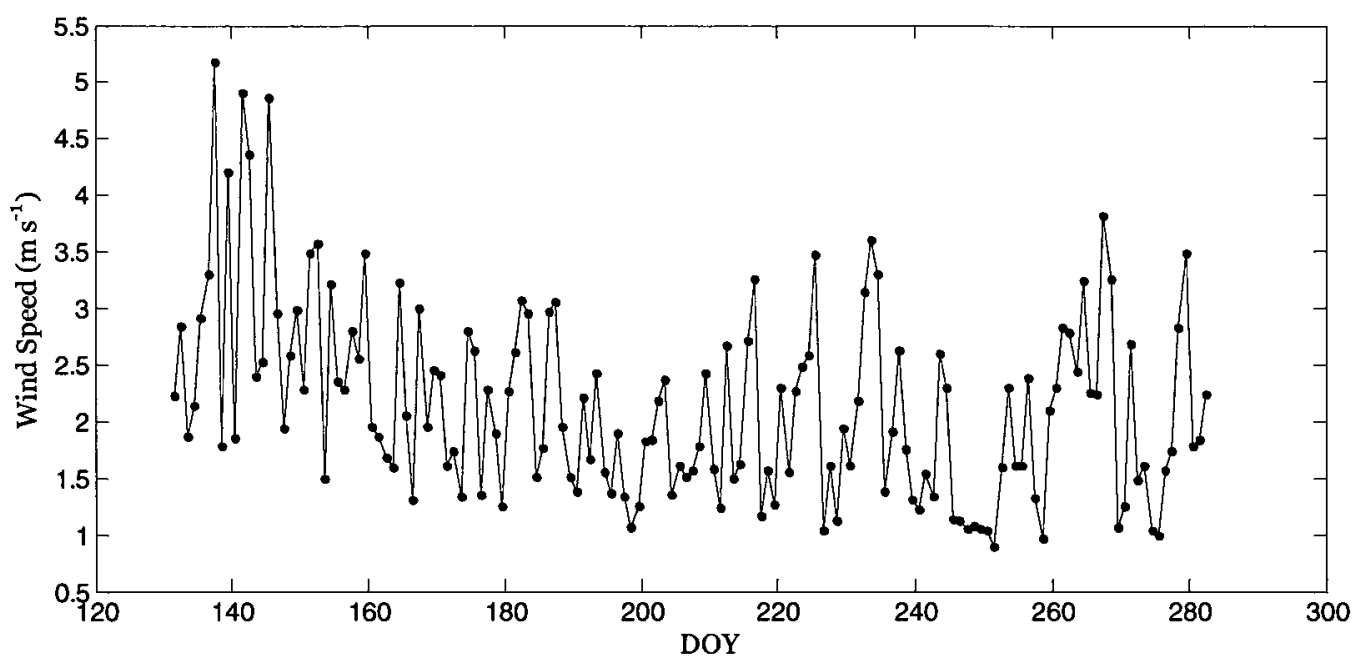

Figure 5.1.4: Seasonal variation in mean daily wind speed measured at Dyke 11A South.

\subsection{Surface Conditions}

\subsubsection{Leaf Area Index}

Leaf area index (LAI) was measured eight times during the study to monitor the growth of vegetation over the course of the growing season (Figure 5.2.1). Although error is incurred using the LAI-2000 for LAI measurements due to the measuring lens being unable to "see" the ground cover below the device, results do show the general trend of vegetation growth at the site. Ground cover was predominantly bare at the beginning of May (Figure 5.2.1), as the jack pine and other tree and shrub seedlings that had been planted only amounted to 0.35 stems $\mathrm{m}^{-2}$. Bud-burst occurred in June (DOY $153-182)$, as the growth of fireweed, sow thistles, buffaloberry, horsetail and barley foxtail increased LAI to over $1 \mathrm{~m}^{2} \mathrm{~m}^{-2}$. Throughout July and August (DOY $183-233$ ) LAI reached a plateau between $2.5-3.5 \mathrm{~m}^{2} \mathrm{~m}^{-2}$ with the vegetation cover being dominated by the growth of fireweed, Canada goldenrod, rough cinquefoil, grasses and sow thistles (which grew $>1 \mathrm{~m}$ high). Mean vegetation height measured within $0.5 \mathrm{~m}^{2}$ 
plots at one end of each LAI transect averaged to $0.5 \pm 0.15 \mathrm{~m}$. Photographs taken during the last site visit on August 21 (DOY 234) showed senescence of some of the vegetation, indicating that the LAI measurements captured the bulk of the growing season.

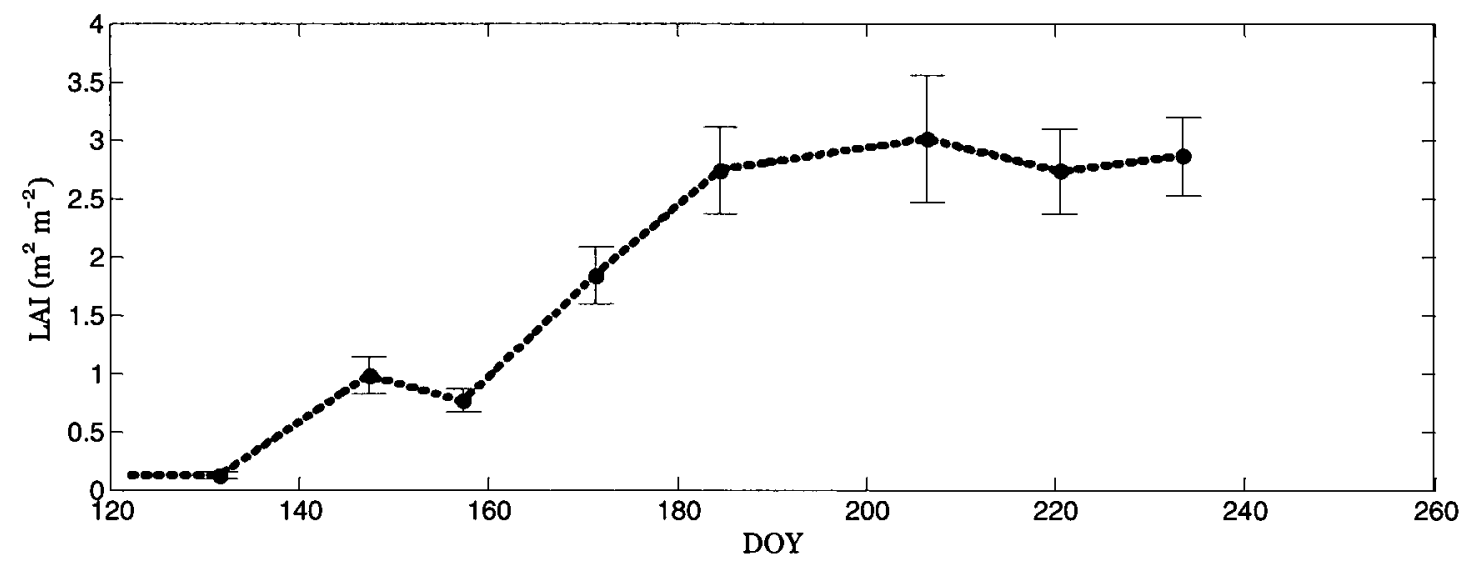

Figure 5.2.1: Time series of mean leaf area index (LAI) measured at Dyke 11A South during the 2009 field season. Measurements occurred approximately bi-weekly from May 10 - August 21 (DOY 131 - 234). Error bars indicate \pm 1 standard error.

\subsubsection{Soil Moisture}

As Dyke 11A South was comparable to a grassland, and studies have established that plant roots in these environments are predominantly confined to the top $0.3 \mathrm{~m}$ of soil (Sims et al., 1978), measurements of $\theta_{\mathrm{s}}$ and $\Psi_{\mathrm{m}}$ within the $0.25 \mathrm{~m}$ soil cover were assumed to encompass the complete root zone for the vegetation at this site. Having only experienced minimal growth prior to the 2008 growing season, the jack pine and other tree seedlings would not have tapped into deeper sources of soil moisture than what was measured. However, should they be able to survive, the moisture stored in the underlying sand will help to promote their growth in the future.

Spring thaw at the end of April enabled the $0.25 \mathrm{~m}$ soil cover to enter the 2008 growing season at field capacity $\left(\theta_{\mathrm{fc}}=0.27 \mathrm{~m}^{3} \mathrm{~m}^{-3}\right.$ in loam soils (Campbell and Norman, 
1998)). Soil moisture declined steadily until a series of rainfall events saturated the cover again in June (beginning DOY 157) (Figure 5.2.2). Frequent precipitation in the summer months allowed the soil cover to maintain adequate moisture for vegetation growth for the majority of the season, as $\theta_{\mathrm{s}}$ never dropped below the wilting point for plants $\left(\theta_{\mathrm{wp}}=\right.$ $0.12 \mathrm{~m}^{3} \mathrm{~m}^{-3}$ in loam soils (Campbell and Norman, 1998)). Minimum levels of $\theta_{\mathrm{s}}$ that were measured at the $0.05,0.15$ and $0.25 \mathrm{~m}$ depths were $0.22,0.19$ and $0.16 \mathrm{~m}^{3} \mathrm{~m}^{-3}$, respectively.

The peat-mineral mixture was found to respond rapidly to precipitation events (Figure 5.2.2). There was little variability in the sand $\theta_{\mathrm{s}}$ for the majority of the season, except during several large storms that occurred in August (DOY 210 - 226) and near the end of the study in October (DOY 280), where $\theta_{\mathrm{s}}$ at $0.4 \mathrm{~m}$ increased from 0.05 to $0.13 \mathrm{~m}^{3}$ $\mathrm{m}^{-3}$ and from 0.07 to $0.13 \mathrm{~m}^{3} \mathrm{~m}^{-3}$, respectively. The increases in $\theta_{\mathrm{s}}$ at $0.4 \mathrm{~m}$ were due to the overlying cover exceeding $\theta_{\mathrm{fc}}$, which resulted in negligible $\Psi_{\mathrm{m}}$ (Figure 5.2.3) and allowed the excess water to drain down into the sand. Beneath this level the $\theta_{\mathrm{s}}$ of the sand at $0.8 \mathrm{~m}$ remained relatively constant at $0.22 \mathrm{~m}^{3} \mathrm{~m}^{-3}$, indicating that it was never impacted by a wetting front in the soil. 


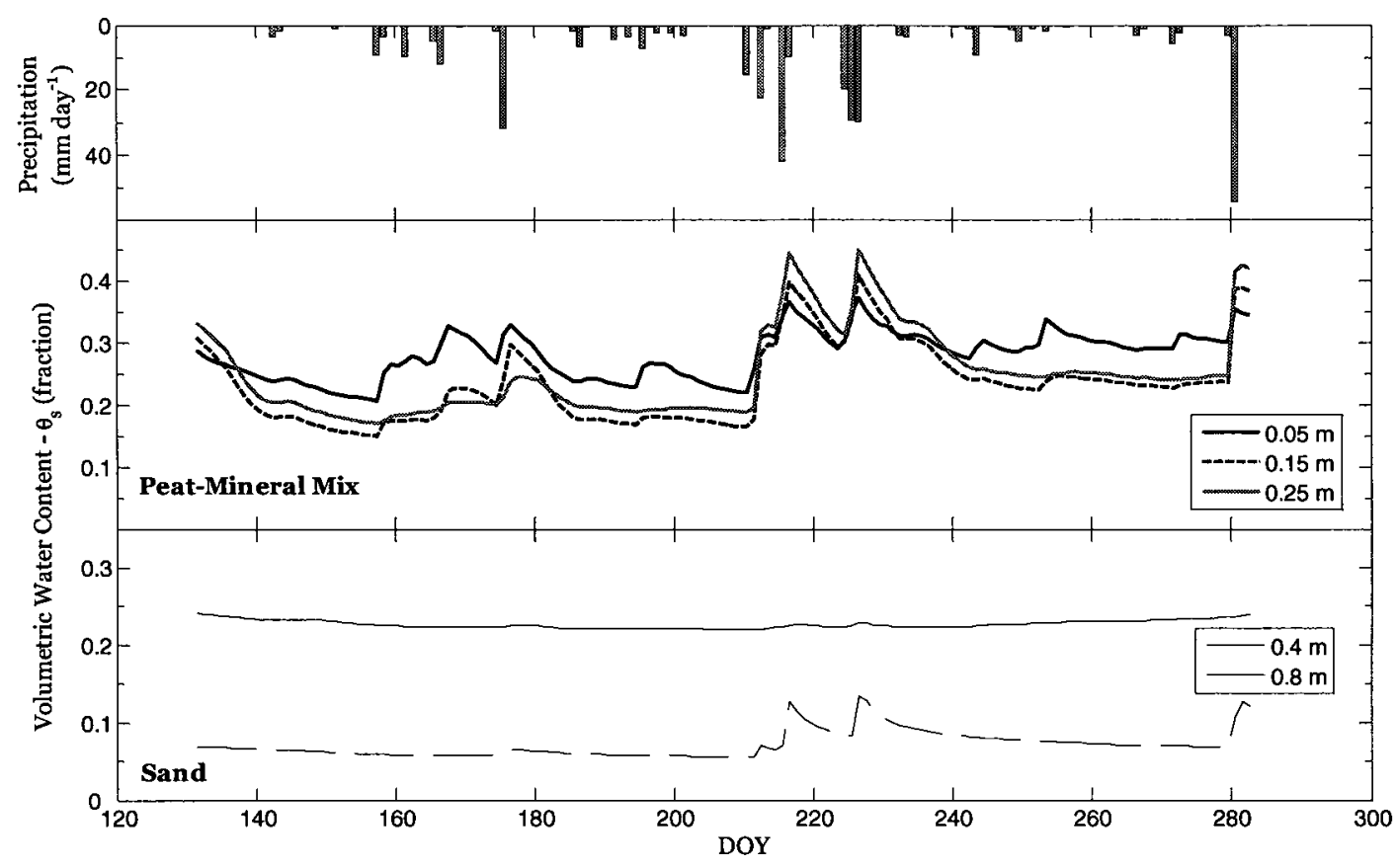

Figure 5.2.2: Seasonal variability of mean daily soil moisture content $\left(\theta_{\mathrm{s}}\right)$ during the 2008 growing season at Dyke 11A South. $\theta_{\mathrm{s}}$ in the soil cover is separated into two separate panels to show the difference between the peat-mineral mix and the underlying sand. Total daily precipitation is also included to show the soil cover's response to rain events.

The trend of $\Psi_{\mathrm{m}}$ was similar to $\theta_{\mathrm{s}}$ (Figure 5.2.3). There was less variability in the $0.15 \mathrm{~m} \Psi_{\mathrm{m}}$ than in the 0.05 and $0.25 \mathrm{~m} \Psi_{\mathrm{m}}$, as $\Psi_{\mathrm{m}}$ at $0.15 \mathrm{~m}$ remained around $-350 \mathrm{kPa}$ between June 2 - August 1 (DOY 154 -214). Being as there was a considerable amount of variation in the $0.15 \mathrm{~m} \theta_{\mathrm{s}}$ during this period (Figure 5.2.2), the flat-lining of the corresponding $\Psi_{\mathrm{m}}$ while the soil was drying at this level was most probably due to cavitation of the L-229 electronic tensiometer. Cavitation refers to a water vapour bubble that develops on the ceramic matrix of the measuring device, which would have lowered the potential energy of the water under tension to a point where the equipment became unresponsive. Heavy rains and rewetting of the soil at the beginning of August appeared to reestablish contact of the ceramic matrix with the soil, as $\Psi_{\mathrm{m}}$ at this level returned to 
follow the same general trend as the levels above and below it again for the remainder of the season.

During this period of equipment failure, $\Psi_{\mathrm{m}}$ at $0.05 \mathrm{~m}$ never decreased below -490 $\mathrm{kPa}$, as it responded rapidly to the many precipitation events that occurred. The $0.25 \mathrm{~m}$ $\Psi_{\mathrm{m}}$ showed greater variability but did not respond notably to small precipitation events. For example, despite the $33 \mathrm{~mm}$ of rain that fell between June 25 - July 28 (DOY 177 $210), \Psi_{\mathrm{m}}$ at $0.25 \mathrm{~m}$ continued to decline from $-8 \mathrm{kPa}$ to $-780 \mathrm{kPa}$.

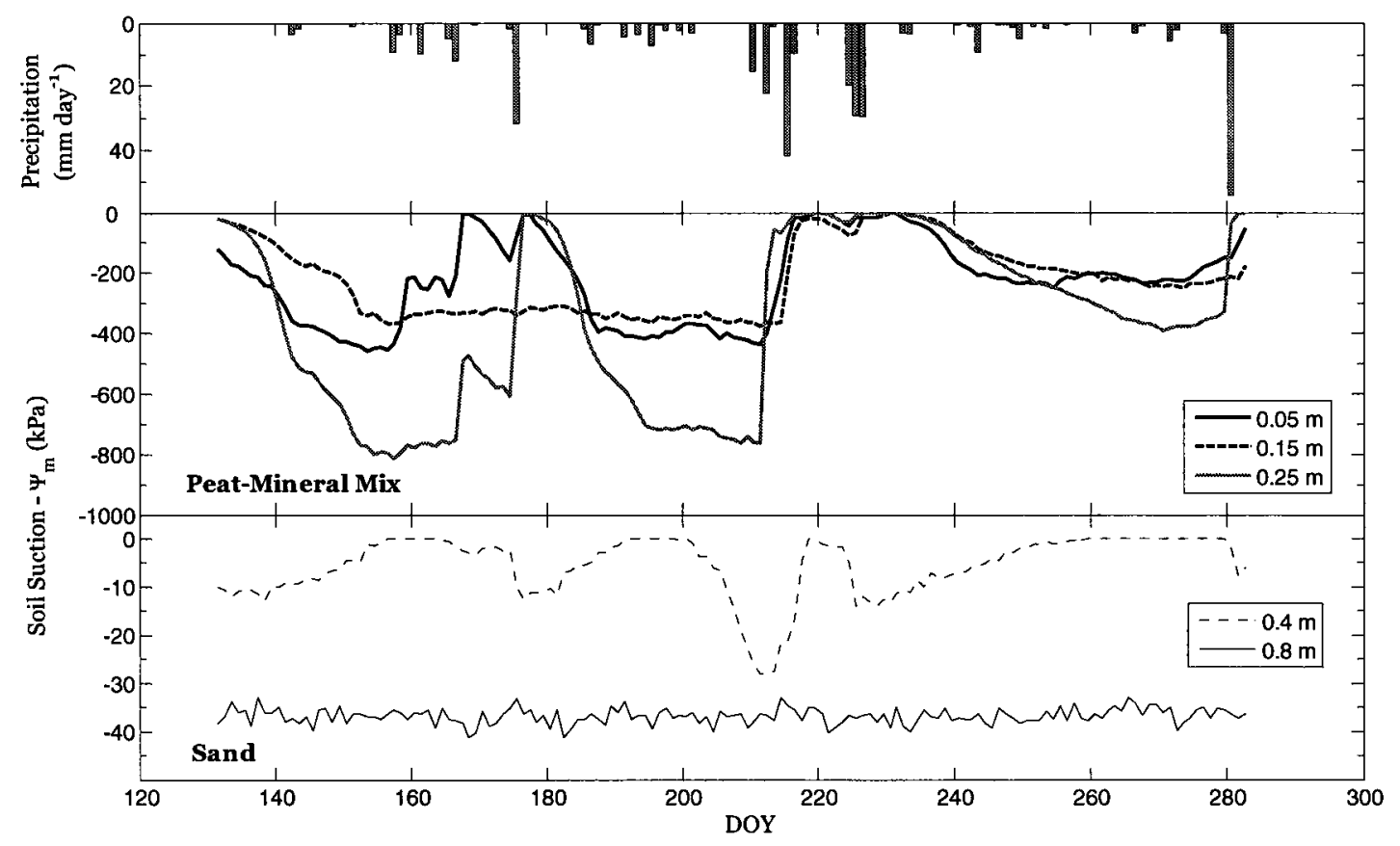

Figure 5.2.3: Seasonal variability of mean daily soil suction $\left(\Psi_{m}\right)$ during the 2008 growing season at Dyke 11A South. $\Psi_{\mathrm{m}}$ in the soil cover is separated into two separate panels to show the difference between the peat-mineral mix and the underlying sand. Total daily precipitation is also included to show the soil cover's response to rain events.

Studies have found that plant roots respond to decreasing amounts of available water in the soil by sending abscisic acid to the leaves that triggers stomatal closure (Kelliher et al., 1993). As such, $\Psi_{\mathrm{m}}$ measurements provided an indication of the level of 
stress experienced by the vegetation that may have limited ET. $\Psi_{\mathrm{m}}$ values indicated that the vegetation at Dyke 11A South would not likely have been drought stressed as $\Psi_{\mathrm{m}}$ remained above the wilting point for most plants $\left(\Psi_{\mathrm{wp}}=-1500 \mathrm{kPa}\right)($ Wilson et al., 1997). The lowest $\Psi_{\mathrm{m}}$ reached at the $0.25 \mathrm{~m}$ level was $-826 \mathrm{kPa}$ on June 5 (DOY 157). $\Psi_{\mathrm{m}}$ in the sand varied much less in magnitude than that of the cover soil, ranging between 0 and $-30 \mathrm{kPa}$ at $0.4 \mathrm{~m}$ and remained constant between -30 and $-40 \mathrm{kPa}$ at the $0.8 \mathrm{~m}$ depth. The increase in variability of $\Psi_{\mathrm{m}}$ at $0.4 \mathrm{~m}$ may be due to a different soil texture that resulted during the placement of the soils at the site. Being as measurements made at this level are close to the capillary break, mixing of the soils may have occurred while spreading the overlying peat/mineral mixture during construction. This is supported by the differences in bulk densities at the two depths within the sand, which are 1.53 and 1.46 $\mathrm{Mg} \mathrm{m}^{-3}$ at the 0.4 and $0.8 \mathrm{~m}$ depths, respectively.

\subsection{Water balance}

As the major water balance components at this site were predominantly vertical, a method to check the reliability of the LE measurements was to conduct an assessment of the measured water balance. As there were no observed runoff pathways at the soil surface, the measurements of P, ET and $\theta_{\mathrm{s}}$ should have captured the majority of the water on site.

The cumulative trends in Figure 5.3, Panel A show that ET exceeded P for roughly the first half of the study. A series of large rain events occurred between July 27 - August 14 (DOY $210-227$ ), resulting in cumulative $P$ to rise from 121 to $285 \mathrm{~mm}$ in 18 days. This allowed $P$ to approach cumulative ET on August 2 (DOY 215), and eventually surpass ET levels on August 12 (DOY 225). As mentioned, the series of 
storms that occurred during this period were unseasonal, as the precipitation deficit that was experienced prior to this is what is normally expected in the region. ET never exceeded $\mathbf{P}$ following this period, as decreasing temperatures and the onset of senescence inhibited ET rates. When measurements ceased on October 8 (DOY 282) the total cumulative $P$ was $385 \mathrm{~mm}$ and cumulative ET was $308 \mathrm{~mm}$.

Figure 5.3, Panel B includes the cumulative change in soil moisture storage $(\Delta \mathrm{S})$ while also showing the difference of $\mathrm{P}$ and ET. The shaded bars indicate the seasonal fluctuation between a soil moisture deficit and surplus in comparison to what was measured. The $\mathrm{P}-\mathrm{ET}$ and $\Delta \mathrm{S}$ traces mirror each other throughout the majority of the season, never deviating by more than $22 \mathrm{~mm}$ before July 30 (DOY 212). There are many possible reasons that might explain the unaccounted water, first of which could be the location of the rain gauge that was located about $0.5 \mathrm{~km}$ away. Even though this distance is small, the precipitation in Fort McMurray occurs typically in localized convective cells, resulting in large spatial variability of total precipitation measured. Soil moisture is also highly variable in space, and the representativeness of one soil moisture profile at a point location is questionable. Furthermore, the spacing of the water content reflectometers and tensiometers buried at varying intervals throughout the soil may have biased the weighted soil moisture values for the profile.

The initial surplus of water coincided with the large gap in the measured LE data that had to be filled from May $16-26$ (DOY $137-147$ ), where only $25 \%$ of the original measured data was available. Following this event, the largest discrepancy occurred after the extended stormy period that ended on August 14 (DOY 227). Up until this point, soil moisture responded in a similar fashion to the $\mathrm{P}-\mathrm{ET}$ trace. Afterwards the slope of $\Delta \mathrm{S}$ 
decreased at a much greater pace until August 19 (DOY 232), causing the net surplus of water to increase over $20 \mathrm{~mm}$. The $164 \mathrm{~mm}$ of rain that fell in a span of 18 days prior would have saturated the soil cover, suggesting that some of this water may have been lost to deep percolation. Another plausible possibility is that some water may have ponded on the surface and been lost to overland flow. Following August 19 (DOY 232) the two traces became more similar, resulting in the shaded bars remaining at a relatively constant level for the remainder of the season. Over the course of the study, a net surplus of $40 \mathrm{~mm}$ of water is suggested by the soil water balance, which is comparable with the $77 \mathrm{~mm}$ from P - ET (Figure 5.3). 


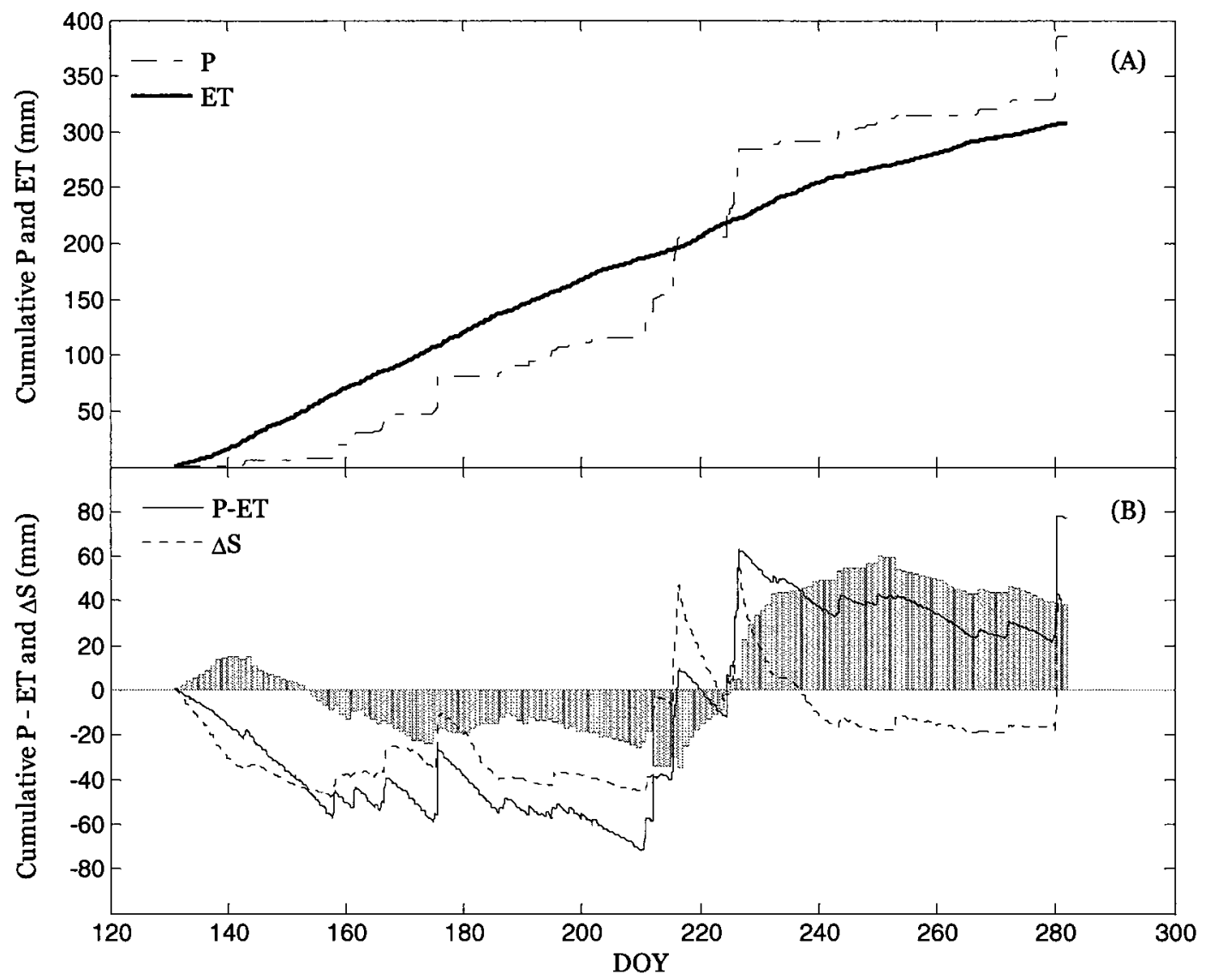

Figure 5.3: (A) Cumulative sum of precipitation (P) and evapotranspiration (ET) from May 10 - October 8 (DOY 131 - 282). (B) Cumulative inventory of all water balance components, including the cumulative change in soil moisture storage $(\Delta S)$ of the entire soil cover (measured to a depth of $0.8 \mathrm{~m}$ ). The shaded bars represent the difference between $\Delta S$ and $P-E T$, indicating a net surplus of $40 \mathrm{~mm}$ of water by the end of the field study.

\section{$5.4 \quad$ Surface Energy Balance}

\subsubsection{Albedo}

One of the major differences seen in the surface energy balances when comparing pre-mining activities to post-mining restoration efforts is the change in the surface albedo. In the oil sands region the heterogeneous, aerodynamically rough and undulating 
dark surfaces of the pre-existing black spruce-dominated forests and muskeg are replaced with surfaces that are largely homogeneous, unidirectional in aspect, aerodynamically smooth (at least initially), and consist of soil and vegetation that is optically brighter.

The mean ( \pm s.d.) surface albedo at Dyke $11 \mathrm{~A}$ South was $0.2 \pm 0.03$ during the 2008 study, which is comparable to an albedo of 0.2 that is common to grasslands and agricultural fields (Stull, 1997). This was much higher than the surrounding boreal landscape, where conifer and wetland sites typically range between $0.07-0.13$ and 0.15 -0.18 , respectively (Baldocchi et al., 2000). In a study of boreal disturbances caused by fire, Chambers and Chapin (2003) found that the albedo of regenerating black spruce stands can change from a very low value of 0.06 immediately following fire to normal levels within $4-7$ years.

There was a significant change in the albedo at Dyke 11A South throughout the study, as indicated by the daily mean maximum $(0.29)$ and minimum $(0.13)$ values shown in Figure 5.4.1. There are several reasons for this high degree of variability, namely changes in solar declination, cloud cover, surface wetness, and the change in stand architecture with the growth of vegetation (Oke, 1987). The generally decreasing seasonal trend in albedo coincided with the growth in vegetation, where increased radiation trapping resulted from the changes in surface geometry as vegetation grew and developed.

There was a decrease in albedo during dry periods and increase during periods of increased precipitation and soil moisture. This finding contradicts the fact that a dark, moist soil has a lower albedo than a dry soil (Oke, 1987). The reason for the discrepancy could be explained from the blooming of the bright, yellow flowers associated with the 
buffalo beans, Canada goldenrod, tansy mustard and sow thistles, whose growth bursts all coincided with an increase in available moisture and a corresponding increase in albedo.

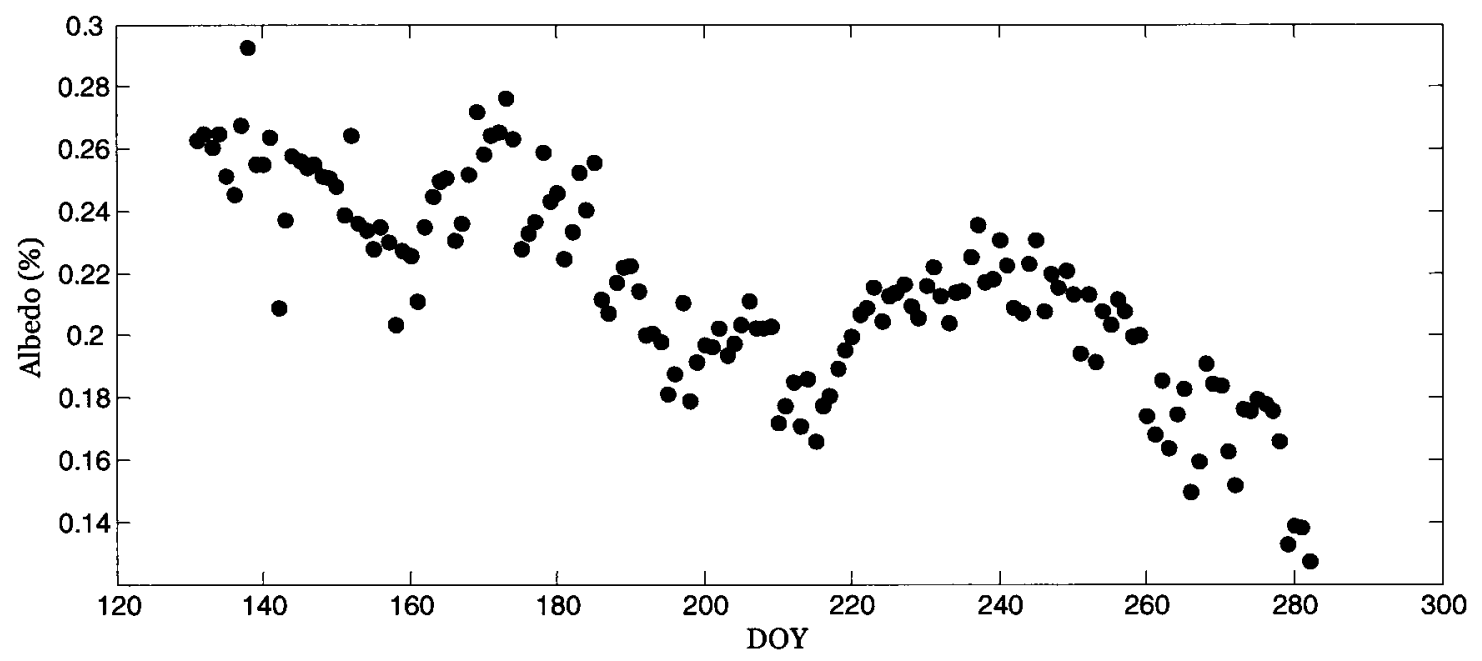

Figure 5.4.1: Seasonal variation of albedo, calculated as the mean $\mathrm{K} \uparrow / \mathrm{K} \downarrow$ between 1100 -1500 from DOY $131-282$.

\subsubsection{Radiation Efficiency $\left(R_{\mathrm{e}}\right)$}

The implications of a high albedo is that there was more incident radiation reflected away from the surface and less available to contribute to net radiation $\left(R_{n}\right)$. This ultimately reduced the site's radiation efficiency $\left(R_{e}=R_{n} / K \downarrow\right)$ and subsequently had an effect on the energy balance through the absolute magnitude of the partitioning of available energy into $H$ and LE. Another factor that reduced $R_{e}$ at Dyke $11 \mathrm{~A}$ South was the site's warm soil temperatures (Figure 5.1.1), which caused more energy to be lost via long-wave radiation (Oke, 1987).

The mean ( \pm s.d.) radiation efficiency during the 2008 growing season, calculated as the mean dry canopy $R_{e}$ between $1100-1500$ during clear sky conditions, was $0.59 \pm$ 0.09. Though not shown, clear sky conditions were determined by incorporating the solar 
constant $\left(1370 \mathrm{~W} \mathrm{~m}^{-2}\right)$ along with the site's geographic coordinates to calculate the highest levels of $K \downarrow$ possible ( $K \downarrow_{\text {max }}$ ) for each day of the growing season (Stull, 1997). The model showed that due to the frequent stormy days that persisted throughout the summer, only 63 days met clear sky conditions $\left(\mathrm{K} \downarrow=0.8 * \mathrm{~K} \downarrow_{\max }\right)$.

The gradual rise and steeper fall in the trend of $R_{e}$ (Figure 5.4.2) coincided with the growth and productivity of vegetation. Monthly averages increased from 0.52 in May (DOY 122 - 152) when the ground was largely bare to 0.66 in July and August (DOY 183 - 244), before dropping back down to 0.52 in September (DOY 245 - 274). These values were comparable to those reported by Chambers and Chapin (2003) in a study of regenerating boreal sites after fire, which ranged from $0.64-0.68$ in mid-summer. The same study reported $R_{e}$ of undisturbed sites to vary from $0.73-0.80$. It can therefore be expected that if succession is able to occur at this site, $R_{e}$ will increase as a result of the planted vegetation out-competing the ruderal species and the canopy cover becoming denser and occupied by the optically darker natural boreal species. Therefore, changes in $R_{e}$ can be used as an indicator of how the site is progressing. 


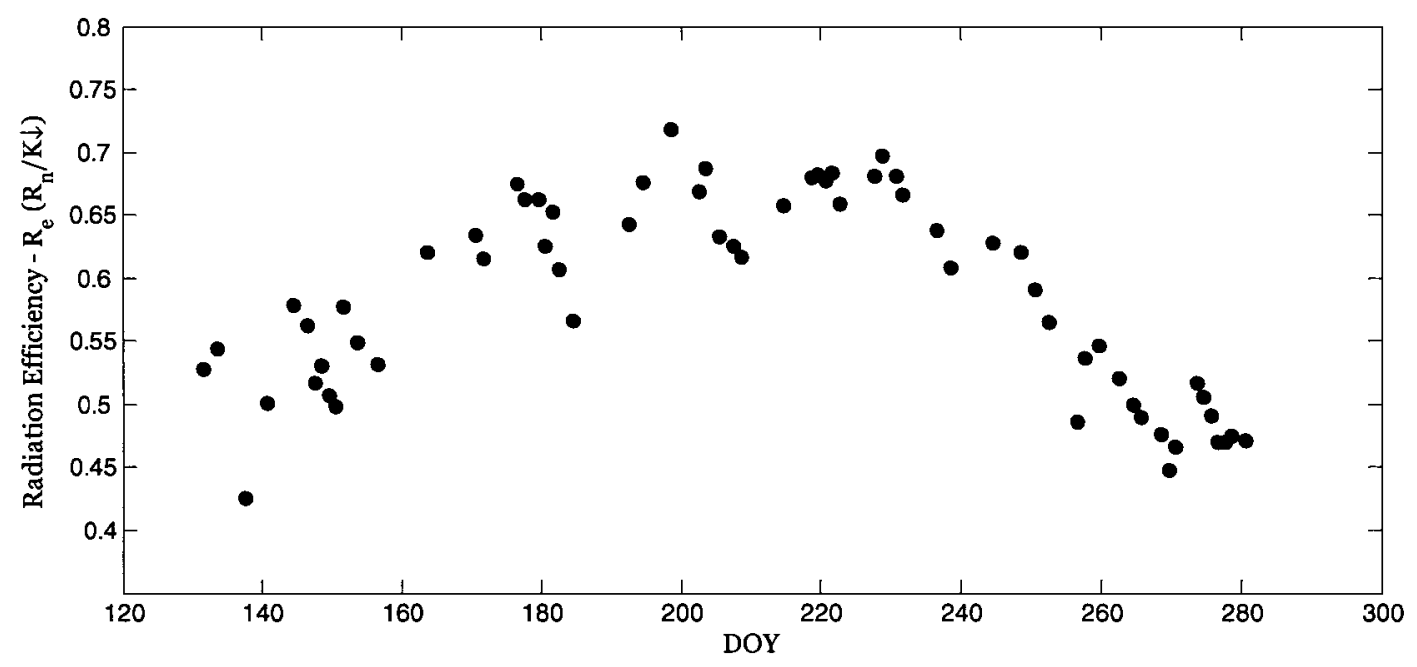

Figure 5.4.2: Seasonal variation of mean radiation efficiency $\left(R_{e}=R_{n} / K \downarrow\right)$, calculated between $1100-1500$ under clear sky conditions $\left(\mathrm{K} \downarrow \geq 0.8 * \mathrm{~K} \downarrow_{\max }, n=63\right)$ for Dyke $11 \mathrm{~A}$ South during the 2008 growing season.

\subsubsection{Net Radiation $\left(R_{n}\right)$}

Net radiation serves as the input to the surface energy balance that influences surface heating, ET rates and net ecosystem productivity. The long-term trend produced a peak in $R_{n}$ after the summer solstice on July 2 (DOY 184), with $24 \mathrm{hr}$ averages ranging from $-35.5-170.7 \mathrm{~W} \mathrm{~m}^{-2}\left(-3.1-14.7 \mathrm{MJ} \mathrm{m}^{-2} \mathrm{~d}^{-1}\right)$ (Figure 5.4.3). This day-to-day variability was primarily due to variable cloud conditions, as summer $R_{n}$ values below 50 $\mathrm{W} \mathrm{m} \mathrm{m}^{-2}\left(4.3 \mathrm{MJ} \mathrm{m}^{-2} \mathrm{~d}^{-1}\right)$ were mostly found to coincide with heavy cloud cover and rain, while maximum $R_{n}$ values (> $12.9 \mathrm{MJ} \mathrm{m}^{-2} \mathrm{~d}^{-1}$ ) occurred during clear sky conditions. 


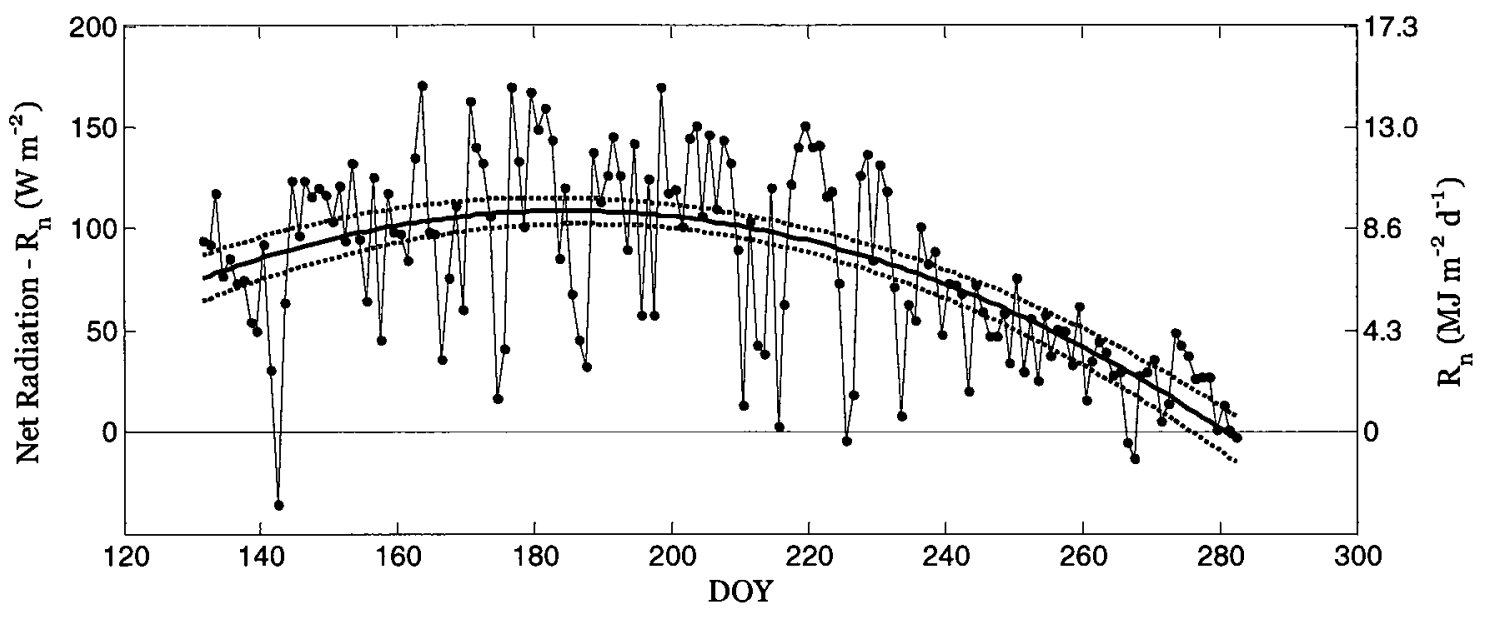

Figure 5.4.3: Seasonal variation of mean daily net radiation $\left(R_{n}\right)$ for Dyke 11A South during the 2008 growing season. Positive values of $R_{n}$ represent net flux towards the surface. The seasonal trend is highlighted (solid line) using a $2^{\text {nd }}$ order polynomial regression $\left(r^{2}=0.43\right)$ with $95 \%$ confidence intervals (dotted lines).

\subsubsection{Latent Heat Flux (LE)}

LE is the most important component of the energy balance to ecosystem functioning because it provides the connection between the energy and water budgets that provide for plants (Brutsaert, 1982). Due to the moist conditions that prevailed during the summer, $L E$ was the largest consumer of $R_{n}$ and remained at a relatively constant ratio throughout the growing season. The ratio of $24 \mathrm{hr}$ sums of $L E / R_{n}(0.55)$ was similar to what Carey (2008) reported for a nearby oil sands reclamation effort during its second year of reclamation, suggesting that newly regenerating vegetation, coupled with an exposed ground surface, result in relatively large ratios of $L E / R_{n}$. In contrast, sites recovering after fire have $L E / R_{n}$ ratios between $0.15-0.35$ (Chambers and Chapin, 2003) due to the deadwood and charcoal that remains that inhibits moisture being available for evaporation. 
The measured daily mean $( \pm$ s.d. $)$ LE at Dyke 11 A South was $5 \pm 1.9 \mathrm{MJ} \mathrm{m}^{-2} \mathrm{~d}^{-1}$ (or $2 \pm 0.8 \mathrm{~mm} \mathrm{~d}^{-1}$ ), (Figure 5.4.4.1). The seasonal trend produced typical maximum daily means that consistently ranged from $6.9-9.4 \mathrm{MJ} \mathrm{m}^{-2} \mathrm{~d}^{-1}$ (or $2.8-3.8 \mathrm{~mm} \mathrm{~d}^{-1}$ ) up until August 20 (DOY 240) before decreasing rather quickly (faster than the trends in $\mathrm{H}$ and G) to minimum values that spanned $1.4-3.5 \mathrm{MJ} \mathrm{m}^{-2} \mathrm{~d}^{-1}$ (or $0.6-1.4 \mathrm{~mm} \mathrm{~d}^{-1}$ ) at the end of the season.

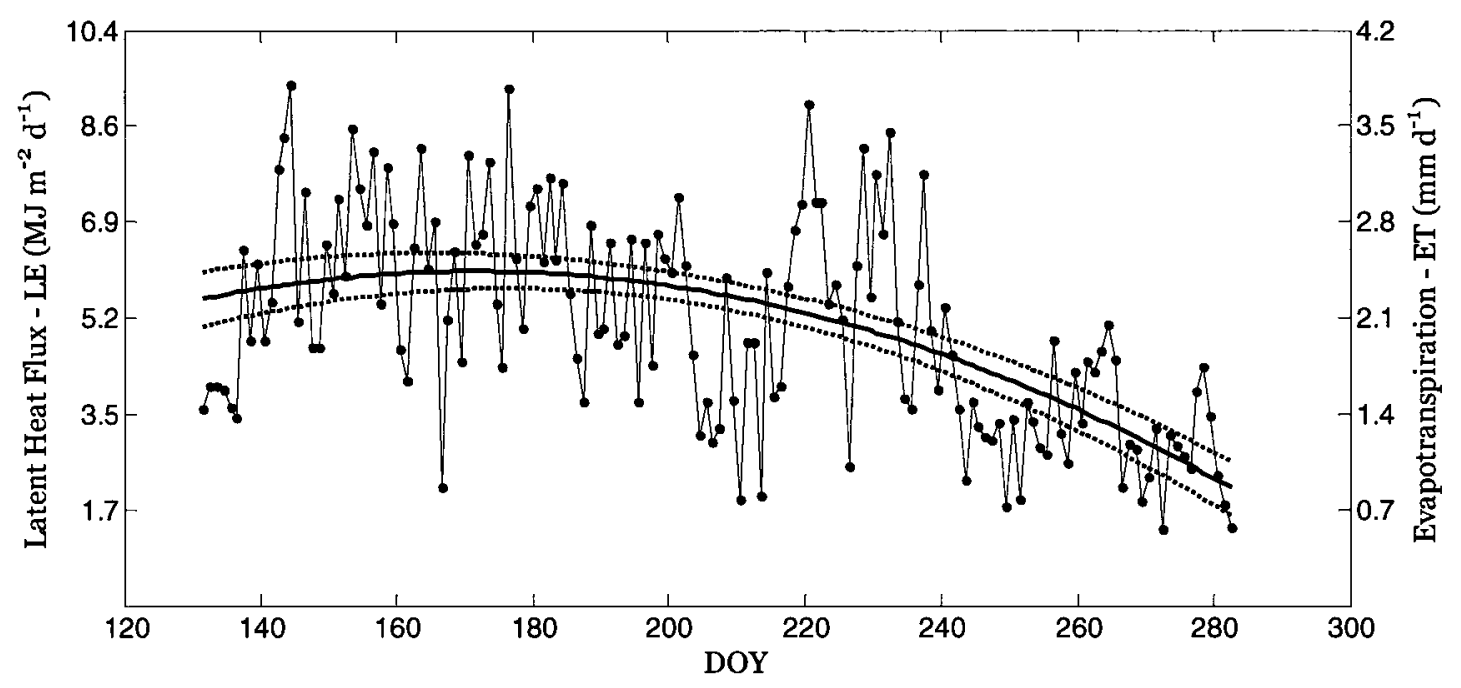

Figure 5.4.4.1: Seasonal variation of daily mean $24 \mathrm{hr}$ latent heat flux (LE) for Dyke 11A South during the 2008 growing season. Positive values of LE represent heat flux directed away from the surface. The seasonal trend is highlighted (solid line) using a $2^{\text {nd }}$ order polynomial regression $\left(r^{2}=0.35\right)$ with $95 \%$ confidence intervals (dotted lines).

Low LAI at the start of the season suggested that the initially high values of LE may have represented soil evaporation, resulting in the steady decline of $\theta_{s}$ up until the beginning of June (Figure 5.2.2). Following this period, LE increased along with LAI and $\theta_{s}$, indicating that the influence of the canopy became a governing factor during the peak of the growing season. One notable period that deviated from the seasonal trend in Figure 5.4.4.1 occurred between July 21 - August 3 (DOY 203 - 216). This coincided 
with similar decreases in the evaporating driving forces of $D, R_{n}$ and $\theta_{s}$, and resulted in a dramatic increase in the Bowen ratio, which for the majority of the season was dominated by LE (Figure 5.4.4.2), as indicated by the mean daytime $(0900-1700) \beta$ of $0.65 \pm 0.46$. Although $\Psi_{\mathrm{m}}$ never approached the wilting point throughout the study, the timing of this dramatic increase in $\beta$ corresponded with a relatively extended period of no rain that resulted in the lowest $\theta_{\mathrm{s}}$ that the soil cover encountered in the summer months (mean $\theta_{\mathrm{s}}<$ 0.2 in top $0.25 \mathrm{~m}$ ). The duration of this dry period may indicate a tipping point in how the system is able to partition $R_{a}$ into $H$ and $L E$, which could have future implications for this site if it encounters a drier summer.

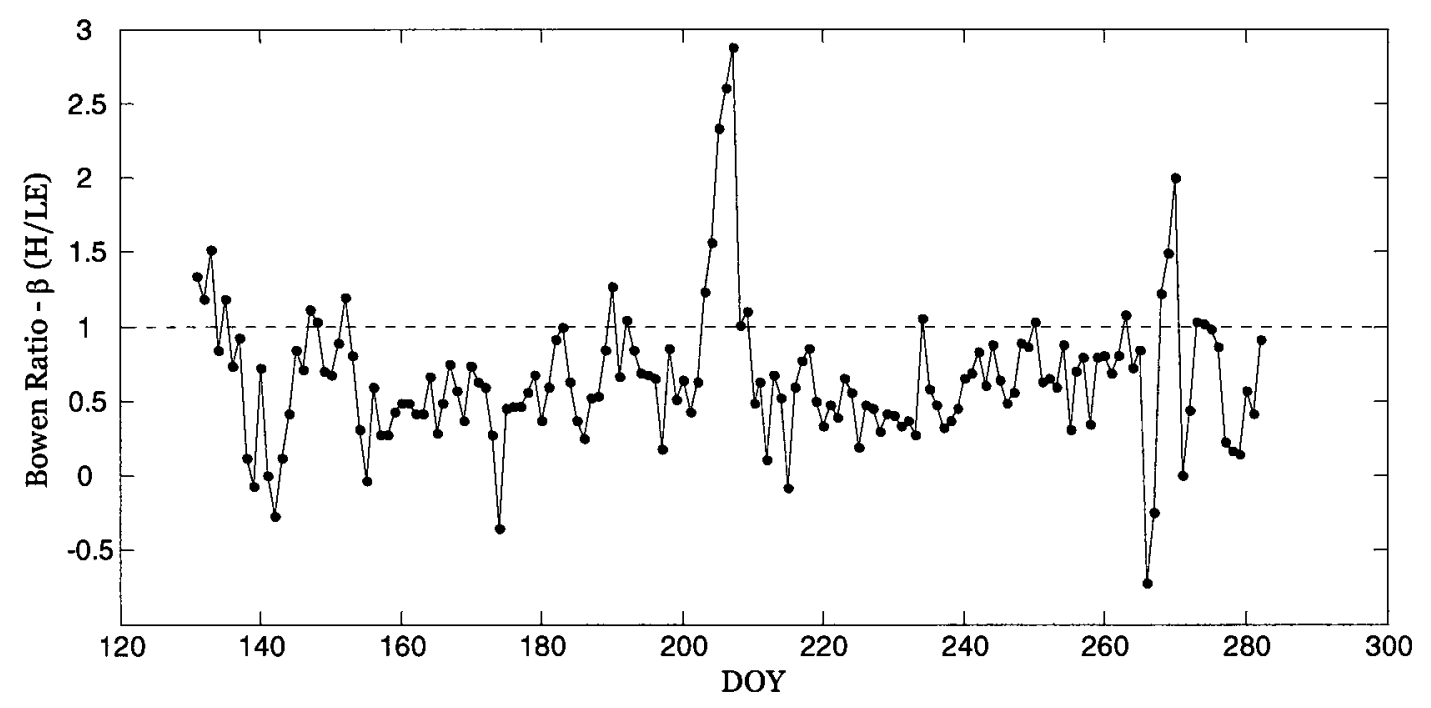

Figure 5.4.4.2: Seasonal variation in the Bowen ratio $(\beta)$, calculated as the ratio of daytime $(0900-1700)$ sums of $\mathrm{H}$ and LE. The dotted line represents the instance where $\mathrm{H}=\mathrm{LE}$.

The surrounding heterogeneous landscape of the Suncor mine site presented the possibility that changes in wind direction might have influenced measurements of LE through variations in advection of moist/dry air from upwind sources. Notable differences in atmospheric humidity were found to vary with wind direction, with 
increased vapour pressure deficits coinciding with winds from the direction of the large area of tailings sand bordering the northern edge of Dyke 11A South and the dry, unreclaimed area to the southeast. Advection of dry air from these areas resulted in increased LE, as distinct spikes can be seen between $300^{\circ}-60^{\circ}$ and between $120^{\circ}-180^{\circ}$ (Figure 5.4.4.3). Conversely, advection of moist air from the pond located to the east and from the forested area around the Athabasca River to the southwest suppressed LE below the mean of $58 \mathrm{~W} \mathrm{~m}^{-2}$. The decrease in LE and the apparent advection of moist air from the east and west may help to explain closure errors that coincided with these directions (Figure 4.9.2), suggesting that there was not sufficient fetch at this site during certain periods. The lowest LE between $240-255^{\circ}$ indicated that the closure error of $+20 \%$ (Figure 4.9.2) could be explained by the advection of increased $\mathrm{H}$ from the large area of black spruce forest located to the southwest. 


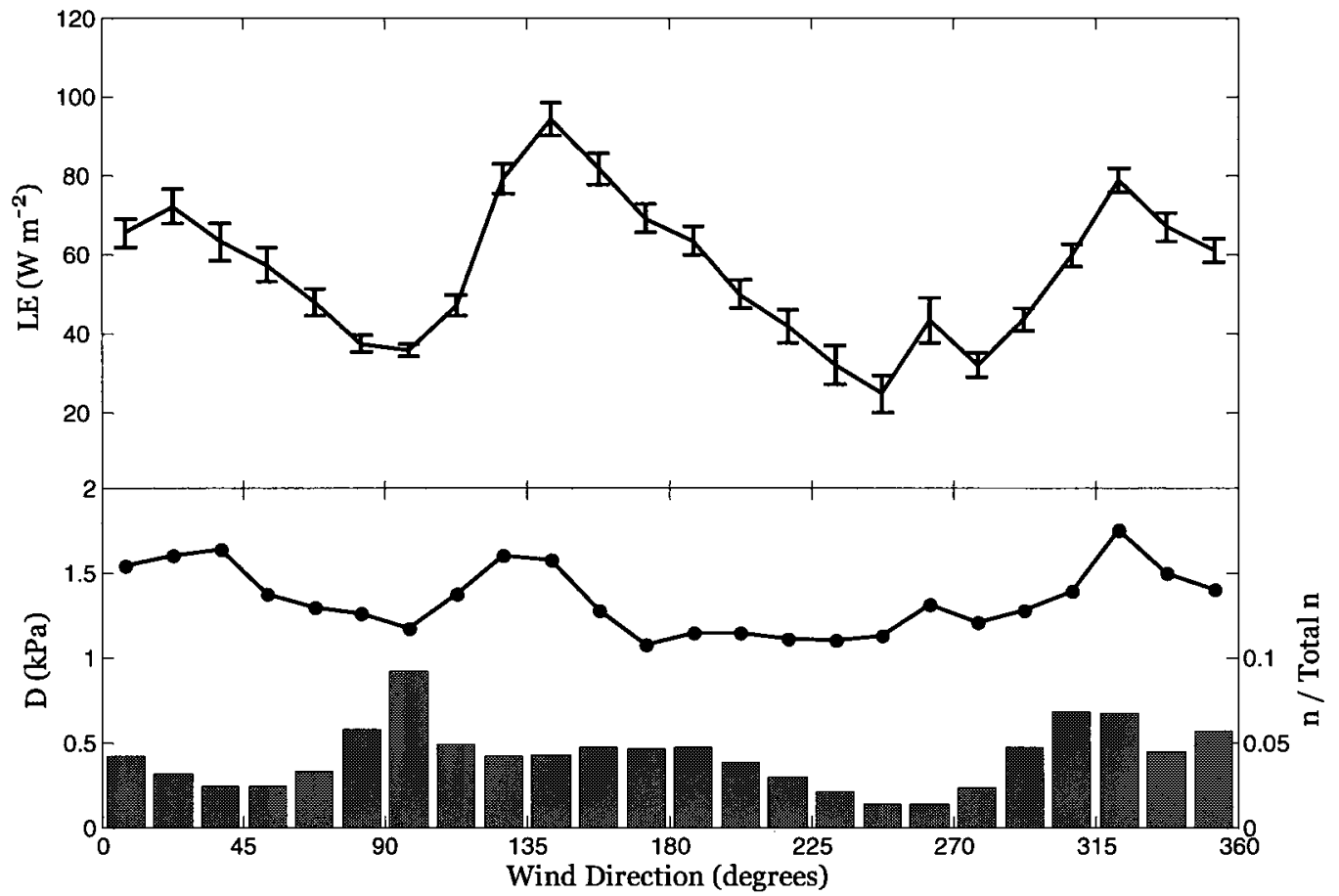

Figure 5.4.4.3: Advection effects of dry air shown by the variations in mean latent heat flux (LE) and vapour pressure deficit (D) with the associated changes in wind direction. Wind direction has been separated into 24 separate $15^{\circ}$ bins. The percentage of total half-hour measurements $(n=7337)$ is represented by shaded bars on the secondary y-axis in the bottom panel.

\subsubsection{Sensible Heat Flux (H)}

More $R_{n}$ was partitioned into $H$ when soil moisture declined to the point where plant stress conditions limited LE. At Dyke 11A South, the ratio of growing season $24 \mathrm{hr}$ sums of $H / R_{n}(0.3)$ was again similar to Carey (2008). The similarity between these studies indicates that due to the large amounts of $R_{n}$ being consumed by $L E$, low values of $H / R_{n}$ can be expected at newly reclaimed sites. In comparison, $H / R_{n}$ at recently burned sites can attain values of $0.4-0.65$ (Chambers and Chapin, 2003) due to the 
deadwood and charcoal left behind after fire, whose black surface is more apt to absorb radiation and limit $\mathrm{LE}$ and $\mathrm{G}$.

The daily and seasonal variability of $\mathrm{H}$ throughout the study was largely a function of $R_{n}$ and soil moisture conditions. Maximum values of $H\left(>70 \mathrm{~W} \mathrm{~m}^{-2}\right.$ or $6 \mathrm{MJ}$ $\mathrm{m}^{-2} \mathrm{~d}^{-1}$ ) occurred as a result of extended periods with no rain that caused soil moisture to decrease to its lowest levels at the end of May (DOY $146-154)$ and July (DOY $204-$ 211). These periods resulted in a coincidental increase in $\beta$ (Figure 5.4.4.2), causing it to exceed 1. Large negative values of $H$ were associated with days with heavy cloud cover and precipitation, where evaporation caused a cooling effect at the surface. The decreasing trend of $\mathrm{H}$ near the end of the season coincided with a similar decline in $\mathbf{R}_{\mathbf{n}}$.

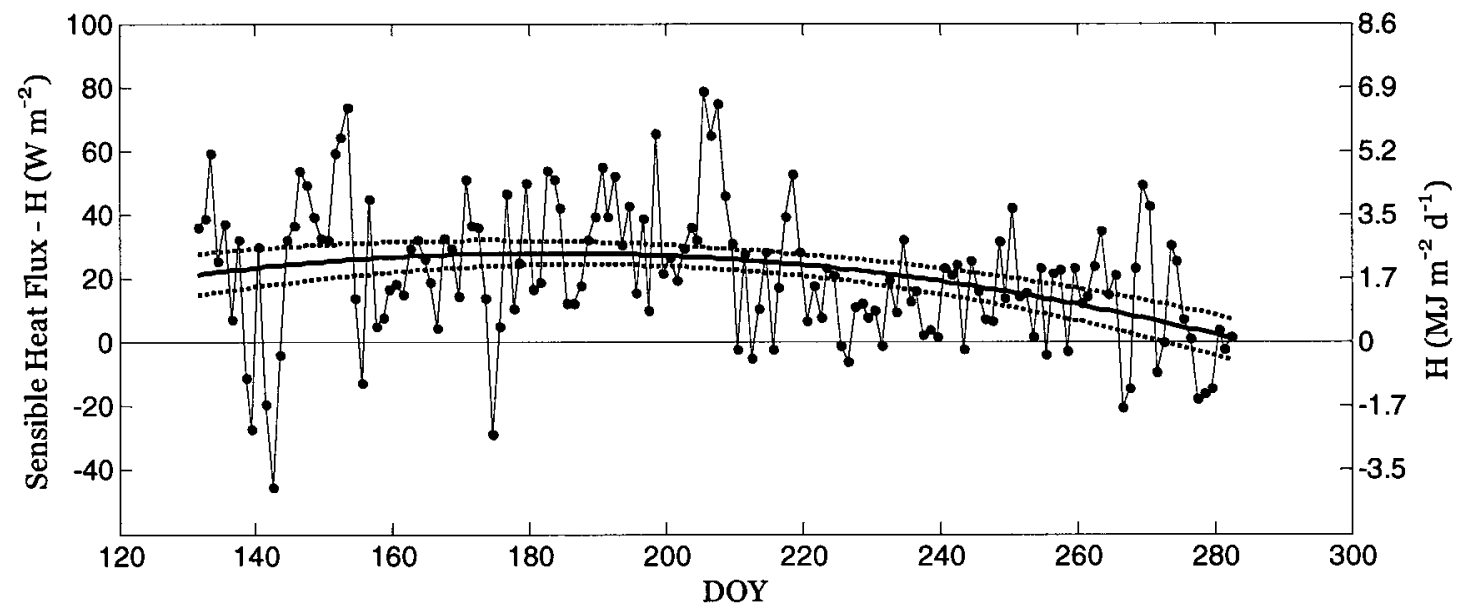

Figure 5.3.5: Time series of mean 24hr sensible heat flux $(\mathrm{H})$ for Dyke 11A South during the 2008 growing season. Positive values of $\mathrm{H}$ represent heat flux directed away from the surface. The seasonal trend is highlighted (solid line) using a $2^{\text {nd }}$ order polynomial regression $\left(\mathrm{r}^{2}=0.12\right)$ with $95 \%$ confidence intervals (dotted lines).

\subsubsection{Ground Heat Flux (G)}

$G$ can alternate as a source or a sink of the available energy $\left(R_{a}=R_{n}-G\right)$ that is partitioned between the turbulent fluxes $\mathrm{H}$ and LE. G consumed the smallest amount of 
$R_{n}$ throughout the growing season, as the ratio of $24 \mathrm{hr}$ sums of $G / R_{n}$ was 0.12 . The fraction of $G / R_{n}$ was initially 0.16 in May, declined with the growth of vegetation to 0.10 by August, and then increased to 0.12 in September. The apparent negative feedback that the growth and senescence of vegetation had on $G / R_{n}$ suggests that if succession occurs in future years, there will be more energy available for $\mathrm{H}$ and LE, and the surface energy budget will change.

Similar to the findings of a grassland study by Kelliher et al. (1993), some half hour measurements of $\mathrm{G}$ were found to exceed $100 \mathrm{~W} \mathrm{~m}^{-2}$. The daily $24 \mathrm{hr}$ mean $( \pm \mathrm{s} . \mathrm{d}$. $\mathrm{G}$ at Dyke 11A South was $2.3 \pm 0.6 \mathrm{MJ} \mathrm{m}^{-2} \mathrm{~d}^{-1}$. Although there was marked diurnal variability, $\mathrm{G}$ was predominantly positive throughout the first half of the study, ranging between -0.4 to $1.5 \mathrm{MJ} \mathrm{m}^{-2} \mathrm{~d}^{-1}$ from May 10 - August 1 (DOY 131 - 214) (Figure 5.4.6). Following this period, a larger amplitude of variation occurred up until August 25 (DOY 238 ), when the source/sink strength of $\mathrm{G}$ fluctuated between $-1.4-1.4 \mathrm{MJ} \mathrm{m}^{-2} \mathrm{~d}^{-1}$. G became a source of energy at the end of the study from August 26-October 10 (DOY $239-282$ ), as daily means were primarily negative, fluctuating between $-1.3-0.5 \mathrm{MJ} \mathrm{m}^{-}$ ${ }^{2} \mathrm{~d}^{-1}$. Negative $G$ during this period was due to $T_{a}$ decreasing at a faster rate than $T_{s}$ (Figure 5.1.1). 


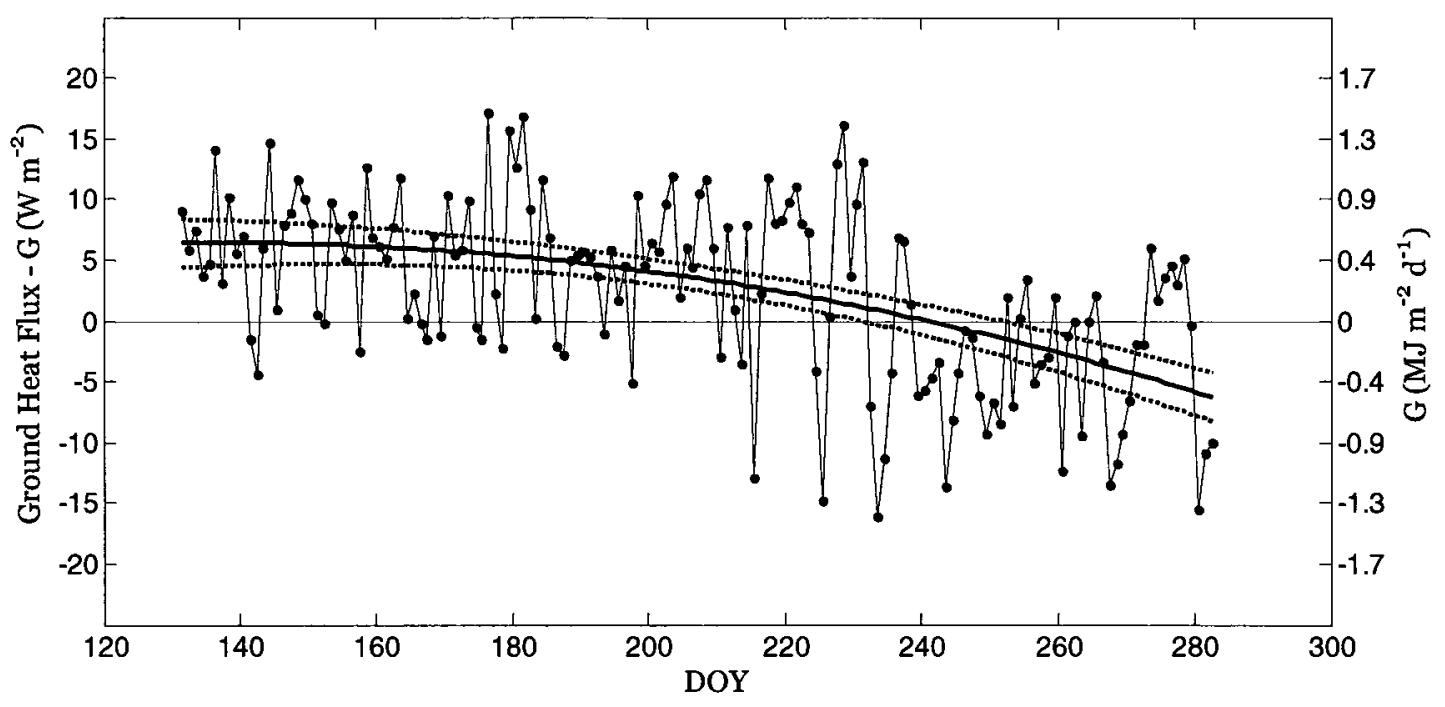

Figure 5.4.6: Seasonal variability of mean $24 \mathrm{hr}$ daily ground heat flux (G) for Dyke 11A South during the 2008 growing season. Positive values of $G$ represent heat flux into the ground (heat sink), while negative values represent $G$ as a heat source of energy into the atmosphere. $\mathrm{G}$ is calculated as the heat flux measured at $0.05 \mathrm{~m}$ plus the heat storage in the soil above (Eq. 4.2.1). The seasonal trend is highlighted (solid line) using a $2^{\text {nd }}$ order polynomial regression $\left(r^{2}=0.27\right)$ with $95 \%$ confidence intervals (dotted lines).

\subsubsection{Seasonal and Diurnal Energy Partitioning}

The magnitude and timing of $R_{n}$ partitioning into $G, H$ and $L E$ changed throughout the growing season in response to changing vegetation cover, available moisture and climate conditions. As these differences were distinguishable in each month (Table 5.4), the following analysis has divided the 2008 growing season into monthly segments to investigate the controls of daily energy partitioning within the system. Attention is focused on daytime $(0900-1700)$ measurements, as this is when the majority of photosynthesis and ET occurs. Constraining the analysis to these periods allows the influence of biotic control to be shown, and thus $\alpha$ (Eq. 2.6) and $\Omega$ (Eq. 2.7) are included in the following discussion. 
May was the pre-leaf period (mean LAI $\left.=0.29 \mathrm{~m}^{2} \mathrm{~m}^{-2}\right)$, that was very dry $(\Sigma \mathrm{P}=$ $7.1 \mathrm{~mm}$ ), but had a soil moisture profile at field capacity after snowmelt. June signified the onset of leaf-out and also coincided with the replenishment of soil moisture $\left(\sum \mathrm{P}=\right.$ $74.7 \mathrm{~mm}$ ) that had been continuously depleted during the dry month of May. July and August represented the peak of the growing season, but differed from each other in that July was hot and relatively dry (maximum D and minimum $\Psi_{\mathrm{m}}$ ) while August was hot and wet (maximum $\mathrm{P}$ and $\Psi_{\mathrm{m}}$ ). September was the period of senescence that experienced little rainfall $\left(\sum \mathrm{P}=24.6 \mathrm{~mm}\right)$ and decreasing daily temperatures $\left(12.7 \pm 4.2^{\circ} \mathrm{C}\right)$. October has been excluded from the following discussion due to only having eight full days of measurements during this period and because it is perceived to not represent the growing season. It should be noted that not all values of the partitioning of $R_{n}$ into $L E, H$ and $G$ add up to 100 because of the errors involved in the flux measurements and the gap filling procedures. 
Table 5.4: Monthly changes in daily (0900 - 1700) mean atmospheric conditions and site characteristics throughout the growing season and their influence on energy partitioning at Dyke 11A South. Soil suction $\left(\Psi_{\mathrm{m}}\right)$ represents the mean $\Psi_{\mathrm{m}}$ in the $0.25 \mathrm{~m}$ soil cover. Bowen ratio $(\beta)$ was calculate from daily averages of $\mathrm{H} / \mathrm{LE}$ for each month. The partitioning of $R_{n}$ into $H, L E$, and $G$ was calculated from the ratio of the sums of gapfilled flux data within respective month. Shaded brackets denote \pm 1 s.d.

\begin{tabular}{|c|c|c|c|c|c|c|}
\hline $\begin{array}{l}\text { Month } \\
\text { (DOY) }\end{array}$ & $\begin{array}{c}\text { May } \\
(131-152)\end{array}$ & $\begin{array}{c}\text { June } \\
(153-182)\end{array}$ & $\begin{array}{c}\text { July } \\
(183-213)\end{array}$ & $\begin{array}{c}\text { Aug } \\
(214-244)\end{array}$ & $\begin{array}{c}\text { Sept } \\
(245-274)\end{array}$ & $\begin{array}{c}\text { Season } \\
(131-274)\end{array}$ \\
\hline $\mathbf{T}$ & 16.3 & 19.7 & 20.8 & 19.7 & 12.7 & 17.5 \\
\hline$\left({ }^{\circ} \mathbf{C}\right)$ & $(3.9)$ & $(4,4)$ & (4.1) & $(6.1)$ & $(4.2)$ & (3.1) \\
\hline$\underset{(\mathbf{m m})}{\sum \mathbf{P}}$ & 7.1 & 74.7 & 70.6 & 150.6 & 24.6 & 327.7 \\
\hline $\begin{array}{c}\mathrm{D} \\
(\mathbf{k P a})\end{array}$ & $\begin{array}{c}1.7 \\
(0.6)\end{array}$ & $\begin{array}{c}2.1 \\
(0.8)\end{array}$ & $\begin{array}{c}2.3 \\
(0.8)\end{array}$ & $\begin{array}{c}2.1 \\
(1.1)\end{array}$ & $\begin{array}{c}1.1 \\
(0.6)\end{array}$ & $\begin{array}{c}1.8 \\
(0.5)\end{array}$ \\
\hline $\begin{array}{c}\Psi_{\mathrm{m}} \\
(\mathrm{kPa})\end{array}$ & $\begin{array}{l}-197.3 \\
(170.2)\end{array}$ & $\begin{array}{l}-346.2 \\
(145.9)\end{array}$ & $\begin{array}{l}-443.3 \\
(82.4)\end{array}$ & $\begin{array}{l}-50.7 \\
(58.3)\end{array}$ & $\begin{array}{l}-239.3 \\
(34.5)\end{array}$ & $\begin{array}{c}269.5 \\
(168.6)\end{array}$ \\
\hline $\begin{array}{c}\mathbf{L A I} \\
\left(\mathbf{m}^{2} \mathbf{m}^{-2}\right)\end{array}$ & 0.29 & 1.48 & 2.51 & 2.72 & N/A & 1.66 \\
\hline $\mathbf{I} \mathbf{H} / \mathbf{R}_{\mathbf{n}}$ & 0.35 & 0.25 & 0.35 & 0.26 & 0.41 & 0.31 \\
\hline $\mathbf{L E} / \mathbf{R}_{\mathbf{n}}$ & 0.52 & 0.52 & 0.42 & 0.52 & 0.55 & 0.50 \\
\hline $\mathbf{G} / \mathbf{R}_{\mathbf{n}}$ & 0.2 & 0.19 & 0.15 & 0.12 & 0.15 & 0.16 \\
\hline $\begin{array}{c}\beta \\
(\mathbf{H} / \mathbf{L E})\end{array}$ & $\begin{array}{c}0.72 \\
(0.48)\end{array}$ & $\begin{array}{c}0.46 \\
(0.24)\end{array}$ & $\begin{array}{c}0.89 \\
(0.65)\end{array}$ & $\begin{array}{c}0.50 \\
(0.23)\end{array}$ & $\begin{array}{c}0.71 \\
(0.49)\end{array}$ & $\begin{array}{c}0.65 \\
(0.46)\end{array}$ \\
\hline $\begin{array}{c}\alpha= \\
L E / L E_{\text {eq }}\end{array}$ & 0.79 & 0.89 & 0.63 & 0.84 & 0.93 & 0.82 \\
\hline $\boldsymbol{\Omega}$ & 0.30 & 0.37 & 0.26 & 0.33 & 0.30 & 0.32 \\
\hline
\end{tabular}

The mean diurnal variation of energy partitioning in May showed $\mathrm{H}$ to have typically exceeded LE late in the morning (Figure 5.4.7), but increasing $T_{a}$ and $D$ caused LE to become the dominant flux by the afternoon. The daytime Bowen ratio $(\beta=0.72 \pm$ 0.48 ) and fraction of $G / R_{n}(0.2)$ were relatively high in May due to a small canopy cover $(\mathrm{LAI}=0.29)$. The lack of vegetation to provide transpiration meant that evaporation of 
soil water was possible due to moist surface soil layers. Steady depletion of $\theta_{\mathrm{s}}$ in the soil cover in May is indicated by a mean $\Psi_{\mathrm{m}}$ of $-197.3 \mathrm{kPa}$ (down from an initial value of only $-50 \mathrm{kPa}$ ). Due to the lack of canopy resistance to evaporation, the resulting LE was high, as indicated by the Priestley-Taylor $\alpha$ coefficient of 0.79 .

The combination of increased LAI, D and precipitation in June resulted in comparatively high LE, arguably through greater transpiration rates and evaporation of intercepted water from the canopy surface following rainfall. Again, limited canopy control of LE resulted in a relatively high $\alpha(0.89)$. More energy was consumed by LE throughout the entire day, peaking close to $180 \mathrm{~W} \mathrm{~m}^{-2}$ by 1400 (Figure 5.4.7). As a result, the ratio of $H / R_{n}$ and the subsequent magnitude and variability of the Bowen ratio $(\beta=0.46 \pm 0.24)$ decreased to seasonal lows.

When LAI began to reach its maximum in July there was a notable decrease in $\mathrm{G} / \mathrm{R}_{\mathrm{n}}$ due to shading of the surface (Table 5.4). The hottest and driest month brought seasonal highs in $\mathrm{T}_{\mathrm{a}}\left(20.3^{\circ} \mathrm{C}\right)$ and $\mathrm{D}(2.3 \mathrm{kPa})$ that led to soil drying to its greatest extent $\left(\Psi_{\mathrm{m}}=-443.3 \mathrm{kPa}\right)$. As a result, season lows of monthly $L E / R_{\mathrm{n}}, \alpha$ and $\Omega$ occurred $(0.47$, 0.63 and 0.26 respectively), indicating that this was the most stressful month for vegetation. A mean $\beta$ of $0.89 \pm 0.65$ (Table 5.4) reflected the small afternoon difference between daytime LE and $\mathrm{H}$ (Figure 5.3.3). The variability of $\beta$ can be explained by the extended dry period during the second half of July that caused maximum daily $\beta$ to approach 3 (Figure 5.4.4.2).

August had similarly high temperatures as July, but was accompanied by much larger amounts of rainfall $\left(\sum \mathrm{P}=150.6 \mathrm{~mm}\right)$. This replenished $\theta_{\mathrm{s}}$ in the soil cover, allowing $\Psi_{\mathrm{m}}$ to return to springtime highs $(-50.7 \mathrm{kPa})$ and resulted in $\alpha$ again approaching 
unity (0.84). August LE was similar in magnitude to that of June (Figure 5.4.7), while the magnitude of $\mathrm{G}$ decreased due to the shading effect of increased canopy cover.

The initially wet soil that resulted from the stormy month of August allowed for high LE in September, enabling $\alpha$ to approach unity (0.93) despite any additional P. The response of $\mathrm{G}$ to the senescence and the drying of vegetation resulted in a small increase in $G / R_{n}$ to 0.15 from the lowest $G / R_{n}(0.12)$ in August. $H$ and $L E$ were of a similar magnitude for the majority of the day in this month due to the low $\mathrm{D}(1.1 \mathrm{kPa})$ available to drive LE.
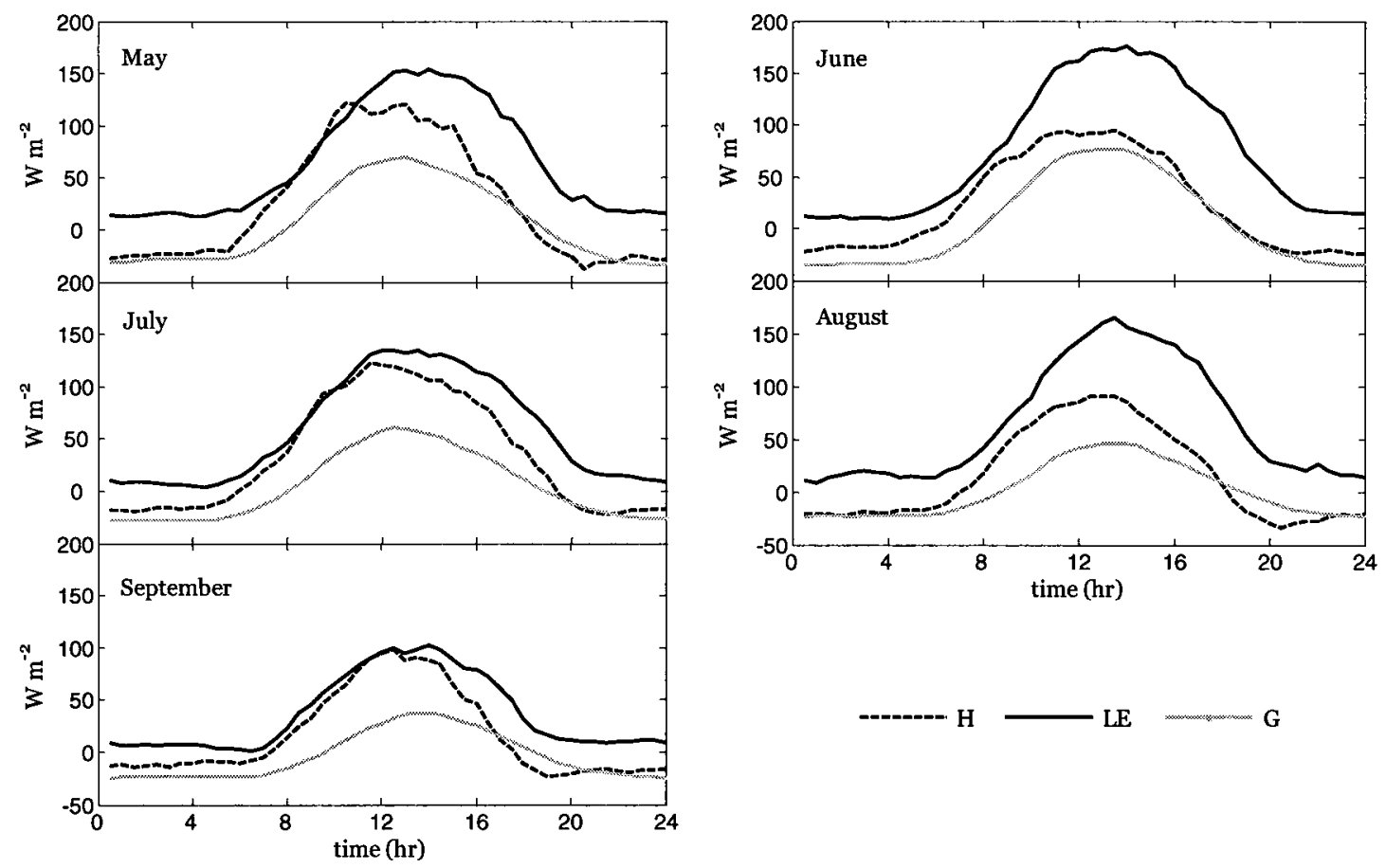

Figure 5.4.7: Mean daily variation of the partitioning of $R_{n}$ into the energy components H, LE and G from May 10 - September 30 (DOY 131 - 282). A summary of climatic and site conditions during each month is included in Table 6. 


\subsection{Controls on ET}

\subsubsection{Aerodynamic vs. Surface Conductance}

Stomatal conductance involves the transfer of $\mathrm{H}_{2} \mathrm{O}$ from the soil through the rootstem-leaf system into the atmosphere (Monteith, 1995). The rate at which this occurs varies between species, as each type of plant responds differently to changing environmental conditions. The estimated bulk surface conductance $\left(g_{s}\right)$ at this site encompasses transpiration from the variety of grasses, ruderals, shrubs and tree seedlings that were planted as well as evaporation from the soil. Aerodynamic conductance $\left(\mathrm{g}_{\mathrm{a}}\right)$ describes the transfer of ET within the atmosphere, and is a function of the turbulent activity in the air above the surface (Oke, 1987). From Equation 4.6.1, $\mathrm{g}_{\mathrm{a}}$ is a function of not only wind speed but also the roughness elements at the surface, and thus will change at this site with the growth of vegetation.

Figure 5.5.1 indicates that $\mathrm{g}_{\mathrm{a}}$ was typically an order of magnitude larger than $\mathrm{g}_{\mathrm{s}}$, with a mean ( \pm s.d.) value of $23.5 \pm 10.8 \mathrm{~mm} \mathrm{~s}^{-1}\left(918 \pm 422 \mathrm{mmol} \mathrm{m}^{-2} \mathrm{~s}^{-1}\right)$. The growth of the reclamation vegetation at Dyke 11A South had an influence on $\mathrm{g}_{\mathrm{a}}$ (Figure 5.5.1, Panel A), increasing from a mean value of $18 \mathrm{~mm} \mathrm{~s}^{-1}\left(702 \mathrm{mmol} \mathrm{m}^{-2} \mathrm{~s}^{-1}\right)$ at the beginning of the season to $29 \mathrm{~mm} \mathrm{~s}^{-1}\left(1132 \mathrm{mmol} \mathrm{m}^{-2} \mathrm{~s}^{-1}\right)$ by October. These levels of $\mathrm{g}_{\mathrm{a}}$ are less than what Wever et al. (2002) measured in the temperate grassland study ( $g_{a}=1350-$ $1500 \mathrm{mmol} \mathrm{m}^{-2} \mathrm{~s}^{-1}$ ), likely due to the fact that the grassland had not been grazed for over 20 years and thus had a taller canopy cover. The values at this site were similar to those that Kelliher et al. (1993) report for grasslands, who indicate that $\mathrm{g}_{\mathrm{a}}$ is generally less than $30 \mathrm{~mm} \mathrm{~s}^{-1}$ at wind speeds less than $3 \mathrm{~m} \mathrm{~s}^{-1}$. 
Although there were no distinct trends in either conductance there was a notable period of low values exhibited, particularly in $\mathrm{g}_{s}$, between July $20-26$ (DOY $202-208$ ) (Figure 5.5.1, Panel B). This coincided with a dry period with calm winds. Photographs showed that the rise in both conductances following this period occurred when the grass species and sow thistles became notably taller. The prominence of these species created more surface heterogeneity and a subsequent increase in aerodynamic roughness in what had initially been a relatively smooth surface. There was also an increase in average wind speed (Figure 5.1.4) during this period, associated with the uncharacteristic stormy weather in August, which when combined with the aforementioned factors explains the increase of $\mathrm{g}_{\mathrm{a}}$ in the latter half of the season.

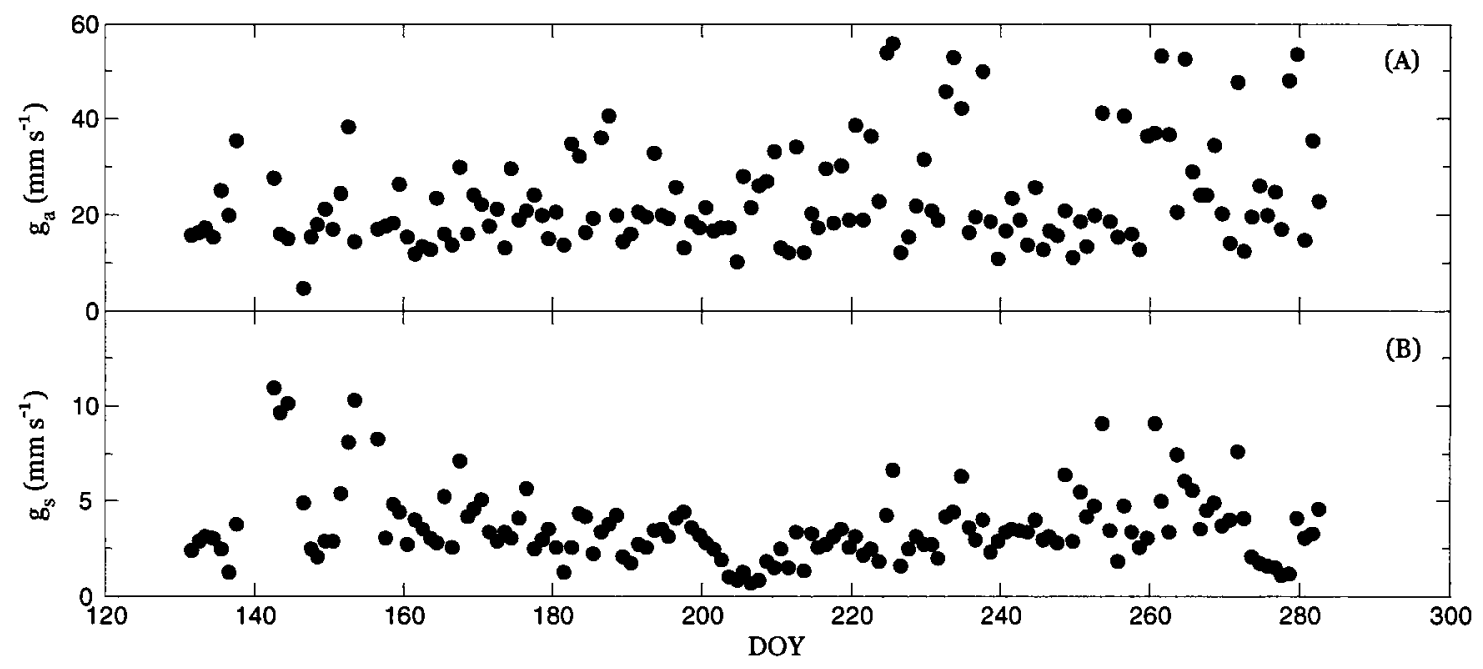

Figure 5.5.1: Comparison of variations in (A) aerodynamic conductance $\left(\mathrm{g}_{\mathrm{a}}\right)$ and (B) bulk surface conductance $\left(\mathrm{g}_{\mathrm{s}}\right)$ measured at Dyke 11A South during the 2008 growing season. Both panels represent mean daytime $(0900-1700)$ values, with $g_{a}$ being calculated using Eq. 4.8.1 and $\mathrm{g}_{\mathrm{s}}$ found by inverting the P-M equation.

\subsubsection{Equilibrium Evaporation}

$\mathrm{LE}_{\mathrm{eq}}$ represents the potential LE that will occur over a freely evaporating wet surface until the atmosphere has become saturated $(\mathrm{D} \rightarrow 0)$. The mean monthly $\alpha$ at 
Dyke 11A South (calculated during dry canopy daytime $(0900-1700)$ conditions) varied between months (Table 5.4), ranging between a low of 0.63 in July and a high of 0.93 in September. Averaged over the course of the growing season, the ratio of $L E / L E_{\text {eq }}$ remained close to unity ( $\alpha=0.82$ ), indicating some biotic control but a closer coupling to available energy.

If canopy control played a major role in governing ET rates, a noticeable difference should have existed between dry canopy ET and free evaporation of intercepted water after rain events. The difference was not found to be significant, as the mean ( \pm s.d.) wet canopy $\alpha(n=61)$ had only a slightly higher ratio at $0.96 \pm 0.28$ than the dry canopy $\alpha(n=81)$ at $0.87 \pm 0.30$. Overall, 19.8 and $36.0 \%$ of dry and wet canopy $\alpha$ were found to be greater than unity, while 12.3 and $16.4 \%$ exceeded the empirically derived Priestley-Taylor $\alpha$ of 1.26 .

Although these values did not suggest large biotic control by the regenerating canopy, there were temporal differences that occurred throughout the study that indicated otherwise. Dry canopy values that exceeded unity and the Priestley-Taylor $\alpha$ tended to occur at the beginning and end of the study, representing the pre-leaf and senescence periods, and hence free evaporation from the soil (Figure 5.5.2.1). Mean $\alpha$ values during the hot summer months of July and August were typically greater during wet periods and much lower during dry periods $(\alpha<0.4)$, indicating greater biotic control on transpired water loss during the peak of the growing season. Table 5.4 showed that biotic control became most evident in July, as the lowest $\alpha(0.63)$ coincided with the greatest atmospheric demand $(\mathrm{D}=2.3)$, indicating that the vegetation was attempting to conserve water as $\theta_{\mathrm{s}}$ was being readily depleted. 


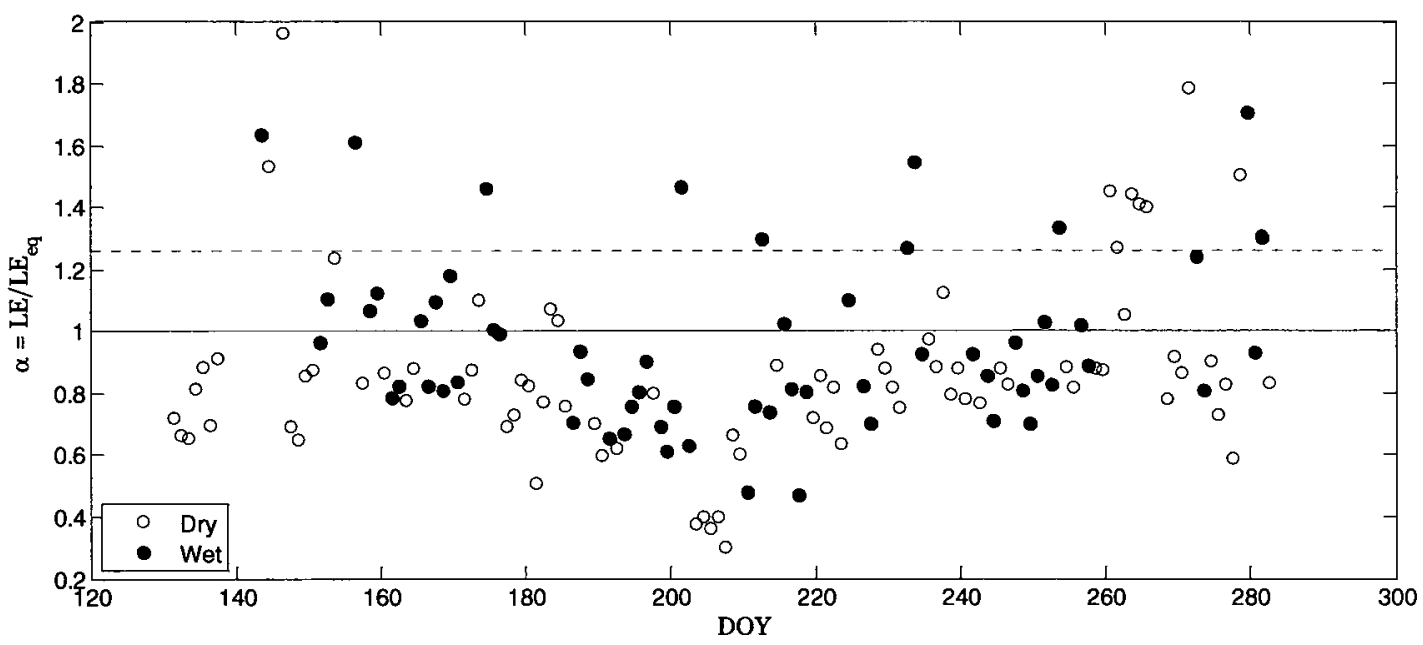

Figure 5.5.2.1: Time series of the mean daytime ( $0900-1700 \mathrm{hrs})$ Priestley-Taylor $\alpha$ coefficient $\left(\alpha=\mathrm{LE} / \mathrm{LE}_{\mathrm{eq}}\right.$ ) during wet (closed circles; $n=59$ ) and dry (open circles; $n=$ 83) canopy conditions from DOY $131-282$. The straight solid line represents $\alpha$ at unity, while the dotted line represents the empirically derived Priestley and Taylor (1972) coefficient $(\alpha=1.26)$.

Many studies have shown $\alpha$ to have a positive non-linear relationship with $\mathrm{g}_{\mathrm{s}}$ (Baldocchi and Vogel, 1997; Blanken et al., 1997; Wilson and Baldocchi, 2000; Wever et al., 2002), as ET will approach its equilibrium rate with increased surface conductance. The following discussion compares the relationship of these factors observed at Dyke 11A South to other nearby studies in natural environments - a northern Alberta temperate grassland (Wever et al., 2002) and a northern Saskatchewan boreal aspen forest (Blanken et al., 1997).

Predictive models of $\alpha$ with respect to $g_{s}$ were taken from both of the aforementioned studies and tested on dry canopy daytime $(0900-1700)$ values observed at Dyke 11A South. In an attempt to capture the influence of the canopy after leaf-out and before senescence, the comparison is made using only dry canopy $\alpha$ and $g_{s}$ values between June 1 - August 31 (DOY $153-244)(n=37)$. Surface conductance in both 
models was converted from $\mathrm{mm} \mathrm{s}^{-1}$ to $\mathrm{mmol} \mathrm{m}^{-2} \mathrm{~s}^{-1}$ using the ideal gas law. The models consisted of an exponential form presented by Blanken et al. (1997) as $\alpha=a_{1} \cdot(1-\exp (-$ $\left.\mathrm{g}_{\mathrm{s}} / \mathrm{a}_{2}\right)$ ) and a logarithmic form taken from Wever et al. (2002), $\alpha=\mathrm{a}_{1} \cdot \ln \left(\mathrm{g}_{\mathrm{s}}\right)-\mathrm{a}_{2}$, where $\mathrm{a}_{1}$ and $\mathrm{a}_{2}$ in both models are fitted constants. Both models gave similar results when applied to the measurements in this study, giving $r^{2}$ values of 0.82 and 0.79 , respectively. The exponential model has been used to draw the line of best fit in Figure 5.5.2.2, Panel A because it is more representative, where the best fit parameters were found to give $\alpha=$ $1.04 \cdot\left(1-\exp \left(-g_{s} / 67.72\right)\right)$. The model predicted that $\alpha$ will approach unity at $g_{s}$ of approximately $218 \mathrm{mmol} \mathrm{m}^{-2} \mathrm{~s}^{-1}$ (or $5.1 \mathrm{~mm} \mathrm{~s}^{-1}$ ) before leveling off soon after (Figure

\subsubsection{2, Panel B).}

Figure 5.5.2.2, Panel B shows $\alpha$ to respond to low levels of $\mathrm{g}_{\mathrm{s}}$ at a much greater rate than the grassland or the aspen forest. In the grassland and aspen studies, $\alpha$ did not approach a value of 1.0 until $\mathrm{g}_{\mathrm{s}}$ reached 545 and $640 \mathrm{mmol} \mathrm{m}^{-2} \mathrm{~s}^{-1}$, respectively, indicating greater biotic control on water loss in these ecosystems. Much of the difference between these environments may possibly be due to the potentially large portion of evaporated water directly from the soil surface, however, the magnitude of soil evaporation was not determined or measured in this study.

The other major difference between these sites is due to the low levels of $g_{s}$ displayed at Dyke 11A South, where the leveling off of $\alpha$ indicates that the capacity of $g_{s}$ to provide to LE is limited. This suggests that it is not possible for the young vegetation at this site to allow $\alpha$ to attain the Priestley-Taylor value of 1.26. 

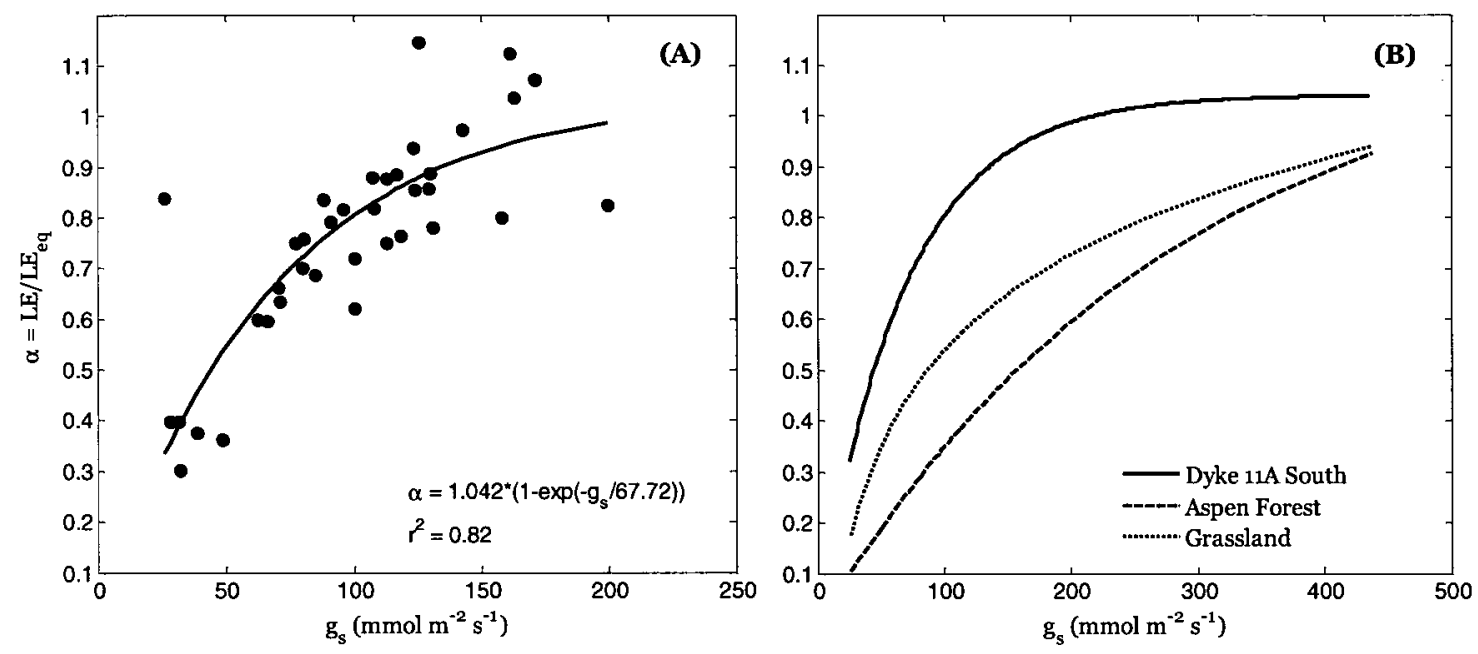

Figure 5.5.2.2: (A) Relationship between bulk surface conductance $\left(\mathrm{g}_{\mathrm{s}}\right)$ and the Priestley-Taylor $\alpha$ coefficient measured during dry canopy daytime (0900 - 1700) conditions from June 1 - August 31 (DOY $153-244)(n=37)$ at Dyke 11A South. The best fit line represents the exponential form taken from Blanken et al., (1997). (B) Comparison of the mean response of $\alpha$ measured at Dyke 11A South with others found in the literature. The exponential line representing the boreal aspen forest (Blanken et al., $1997)$ is in the same form as this study, while that of the northern temperate grassland (Wever et al., 2002) is in the logarithmic form $\alpha=\mathrm{a}_{1} \cdot \ln \left(\mathrm{g}_{\mathrm{s}}\right)-\mathrm{a}_{2}$.

\subsubsection{Jarvis-McNaughton Decoupling Coefficient ( $\quad$ ( )}

As indicated in Eq. 2.7, the change of the ratio of $g_{a}$ to $g_{s}$ in response to the environmental conditions determines the Jarvis-McNaughton (1986) decoupling coefficient $(\Omega)$, and hence the coupling of the 'big leaf' system to meteorological conditions. Values of $\Omega$ can vary between 0 and 1 , with values closer to 0 indicative of strong control on water loss and thus a closer coupling to $\mathrm{g}_{\mathrm{s}}$ and $\mathrm{D}$ while values approaching 1 represent a system that is more sensitive to changes in $R_{n}$ (Wilson and Baldocchi, 2000).

The daily mean ( \pm s.d.) value of $\Omega$ at Dyke 11 A South was $0.32 \pm 0.12$, indicating that the surface did exhibit some degree of canopy control on water loss. There was 
some variability in $\Omega$ between the growing season months, as Figure 5.5.3.1 shows the response of the system to the dry spell that occurred at the end of July. $\Omega$ increased from a mean of 0.37 in May to 0.39 in June due to the initiation of leaf-out and increased precipitation, but then decreased quite dramatically to a mean of 0.27 in July. These results, as expected, are slightly higher than the $\Omega$ values reported for a mature grassland (0.25 - 0.3) by Wever et al. (2002), indicating less biotic control at this site.

The drop in $\Omega$ between July $21-28$ (DOY $203-210$ ), where values fluctuated between $0.11-0.23$, occurred during one of the longest dry periods of the summer. $\mathrm{D}$ was quick to increase during this period, and as a result $\mathrm{g}_{\mathrm{s}}$ decreased as evaporative demand increased and soil moisture decreased. Again, it is uncertain if the decrease in $\mathbf{g}_{s}$ was due primarily to plant stress or a decrease in evaporation directly from the soil due to drying of the upper soil layer. Precipitation in August resulted in an increase in $\mathrm{g}_{s}$ and allowed $\Omega$ to rise back to a mean of 0.32 . Despite September only receiving $24.6 \mathrm{~mm}$ of rain, there was only a marginal decline in $\Omega(0.31)$, which can be attributed to a low vapour pressure deficit and the onset of senescence. 


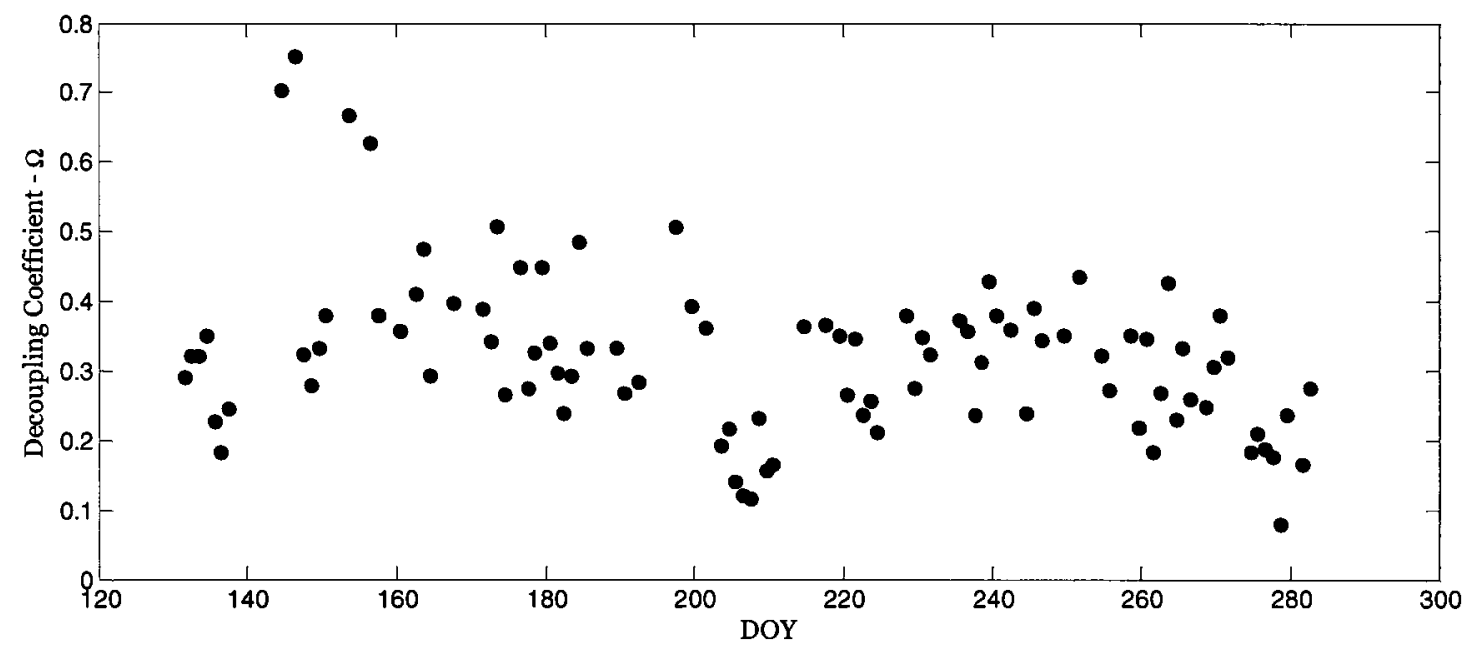

Figure 5.5.3.1: Variation of the dimensionless Jarvis-McNaughton decoupling coefficient $(\Omega)$ at Dyke 11A South during the 2008 growing season. Values of $\Omega$ were calculated during dry canopy daytime $(0900-1700)$ conditions.

The low $\Omega$ values that occurred at the end of July (which coincided with only 8 days of no rain) could have implications for the restoration efforts at Dyke 11A South. Had August not received unseasonably high precipitation (double the climate normal), it is likely that the $\Omega$ would have continued to decline as $\Psi_{\mathrm{m}}$ decreased and caused the vegetation to experience a prolonged period of moisture stress.

Figure 5.5.3.2 shows the progression of $\Omega$ throughout the day. Other studies have found that $\Omega$ will typically decrease as the day progresses, due to decreasing $g_{s}$ that responds to escalating $\mathrm{D}$, where $\mathrm{D}$ tends to peak in the late afternoon when temperatures are greatest (Hinckley et al., 1994; Wever et al., 2002; Moore, 2008). There was no discernible trend shown in any of the summer months, as $\Omega$ was typically higher at 1700 than it was in the morning, indicating that some of the $\mathrm{g}_{\mathrm{s}}$ must have derived from soil evaporation. September was the only month that showed the expected pattern, suggesting that soil evaporation was no longer contributing to $\mathrm{g}_{\mathrm{s}}$ (due to low $\mathrm{D}$ ) and that the plants 
that were still functioning into the late summer were those that were the most tightly coupled to the meteorological conditions and able to conserve water.

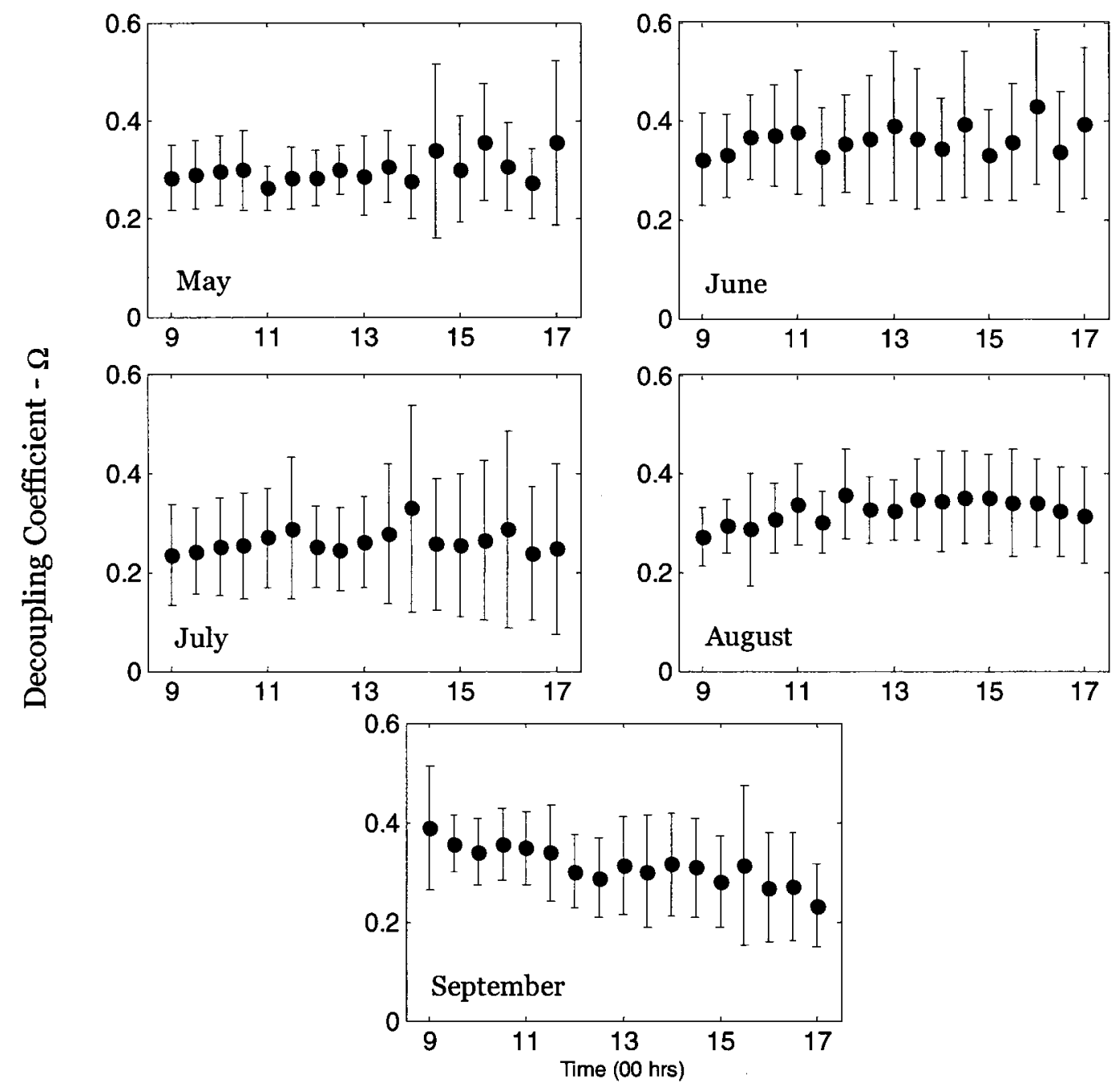

Figure 5.5.3.2: Monthly changes in half-hourly mean daily variation of the decoupling coefficient $(\Omega)$ during dry canopy daytime $(0900-1700)$ conditions. Vertical bars indicate \pm 1 s.d.

\subsubsection{ET sensitivity analysis}

As indicated in the P-M equation, the daily and seasonal variability of ET is primarily influenced by available radiation $\left(R_{a}=R_{n}-G\right)$, the atmospheric demand for 
water vapour (D) and canopy control $\left(\theta_{\mathrm{s}}\right.$ and $\left.\mathrm{g}_{\mathrm{s}}\right)$. Figure 5.5.4.1 displays bi-weekly means of dry canopy ( $>24 \mathrm{hrs}$ after rainfall), daytime conditions $(0900-1700)$ in order to display the trend of both ET and each of these parameters throughout the season. LE followed the same general trend as the atmospheric forcings $\left(R_{a}\right.$ and $\left.D\right)$ for the majority of the season, indicating a strong coupling to the atmosphere. LE deviated from this trend and was limited more by canopy control when soil moisture decreased during the dry month of July, at which time $g_{s}$ and LE both decreased.

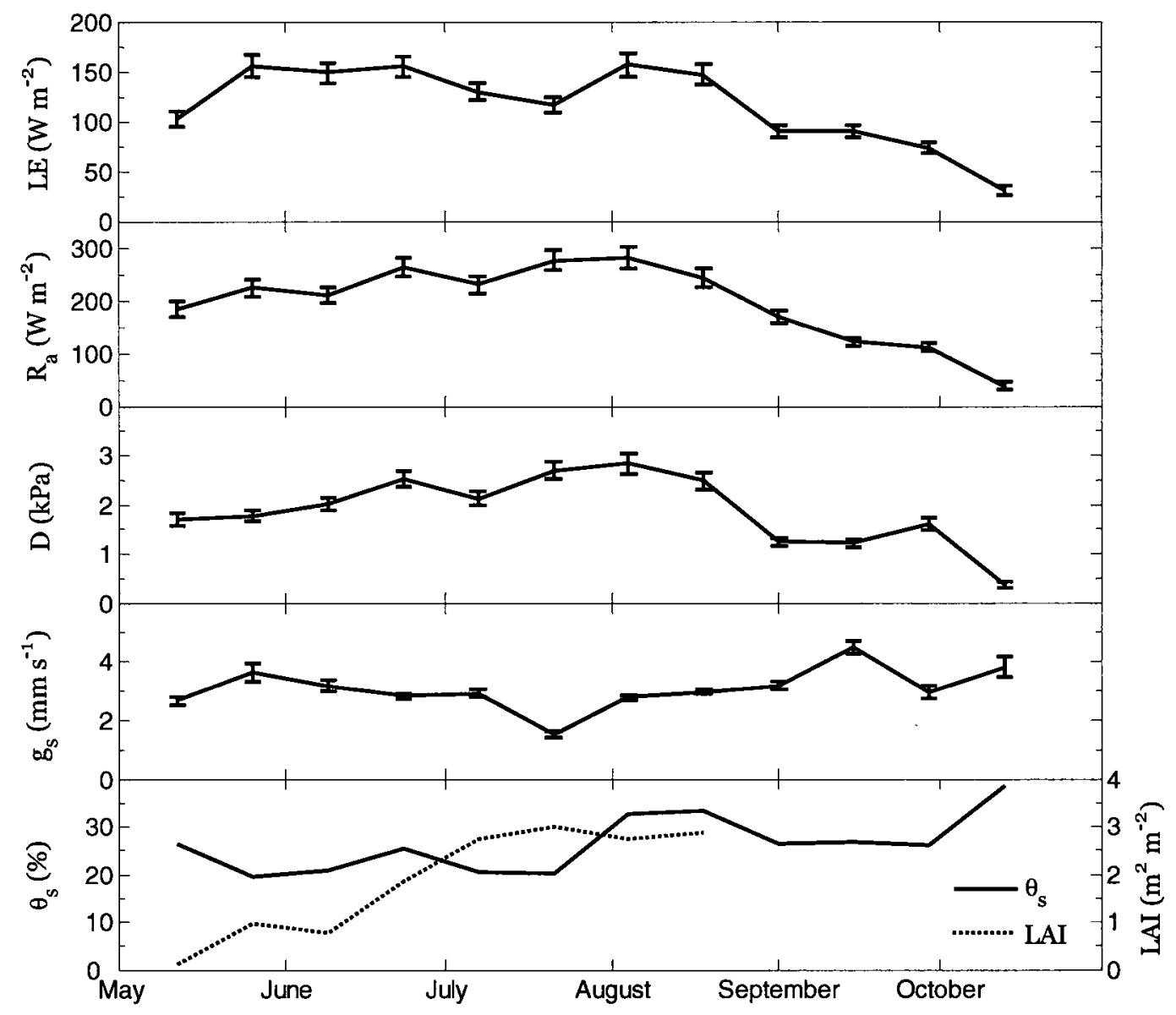

Figure 5.5.4.1: Seasonal variation of latent heat flux (LE), available radiation $\left(R_{a}\right)$, vapour pressure deficit $(D)$, bulk surface conductance $\left(\mathrm{g}_{\mathrm{s}}\right)$, volumetric soil water content $\left(\theta_{\mathrm{s}}\right)$ and leaf area index (LAI). Plotted values represent two week means calculated from dry canopy, daytime $(0900-1700)$ conditions. Error bars represent \pm 1 standard error. 
In order to quantitatively assess the sensitivity of ET to changes in each of the three major controls $\left(\mathrm{R}_{\mathrm{a}}, \mathrm{D}\right.$ and $\left.\mathrm{g}_{\mathrm{s}}\right)$ as the season progressed, a partial derivative analysis of the P-M equation was conducted following the method outlined by Wilson and Baldocchi (2000). Assuming that $\gamma, \rho, s$ and $\mathrm{g}_{\mathrm{a}}$ remained constant (with the latter being acceptable since $\Omega$ did not change appreciably between months), the mean monthly ET was rewritten in the total derivative form:

$$
d E T=\frac{\partial E T}{\partial R_{a}} d R_{a}+\frac{\partial E T}{\partial D} d D+\frac{\partial E T}{\partial g_{s}} d g_{s}+\frac{\partial E T}{\partial l b} d l b
$$

where $\mathrm{lb}$ represents the imbalance term that is incurred by assuming that the aforementioned parameters remained constant. In order to evaluate the cause of the variability in ET between two different months the components of Eq. 5.2 were then calculated as:

$$
\Delta E T=\frac{\overline{\partial E T}}{\partial R_{a}} \Delta R_{a}+\frac{\overline{\partial E T}}{\partial D} \Delta D+\frac{\overline{\partial E T}}{\partial g_{s}} \Delta g_{s}+\frac{\overline{\partial E T}}{\partial l b} \Delta l b
$$

with the overbar indicating the mean between the two combined months and $\Delta$ representing the difference between them. The partial derivatives were evaluated between each successive month to provide a better understanding of the seasonal controls of ET at this newly reclaimed site.

The general trend throughout the study (Figure 5.5.4.2) displayed an enhancement of all driving factors $\left(R_{a}, D, g_{s}\right)$ in June, resulting in a significant increase in ET $(>0.05$ $\mathrm{mm} \mathrm{hr}^{-1}$ ) rates following the pre-leaf period in May. This increase in $\mathrm{g}_{\mathrm{s}}$ and ET at the beginning of the season has also been found in other studies, and has been attributed to high soil moisture and the initiation of leaf emergence (Saigusa et al., 1998; Wever et al., 2002). The fact that all three driving factors increased simultaneously indicated lack of 
canopy control, suggesting that soil evaporation was a large contributor to $\mathrm{g}_{\mathrm{s}}$ at this time. Dry conditions in July resulted in reduced $\mathrm{g}_{\mathrm{s}}$ due to stomatal closure of the vegetation and a decrease in surface moisture being available for evaporation from the soil, causing a corresponding decrease in the magnitude of LE despite an increase in $R_{a}$ and $D$.

Compared to July, August had a surplus of $\mathrm{P}$ which saturated the soil cover and provided ample soil moisture for the vegetation, resulting in an increase in $g_{s}$ and thus LE. Canopy conductance continued to increase in September, however less radiation and cooler conditions resulted in a smaller D and ultimately much lower rates of ET, which were shown to decrease by $0.07 \mathrm{~mm} \mathrm{hr}^{-1}$. The small magnitude of the imbalance term between months indicated that the P-M equation used in this procedure performed reasonably well.

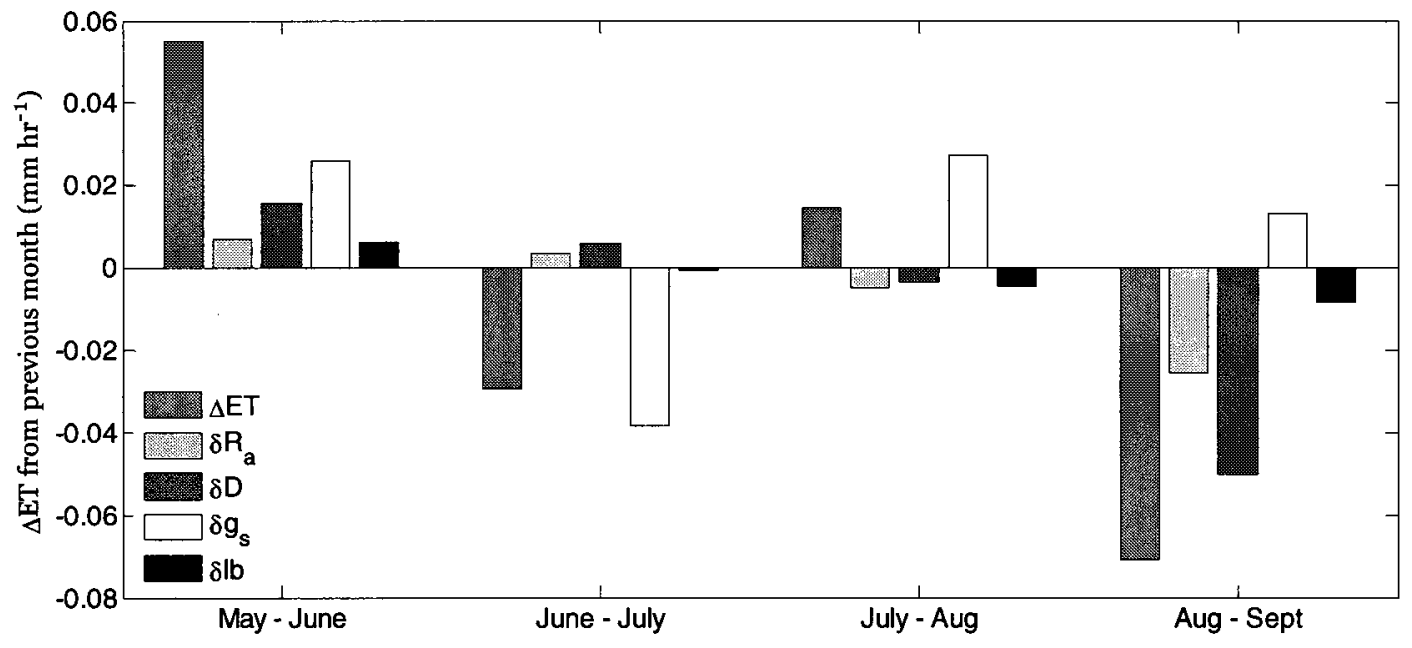

Figure 5.5.4.2: Results from the ET sensitivity analysis showing total change in dry canopy daytime (0900 - 1700) ET rates in succeeding months as well as the portion of that change derived analytically from Eq. 5.2 due to changes in available energy $\left(R_{a}\right)$, vapour pressure deficit (D), surface conductance $\left(\mathrm{g}_{\mathrm{s}}\right)$. An imbalance term (lb) is also included to account for the assumption that $\gamma, \rho, s$ and $\mathrm{g}_{\mathrm{a}}$ remained constant. 


\subsection{Controls on Surface Conductance}

It has been well established that plants respond in varying degrees to changes in photosynthetic active radiation (Q), $T_{a}, D$ and $\theta_{s}$ (Jarvis, 1976; Stewart, 1988). Due to this finding, many studies have conducted analyses on the relationship that $\mathrm{g}_{\mathrm{s}}$ has with these variables for the purpose of assessing the physiological control of water loss from the canopy (Blanken et al., 1997; Humphreys et al., 2003; Wever et al., 2002). An investigation of the relationship of $g_{s}$ at Dyke 11A South to these variables showed $g_{s}$ to be largely insensitive to $Q$ and more tightly coupled to $T_{a}, D$ and $\theta_{s}$.

In an attempt to capture the true physiological control of the canopy at Dyke 11A South, the results displayed in Figure 5.6.1 represent daily means from measurements taken during dry canopy daytime (0900 - 1700) conditions from June 1 - August 31 (DOY $153-244)(n=38)$. Similar to Figure 5.5.2.2, this period was chosen because it represented the post-leaf-out/pre-senescence period. 

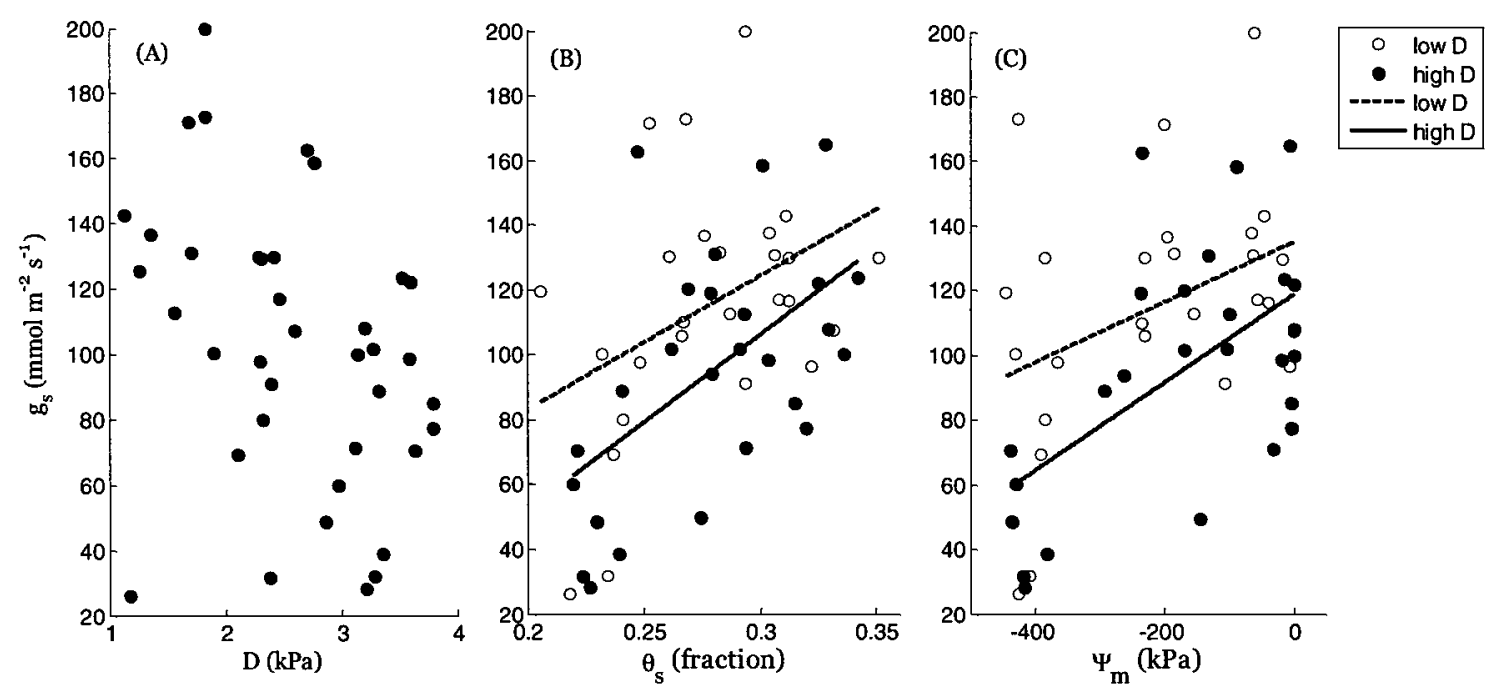

Figure 5.6.1: Relationships between mean daily values of surface conductance $\left(\mathrm{g}_{\mathrm{s}}\right)$ with (A) vapour pressure deficit (D), (B) volumetric soil moisture $\left(\theta_{\mathrm{s}}\right)$ and $(\mathrm{C})$ soil matric suction $\left(\Psi_{m}\right)$. The results displayed in Panels $B$ and $C$ have been binned using measurements that correspond to being above and below the median $\mathrm{D}$ of $2.6 \mathrm{kPa}$. All values represent daily means from measurements taken during dry canopy daytime (0900 - 1700) conditions from June 1 - August 31 (DOY 153 - 244) $(n=38)$.

Unlike most studies that tend to show a distinct non-linear relationship between D and $\mathrm{g}_{\mathrm{s}}$ (Blanken et al., 1997; Humphreys et al., 2003; Wever et al., 2002), the connection was not as obvious at Dyke 11A South, as a comparison of daily means showed an almost linear decline in $\mathrm{g}_{\mathrm{s}}$ with increasing $\mathrm{D}$ (Figure 5.6.1, Panel A). The fact that $\mathrm{g}_{\mathrm{s}}$ did not display a clear nonlinear relationship to $\mathrm{D}$ suggests that the stomata of the vegetation at this site may have been responding more to the influence of $\mathrm{D}$ rather than the transpiration rate itself (Blanken et al., 1997), and thus were incurring high water losses during photosynthesis.

To further check to see if stomatal control was evident, the response of $g_{s}$ to $\theta_{s}$ and $\Psi_{\mathrm{m}}$ was evaluated in Figure 5.6.1, Panels B and C. The displayed results have been binned according to those values that correspond to low and high atmospheric demand, 
using the median D value of $2.6 \mathrm{kPa}$. The trend lines in Panel $\mathrm{C}$ are not drawn to suggest that $g_{s}$ has a linear relationship with either $\theta_{s}$ or $\Psi_{m}$, but are rather only included to help elucidate any difference between the response of $\mathbf{g}_{s}$ in the two relationships during periods of high and low atmospheric demand. The slightly larger difference between the two D regimes in Panel C vs. Panel B indicates that the reclamation plants were exhibiting a small degree of canopy control on water loss. Support for this claim comes from the fact that when plants extract water from the soil, the roots must overcome the $\Psi_{\mathrm{m}}$ that is holding water to the soil particle in order to deliver the water up through the stem to the leaf. The resistance imposed by $\Psi_{\mathrm{m}}$ therefore makes it more tightly coupled to the leaf water potential (and hence $\mathrm{g}_{\mathrm{s}}$ ) than $\theta_{\mathrm{s}}$ (Campbell and Norman, 1998).

Figure 5.6.2 demonstrates the effect that the potential governing parameters typically had on daytime $\mathrm{g}_{s}$ at Dyke 11A South. The time series consists of four days (August 5-8) that exhibited relatively clear skies and a full soil moisture profile, as 42 $\mathrm{mm}$ of rain had fallen in a span of 48 hours two days prior. The example represents the progression of $T_{a}$ and $D$ reaching their maximum observed seasonal values $\left(32.3^{\circ} \mathrm{C}\right.$ and $4.8 \mathrm{kPa}$, respectively) on August 8 (DOY 221). Consequently, the example also represents a period of low $\mathrm{g}_{\mathrm{s}}$, as the four days coincide with the full leaf period when LAI reached its maximum (Figure 5.2.1). 

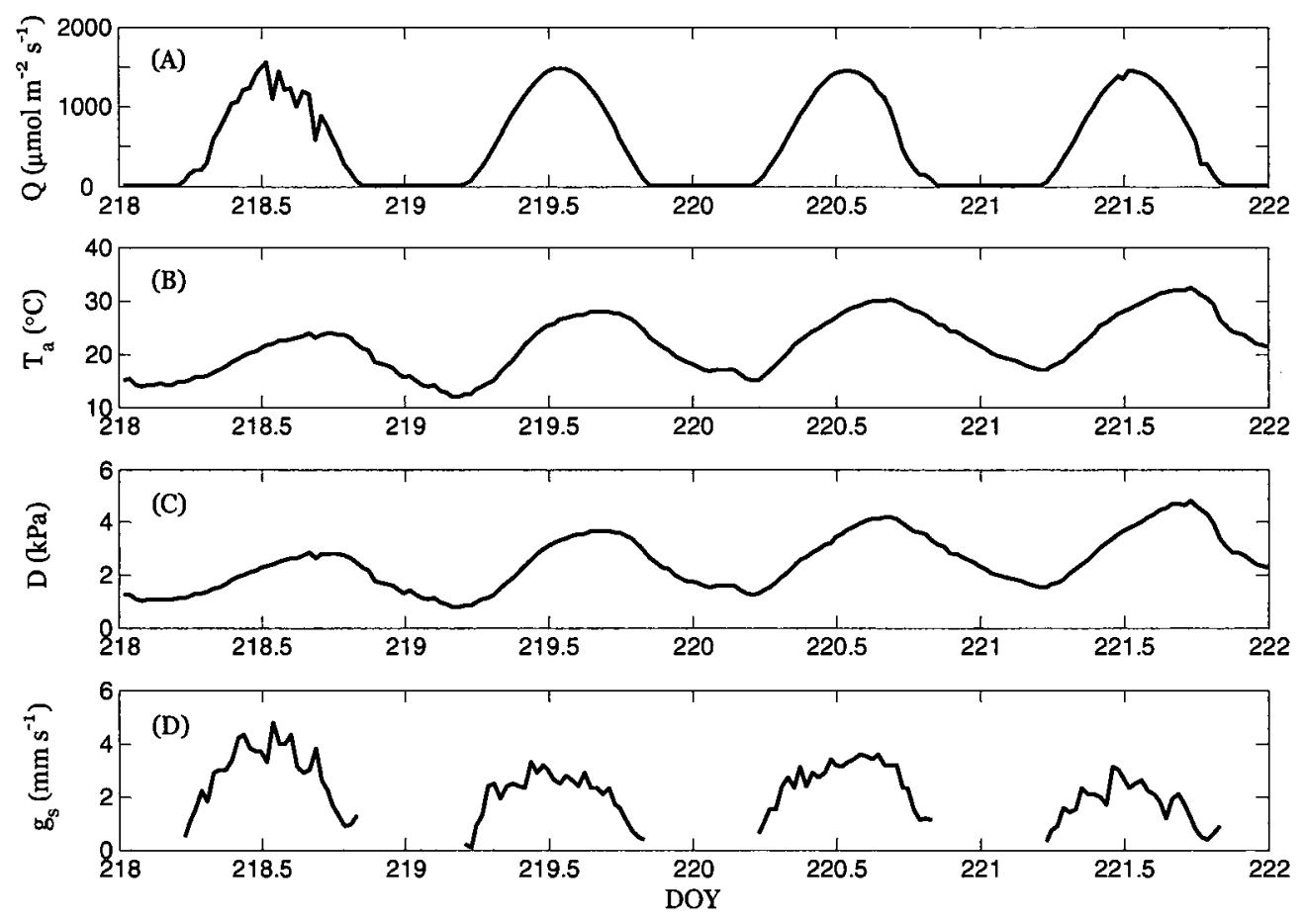

Figure 5.6.2: Example of half-hour measurements showing the response of (Panel D) surface conductance $\left(\mathrm{g}_{\mathrm{s}}\right)$ to (Panel $\mathrm{A}$ ) incident photosynthetic active radiation $(\mathrm{Q})$, (Panel B) air temperature $\left(T_{a}\right)$ and (Panel $\left.C\right)$ atmospheric vapour pressure deficit (D) from August 5-8 (DOY 218-221). The time series corresponds with the progression towards the maximum seasonal $\mathrm{T}_{\mathrm{a}}\left(32.3^{\circ} \mathrm{C}\right)$ and $\mathrm{D}(4.8 \mathrm{kPa})$ on DOY 221 , as well as a period with a full soil moisture profile that was provided from $42 \mathrm{~mm}$ of rain that fell on August 2 -3 (DOY 215-216).

In all four days the trend of $\mathrm{g}_{\mathrm{s}}$ appeared to follow that of $\mathrm{Q}$, supporting the premise that the lack of relation between $\mathrm{g}_{\mathrm{s}}$ and $\mathrm{Q}$ noted above was due to the incongruent timing of the full leaf period and maximum $\mathrm{Q}$. The timing of $\mathrm{g}_{\mathrm{s}}$ peaking around noon caused maximum $\mathrm{g}_{s}$ to have occurred at a time when $\mathrm{T}_{\mathrm{a}}$ and $\mathrm{D}$ were increasing to high levels. This suggests that maximum photosynthesis was occurring at the expense of high water losses. Unlike other grassland studies that have shown an almost linear decrease in $\mathrm{g}_{\mathrm{s}}$ to begin late in the morning (Adams et al., 1991), this 
example showed daily $g_{s}$ to remain high until the mid-afternoon when $T_{a}$ and $D$ were approaching maximum levels. The near-linear decline in $\mathrm{g}_{s}$ at this site didn't occur until late afternoon when $\mathrm{D}$ had reached its peak and $\mathrm{Q}$ was decreasing. The strong connection between $\mathrm{g}_{\mathrm{s}}$ and $\mathrm{D}$ was evident in the progression of days from DOY 218 to 221 , as mean daytime $\mathrm{D}$ increased from 2.4 to $3.9 \mathrm{kPa}$, while $\mathrm{g}_{\mathrm{s}}$ fell from a mean of $3.6 \mathrm{~mm} \mathrm{~s}^{-1}$ (139 $\left.\mathrm{mmol} \mathrm{m} \mathrm{m}^{-1}\right)$ to $2.2 \mathrm{~mm} \mathrm{~s}^{-1}\left(85 \mathrm{mmol} \mathrm{m}^{-2} \mathrm{~s}^{-1}\right)$. The slight increase in $\mathrm{g}_{\mathrm{s}}$ on DOY 220 that deviated from the trend could not be explained by any of the measured variables, but may have been a result of high $\mathrm{D}$ levels increasing the amount of soil evaporation.

\subsection{Carbon Balance}

\subsubsection{Seasonal $\mathrm{CO}_{2}$ flux}

An examination of the carbon balance provided an opportunity to further examine the influence of $g_{s}$ on site productivity. As the process of photosynthesis involves water vapor transferring through the same stomata as $\mathrm{CO}_{2}$, any assimilation of carbon that occurs is accompanied by transpiration (Campbell and Norman, 1998). Therefore, a comparison of NEE to $\mathrm{g}_{s}$ can potentially aid in distinguishing between the control of the vegetation on ET through increased transpiration versus that which was associated with free evaporation from the soil.

Dyke 11A South was a net sink for $\mathrm{CO}_{2}$ throughout the course of the growing season, as total NEP accumulated $55.1 \mathrm{~g} \mathrm{C} \mathrm{m}^{-2}$ over the entire study period. The bulk of carbon sequestration occurred prior to the maximum LAI measurements (Figure 5.2.1), with daily averages of NEE remaining relatively consistent around $-1.2 \mathrm{~g} \mathrm{C} \mathrm{m}^{-2} \mathrm{~d}^{-1}$ until June 21 (DOY 173) (Figure 5.7.1). Strong photosynthesis during the months of May and June supports the earlier claim that $g_{s}$ tends to be particularly enhanced during leaf-out 
(Saigusa et al., 1998; Wever et al., 2002) and would have been a significant contributor to the high rates of $\mathrm{LE}$.

With the exception of DOY 164 and 168, where mean daily NEP was 2.5 and 3.1 $\mathrm{g} \mathrm{C} \mathrm{m}^{-2} \mathrm{~d}^{-1}$, mean daily NEP at Dyke 11A South fell short of the range that Flanagan et al. (2002) reported for a northern temperate grassland $\left(2.4-5 \mathrm{~g} \mathrm{C} \mathrm{m}^{-2} \mathrm{day}^{-1}\right)$. The trend of NEE is similar to that of $g_{s}$ (Figure 5.5.1), as the surface was found to be a greater sink of carbon in May, June and the latter part of August (Figure 5.7.1). During the dry period in July when $\alpha$ was relatively low (DOY 185 - 215), NEE was near neutral (Figure 5.7.1) and $g_{s}$ was low, suggesting that drier conditions were less suitable for the growth of the plants at this site. However, lower amounts of $\mathrm{CO}_{2}$ uptake also coincided with slightly higher R, presumably due to warmer temperatures. The period between DOY 203 and 231 was also associated with little $\mathrm{CO}_{2}$ uptake, but this was a period of high soil moisture and thus the near-neutral NEE was due more to enhanced $R$ rather than decreased GEP. Radiation began to decline quickly by DOY 230 which coincided with an almost linear decline in both GEP and R and a rise in NEE. Photographs indicate that by August 21 (DOY 234), senescence of some of the plants at the site had occurred. 


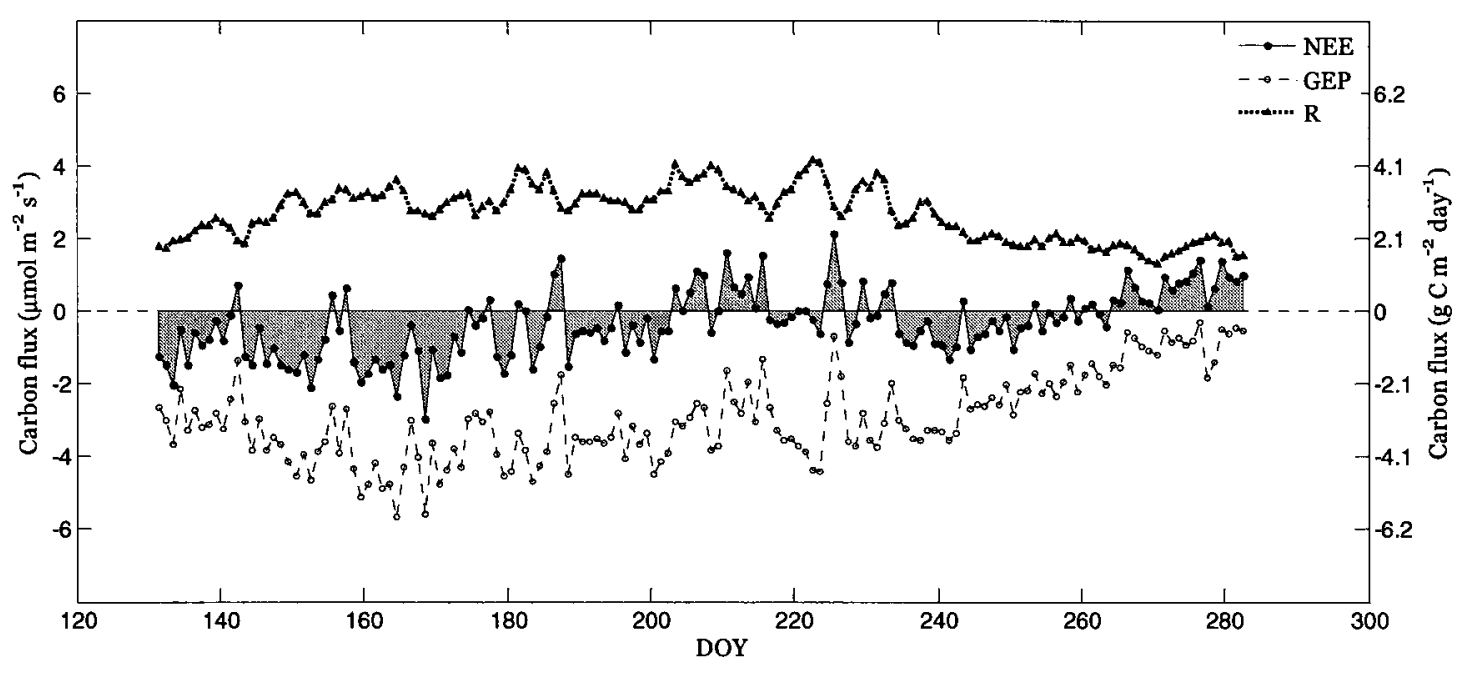

Figure 5.7.1: Seasonal variation of the mean daily carbon flux at Dyke 11A South during the 2008 growing season, encapsulating the contributions of respiration (R) and gross ecosystem productivity (GEP) to net ecosystem exchange (NEE). The conventional sign of GEP has been switched to a negative to illustrate uptake of $\mathrm{CO}_{2}$ during photosynthesis. The NEE trace has been shaded to elucidate the gain/loss of $\mathrm{CO}_{2}$ from the atmosphere, with positive/negative values indicating the surface (0) as being a $\mathrm{CO}_{2}$ source/sink.

\subsubsection{Diurnal $\mathrm{CO}_{2}$ flux}

Figure 5.7.2 shows the mean diurnal variation of NEE for each month of the growing season to illustrate how the timing and magnitude of NEE changed from May to September.

There was a marked effect of increasing temperatures on nighttime respiration, as the mean $\mathrm{R}$ during the warmest months (June - August) remained over $3 \mu \mathrm{mol} \mathrm{m} \mathrm{m}^{-2}$, while the cooler temperatures in May and August resulted in means closer to $2 \mu \mathrm{mol} \mathrm{m}{ }^{-2}$ $\mathrm{s}^{-1}$ (Figure 5.7.2).

NEE appeared to be tightly linked to $Q$ (Figure 5.7.2), as daily maximums were found to increase from May until the summer solstice in June before steadily decreasing 
to smaller values with the shorter days in September. The greatest NEE of $-6.3 \mu \mathrm{mol} \mathrm{m}{ }^{-2}$ $\mathrm{s}^{-1}$ that occurred in June and the smallest NEE of $-3.5 \mu \mathrm{mol} \mathrm{m} \mathrm{m}^{-2} \mathrm{~s}^{-1}$ occurring in September were representative of the onset of the leaf out and senescence periods. When LAI was greatest, near-noon values of NEE during July and August were able to attain similar levels (around $-5 \mu \mathrm{mol} \mathrm{m} \mathrm{m}^{-2}$ ).

The pronounced decrease in NEE near $1100 \mathrm{hrs,} \mathrm{particularly} \mathrm{during} \mathrm{the} \mathrm{hot} \mathrm{and}$ dry month of July when soil moisture was limited (low $\Psi_{\mathrm{m}}$ ), indicated enhanced stomatal limitations to gas exchange than was previously shown in the patterns of $g_{s}$ and $\Omega$ (Figure 5.5.3.2), providing further support that there was a significant contribution of evaporation from the soil.

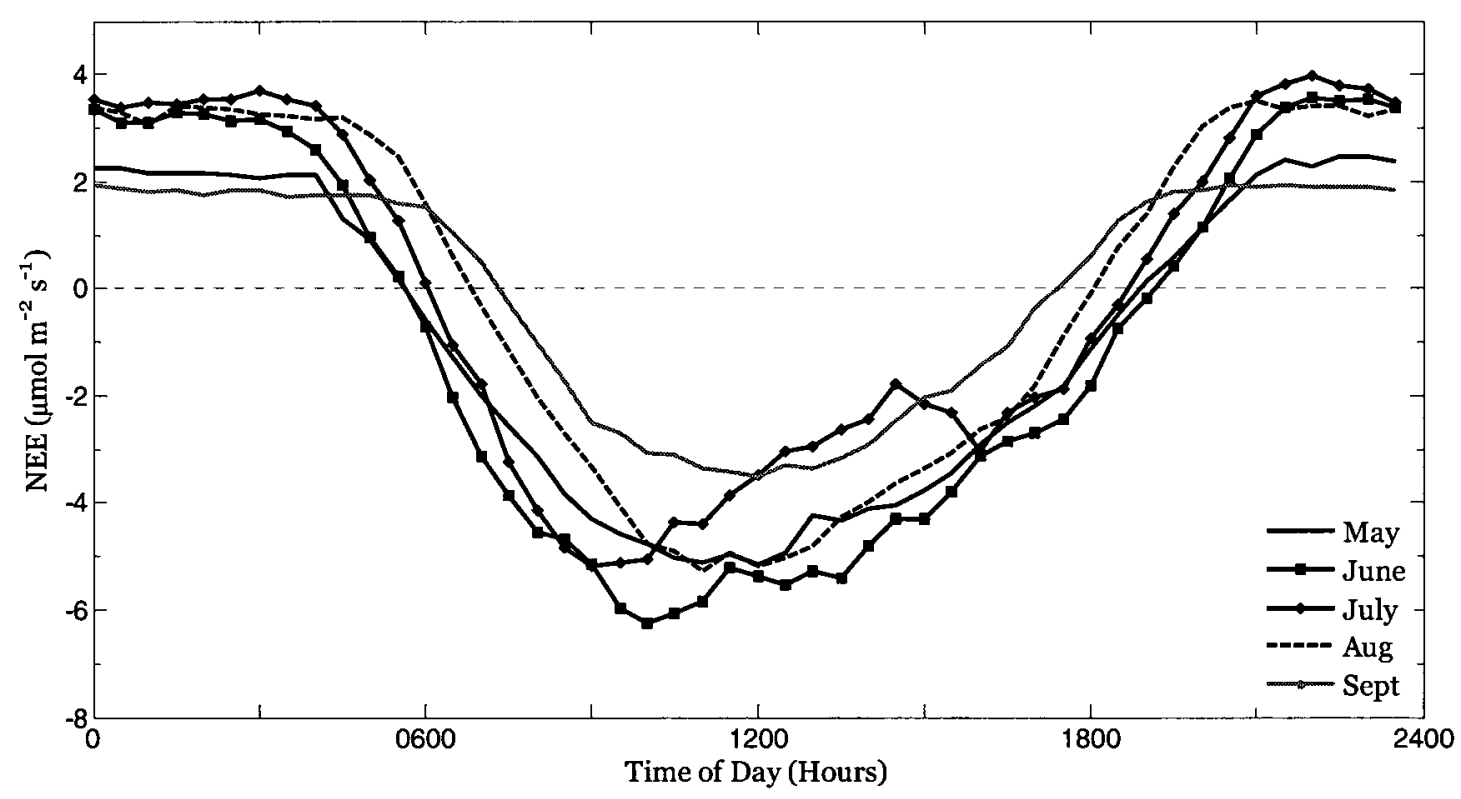

Figure 5.7.2: Mean diurnal variation of half-hour measurements of net ecosystem exchange $(\mathrm{NEE}=-\mathrm{NEP})$ for the months May through September at Dyke 11A South during the 2008 growing season. 


\subsection{Water use efficiency}

An examination of this site's water use efficiency $($ WUE $=$ dGEP/dET), which describes the ratio of carbon gain during $\mathrm{CO}_{2}$ assimilation to water loss during transpiration, provided a means to further investigate the control that the stomata of the big leaf surface had on the system. Lower stomatal conductance will usually result in higher WUE because it tends to limit water loss through transpiration more than $\mathrm{CO}_{2}$ assimilation (Ponton et al., 2006). WUE is important to the survival, productivity and overall health of the plants within an ecosystem, as it signals how the system will respond to naturally varying soil moisture levels and how it might cope with possible droughts.

Following the method proposed by Kljun et al. (2006), WUE in this study was calculated as the slope of two week means of the measured/modeled GEP versus ET. WUE at this site during the 2008 field season was $1.45 \mathrm{~g} \mathrm{C} \mathrm{kg}^{-1} \mathrm{H}_{2} \mathrm{O}$ (Figure 5.8). This was slightly less than what Wever et al. (2002) reported from a three year study of a northern temperate grassland, where WUE ranged from $1.68-2.09 \mathrm{~g} \mathrm{C} \mathrm{kg}^{-1} \mathrm{H}_{2} \mathrm{O}$ between years, and was closer to the $1.5 \mathrm{~g} \mathrm{C} \mathrm{kg}^{-1} \mathrm{H}_{2} \mathrm{O}$ that Liang et al. (1989) reported for a shortgrass/shrub steppe environment in northern Colorado. Even though soil evaporation resulted in a decrease in the ratio of carbon gain to water loss, the fact that the WUE at Dyke 11A South falls just shy of the ranges of other comparable natural ecosystems during only its second year of reclamation implies that the system was functioning in a relatively natural fashion, and that the site was able to endure its second year of rehabilitation successfully. 


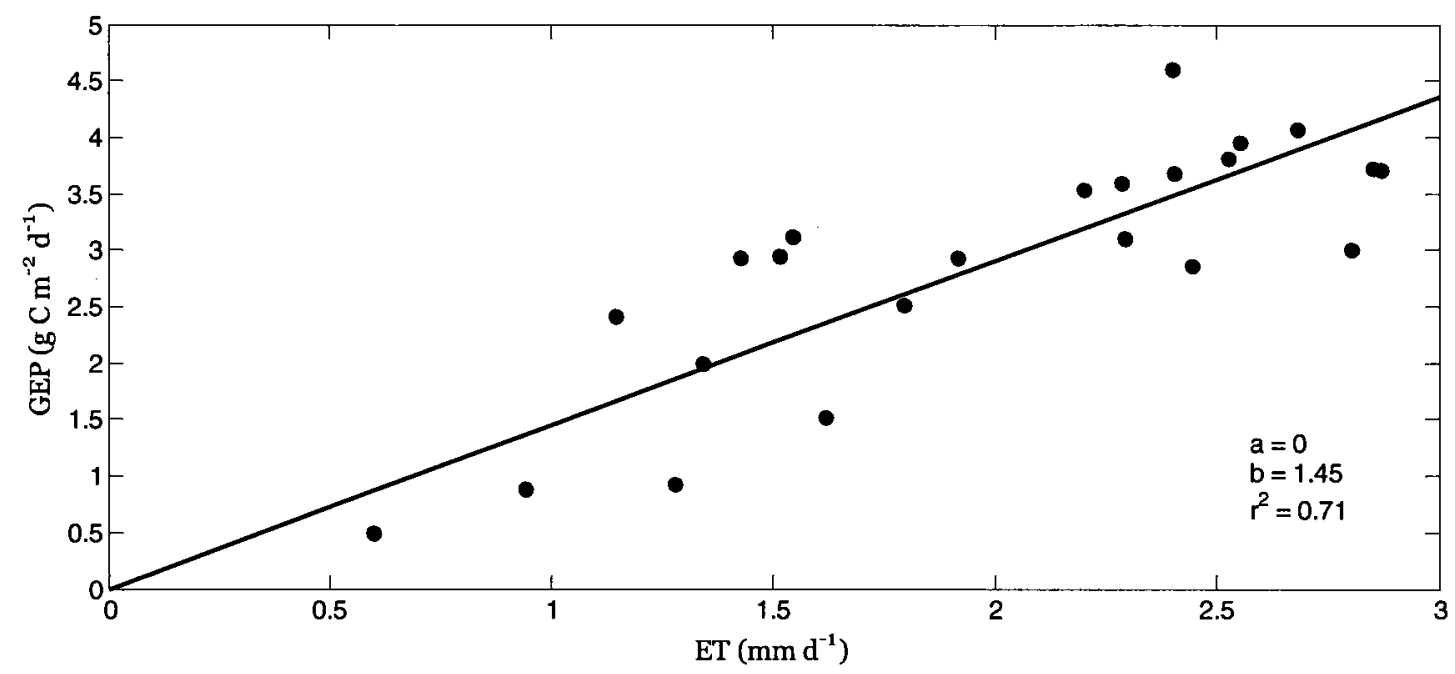

Figure 5.8: Growing season gross ecosystem productivity (GEP) versus evapotranspiration (ET) (weekly averages) observed at Dyke 11A South. a denotes the intercept $\left(\mathrm{g} \mathrm{C} \mathrm{m}^{-2} \mathrm{~d}^{-1}\right)$ and $\mathrm{b}$ denotes the slope $\left(\mathrm{g} \mathrm{C} \mathrm{m}^{-2} \mathrm{~d}^{-1} \mathrm{~mm}^{-1} \mathrm{H}_{2} \mathrm{O} \mathrm{d}^{-1}\right.$ or $\mathrm{g} \mathrm{C} \mathrm{kg}^{-1}$ $\mathrm{H}_{2} \mathrm{O}$ ), which describes the water use efficiency (WUE) of the canopy (Kljun et al., 2006). 


\subsection{Summary}

This study measured the micrometeorological fluxes of mass and energy atop a reclamation soil cover during its second year of regeneration. The assessment of the magnitude and seasonal variability in energy and mass fluxes was primarily concerned with the partitioning of $R_{n}$ and its influences on the mass fluxes of (1-a) water vapour and (1-b) $\mathrm{CO}_{2}$. Mean partitioning of $\mathrm{R}_{\mathrm{n}}$ into $\mathrm{H}, \mathrm{LE}$ and $\mathrm{G}$ over the season was $0.3,0.55$ and 0.12 , respectively. The majority of the variance in partitioning was split between $\mathrm{H}$ and $\mathrm{G}$, as $\mathrm{LE} / \mathrm{R}_{\mathrm{n}}$ remained relatively constant throughout the growing season. This resulted in a mean daytime Bowen ratio at Dyke 11A South being typically dominated by LE ( $\beta=$ $0.65 \pm 0.46$ ), with the exception of a notable increase during a brief dry spell in July that saw it increase to 2.9. Mean ET for the season was $2 \pm 0.8 \mathrm{~mm} \mathrm{~d}^{-1}$ and amounted to a total of $308 \mathrm{~mm}$ by the end of the study.

(1-b) Dyke 11A South was found to be a net sink of carbon, with the sum of NEP amounting to $55.1 \mathrm{~g} \mathrm{C} \mathrm{m}^{-2}$ over the growing season. The bulk of this carbon sequestration occurred during the months of May and June, highlighting the enhancement of photosynthetic activity during the period of leaf-out. In contrast to the daily patterns that showed both $\mathrm{g}_{\mathrm{s}}$ and $\mathrm{D}$ to remain high late in the afternoon, stomatal control was apparent in the mean diurnal variation of NEP, with maximum photosynthesis occurring before noon and decreasing in response to increasing vapour pressure deficits in the afternoon. The fact that $g_{s}$ did not show the same resistance to $\mathrm{D}$ suggests that a portion of afternoon $\mathrm{g}_{\mathrm{s}}$ was attributable to free soil evaporation.

The assessment of the controls on ET was conducted by (2-a) analyzing several empirical parameters that are known to help describe ET and (2-b) performing an ET 
sensitivity analysis to see how seasonal variations in the governing parameters of the P-M equation affected rates of ET.

(2-a) The atmospheric demand for water vapour was found to be the primary control of seasonal variations in ET. This finding was supported by significant changes in ET rates with advection of dry air that changed with upwind source areas. A mean Priestley-Taylor $\alpha$ of 0.82 indicated that the surface was evaporating relatively freely, but did exhibit a certain degree of biotic control. A mean $\Omega$ of $0.32 \pm 0.12$ suggested that this biotic control was more closely coupled to $\theta_{\mathrm{s}}$ and $\mathrm{D}$ rather than $\mathrm{R}_{\mathrm{a}}$. However, being as soil moisture never became limiting to $\mathrm{g}_{\mathrm{s}}$ due to frequent inputs of precipitation, $\theta_{\mathrm{s}}$ was less of a factor than $D$.

(2-b) Results from the ET sensitivity analysis showed that the control over ET changed month-to-month. The seasonal progression saw an enhancement of all driving factors $\left(R_{a}, D\right.$ and $\left.g_{s}\right)$ in June, resulting in a significant increase in ET $\left(>1.3 \mathrm{~mm} \mathrm{~d}^{-1}\right)$. A decrease in ET rates of $0.7 \mathrm{~mm} \mathrm{~d}^{-1}$ indicated that stomatal control became evident during the dry month of July when $\theta_{\mathrm{s}}$ continually decreased and $\Psi_{\mathrm{m}}$ reached summer-time lows of $-767 \mathrm{kPa}$. This period saw daily $\Omega$ values decrease to as low as 0.11 from a mean of 0.26. Plant stress was relieved when $150 \mathrm{~mm}$ of rain fell in August, causing $\mathrm{g}_{\mathrm{s}}$ to recover and $\alpha$ to approach unity in September.

All analyses pointed towards the conclusion that the atmospheric demand for water vapour exhibited a strong control on the seasonal variations of LE in this system and that evaporation of $\theta_{\mathrm{s}}$ was a major contributor to ET. The inability of the ruderal species that had colonized the site to exert much stomatal control to become productive resulted in this site having a lower WUE than other natural grassland ecosystems. 


\subsection{Concluding Remarks}

In order for oil sands mining operators to fulfill environmental stewardship obligations and meet operational requirements, it is necessary for the industry to establish the most optimal conditions for ecosystem recovery post-mining activities. The reclamation experiment presented in this study represents a critical test for reclamation success for many reasons. The ET soil cover used may help to establish the lowest acceptable limits of reclamation measures needed to promote successful regeneration of disturbed areas. As the reclamation cover in question is constructed with the thinnest soil cover on trial, this experiment offers the greatest cost-benefit for reclamation funding. With projections to expand oil sands mining activities over $8000 \mathrm{~km}^{2}$ in the next decade, and the future value of crude oil currently being questioned, it is imperative that a means of providing the proper measures of rehabilitation remain in reach. Furthermore, the impending success/failure of this site may help regulators to identify what a 'reclaimed site' actually means, as there is currently no such definition in Alberta's Environmental Protection and Enhancement Act

Due to the strong influence of the boreal region on global climate, the ongoing large-scale land disturbance could potentially have significant implications for the regional weather of northern Alberta and Saskatchewan. Creating uplands topography in an area that is vastly dominated by low-lying wetlands and black-spruce dominated forests is drastically altering the hydrology and microclimate of the Athabasca oil sands region. The natural vegetation that is established in the area exists there because it has adapted to the in situ soil moisture regime and is able to cope with the high atmospheric demand of the region. It is therefore vital to the success of these reclamation efforts that 
each engineered cover is able to maintain sufficient water to provide for plant growth and promote rapid regeneration.

Following Carey (2008), this is the second study of its kind that has established the fact that newly regenerating soil covers in the Fort McMurray region need to be able to retain ample water to supply high levels of ET, as both studies have found that LE consumes a significant portion of $R_{n}$ in these ecosystems.

The extremely low $\Omega$ values that occurred at the end of July (which coincided with only 8 consecutive days without rain) could have future implications for the restoration efforts at Dyke 11A South. Had August not received unseasonably high precipitation (double the climate normal), it is likely that the $\Omega$ would have continued to decline. This conclusion is plausible because even though July was considered to be the 'dry' month during this growing season, it still received average precipitation. The results suggest that a $0.25 \mathrm{~m}$ soil cover may not provide a high enough water storage capacity because without the excess precipitation in August, the soil moisture profile would not have been recharged, soil suction levels would have continued to decrease and the vegetation would have experienced a prolonged period of stress.

As the 2008 growing season was favorable for plant development, and Dyke 11A South has only experienced two full growing seasons, it is too early to project whether this reclamation trial is going to fail or succeed. Future research at Dyke 11A South will provide the opportunity to examine how the ecosystem responds to the inter-annual variability of natural climatic forcings. This will ultimately decide how the results presented in this study will be interpreted. Come what may, specific environmental indicators can be taken from this study to help forecast the impending success or failure 
of future reclamation efforts due to a greater awareness of the system ecohydrology and biometeorology. A continuation of these restoration trials will allow oil sands operators to tailor future reclamation covers to their individual micro-climates and allow for mitigation strategies to be implemented earlier if needed to prevent ecosystem collapse. 


\section{References}

Adams RS, Black TA and Fleming RL. 1991. Evapotranspiration and surface conductance in a high elevation, grass-covered forest clearcut. Agricultural and Forest Meteorology, 56, 173 - 193.

Albright WH, Benson CH, Gee GW, Roesler AC, Abichou T, Apiwantragoon P, Lyles BF, Rock SA. 2004. Field water balance of landfill final covers. Journal of Environmental Quality, 33, 2317-2332.

Amiro BD, Barr AG, Black TA, Iwashita H, Kljun N, McCaughey JH, Morgenstern K, Murayama S, Nesic Z, Orchansky AL, Saigusa N. 2006. Carbon, energy, and water fluxes at mature and disturbed forest sites, Saskatchewan, Canada. Agriculture and Forest Meteorology, 136, 237-251.

Baldocchi DD. 2003. Assessing the eddy covariance technique for evaluating carbon dioxide exchange rates of ecosystems: past, present and future. Global Change Biology, 9, 479-492.

Baldocchi DD, Hicks BB, Meyers TP. 1988. Measuring biosphere-atmosphere exchanges of biologically related gases with micrometeorological methods. Ecology, 69, 1331-1340.

Baldocchi DD, Kelliher FM, Black TA and Jarvis P. 2000. Climate and vegetation controls on boreal zone energy exchange. Global Change Biology, Suppl. 1, 69-83.

Baldocchi DD, Vogel CA and Hall B. 1997. Seasonal variation of energy and water vapor exchange rates above and below a boreal jack pine forest canopy. Journal of Geophysical Research, 102(D24), 28939 - 28951.

Betts AK and Ball JH. 1997. Albedo over the boreal forest. Journal of Geophysical Research, 102(D24), $28901-28909$.

Blanken PD, Black TA, Yang PC, Neumann HH, Nesic Z, Staebler R, den Hartog G, Novak MD and Lee X. 1997. Energy balance and canopy conductance of a boreal aspen forest: Partitioning overstory and understory components. Journal of Geophysical Research, 102(D24), 28915 - 28927.

Blanken PD, Black TA, Neumann HH, den Hartog G, Yang PC, Nesic Z, Lee X. 2001. The seasonal water and energy exchange above and within a boreal aspen forest. Journal of Hydrology, 245, 118-136.

Brutsaert WH. 1982. Evaporation into the atmosphere. D. Reidel Publishing Company. London, England. 299 pp. 
Bunce JA. 1985. Effect of boundary layer conductance on the response of stomata to humidity. Plant, Cell and Environment, 8, 55 - 57.

Campbell DI. 1989. Energy balance and transpiration from tussock grassland in New Zealand. Boundary Layer Meteorology, 46, 133 - 152.

Campbell DI and Norman JM. 1998. An introduction to environmental biophysics, $2^{\text {nd }}$ ed. Springer-Verlag, New York, NY, 286 pp.

Canadian Legal Information Institute. 2008. Conservation and Reclamation Regulation, Alta. Reg. 115/1993 in Environmental Protection and Enhancement Act, R.S.A. 2000, c. E-12. http://www.canlii.org/ab/laws/regu/1993r.115/20080215/whole.html

Carey SK. 2008. Growing season energy and water exchange from an oil sands overburden reclamation cover, Fort McMurray, Alberta, Canada. Hydrological Processes, 22, 2847 - 2857.

Cava D, Contini D, Donateo A and Martano P. 2008. Analysis of short-term closure of the surface energy balance above short vegetation. Agricultural and Forest Meteorology, $148,82-93$.

Chambers SD and Chapin FS. 2003. Fire effects on surface-atmosphere energy exchange in Alaskan black spruce ecosystems: Implications for feedbacks to regional climate. Journal of Geophysical Research, 108(D1), 8145, doi: 10.1029/2001JD000530.

Devito K, Creed I, Gan T, Mendoza C, Petrone R, Silins U, Smerdon B. 2005. A framework for broad-scale classification of hydrologic response units on the Boreal Plain: is topography the last thing to consider? Hydrological Processes, 19, 1705-1714.

Drewitt GB, Black TA, Nesic Z, Humphreys ER, Jork EM, Swanson R, Ethier GJ, Griffis $\mathrm{T}$ and Morgenstern K. 2002. Measuring forest floor $\mathrm{CO}_{2}$ fluxes in a Douglas-fir forest. Agricultural and Forest Meteorology, 110, 299 - 317.

Elshorbagy A, Jutla A, Barbour SL, Kells J. 2005. System dynamics approach to assess the sustainability of reclamation of disturbed watersheds. Canadian Journal of Civil Engineering, 32, 1-15.

Flanagan LB, Wever LA, Carlson PJ. 2002. Seasonal and interannual variation in carbon dioxide exchange and carbon balance in a northern temperate grassland. Global Change Biology, 8, $599-615$.

Foken T. 2008. The energy balance closure problem: an overview. Ecological Applications, 18(6), 1351 - 1367.

Foken T and Wichura B. 1996. Tools for quality assessment of surface-based flux measurements. Agricultural and Forest Meteorology, 78, 83 - 105. 
Gardner WR. 1983. Soil properties and efficient water use: An overview. In: Taylor HM, Jordan WR, Sinclair TR (eds), Limitations to efficient water use in crop production. American Society of Agronomy, Madison, Wisconsin, USA, 45 - 64 pp.

Gash JHC, Valente F and David JS. 1999. Estimates and measurements of evaporation from wet sparse pine forest in Portugal. Agricultural and Forest Meteorology, 94, 149 158.

Hauser VL, Weand BL, Gill MD. 2001. Natural covers for landfills and buried waste. Journal of Environmental Engineering, 127, 768-775.

Hinckley TM, Brooks JR, Cermak J, Ceulemans R, Kucera J, Meinzer FC and Roberts DA. 1994. Water flux in a hybrid poplar stand. Tree Physiology, 14, $1005-1018$.

Humphreys ER, Black TA, Ethier GJ, Drewitt GB, Spittlehouse DL, Jork E-M, Nesic Z and Livingston NJ. 2003. Annual and seasonal variability of sensible and latent heat fluxes above a coastal Douglas-fir forest, British Columbia, Canada. Agricultural and Forest Meteorology, 115, 109 - 125.

Irwin JS and Binkowski FS. 1981. Estimation of the Monin-Obukhov length using onsite instrumentation. Atmospheric Environment, 15, 1091 - 1094.

Jarvis JB. 1976. The interpretation of the variations in leaf water potential and stomatal conductance found in canopies in the field. Philosophical Transactions of the Royal Society of London, 273, 593 - 610.

Jarvis PG, Massheder JM, Hale SE, Moncrieff JB, Rayment M, Scott SL. 1997. Seasonal variation of carbon dioxide, water vapour, and energy exchanges of a boreal black spruce forest. Journal of Geophysical Research, 102 (D24), 28953-28966.

Jarvis PG, McNaughton KG. 1986. Stomatal control of transpiration: scaling up from leaf to region. Advances in ecological research, 15, 1-49.

Kaimal JC and Finnigan JJ. 1994. Atmospheric boundary layer flows: Their structure and measurement. Oxford University Press, New York, 289 pp.

Kaimal JC, Wyngaard JC, Izumi Y and Coté OR. 1972. Spectral characteristics of surface-layer turbulence. Quarterly Journal of the Royal Meteorological Society, 98, 563 $-589$.

Kelliher FM, Leuning R and Schulze ED. 1993. Evaporation and canopy characteristics of coniferous forests and grasslands. Oecologia, 95, $1-16$. 
Kljun N, Calanca P, Rotach MW, Schmid HP. 2004. A simple parameterization for flux footprint predictions. Boundary-Layer Meteorology, 112, 503 - 523. Online source: http://footprint.kljun.net/

Kljun N, Black TA, Griffis TJ, Barr AG, Gaumont-Guay D, Morgenstern K, McCaughey JH and Nesic Z. 2006. Response of net ecosystem productivity of three boreal forest stands to drought. Ecosystems, 9, $1128-1144$.

Knapp AK and Smith MD. 2001. Variation among biomes in temporal dynamics of aboveground primary production. Science, 291, $481-484$.

Lee X, Massman W, Law BE. 2004. Handbook of micrometeorology. A guide for surface flux measurement and analysis. Kluwer Academic Press, Dordrecht, 250 pp.

Liang YM, Hazlett DL and Lauenroth WK. 1989. Biomass dynamics and water use efficiencies of five plant communities in the shortgrass steppe. Oecologia, 80, $148-153$.

Litvak ML, Miller S, Wofsy S and Goulden M. 2003. Effect of stand age on whole ecosystem $\mathrm{CO}_{2}$ exchange in the Canadian boreal forest. Journal of Geophysical Research, 108(D3), doi: 10.1029/2001JD000854.

Menzel L. 1996. Modelling canopy resistances and transpiration of grassland. Physics and Chemistry of the Earth, 21, 123 - 129.

Moncrieff JB, Malhi Y, Leuning R. 1996. The propogation of errors in long-term measurements of land-atmosphere fluxes of carbon and water. Global Change Biology, $2,231-240$.

Monteith JL. 1981. Evaporation and surface temperature. Quarterly Journal of the Royal Meteorological Society, 107, 1-27.

Monteith JL. 1995. Accommodation between transpiring vegetation and the convective boundary layer. Journal of Hydrology, 166, 251-263.

Monteith JL, Unsworth MH. 1990. Principles of Environmental Physics, $2^{\text {nd }}$ ed. Routledge, Chapman and Hall, Inc. New York, NY. 291 pp.

Moore PA. 2008. Micrometeorological fluxes and controls on evapotranspiration for a jack pine stand growing on reclamation soil cover, Fort McMurray, Alberta. M.Sc. Thesis, Carleton University, Canada, $161 \mathrm{pp}$.

Oke TR. 1987. Boundary layer climates, $2^{\text {nd }}$ ed. Routledge. New York, NY. 435 pp.

Palynchuk B and Guo Y. 2008. Threshold analysis of rainstorm depth and duration statistics at Toronto, Canada. Journal of Hydrology, 348, 535 - 545. 
Penman HL. 1948. Natural evaporation from open water, bare soil and grass.

Proceedings of the Royal Society of London. Series A, Mathematical and Physical Sciences, 193, 120-145.

Ponton S, Flanagan LB, Alstad KP, Johnson BG, Morgenstern K, Kljun N, Black TA and Barr AG. 2006. Comparison of ecosystem water-use efficiency among Douglas-fir forest, aspen forest and grassland using eddy covariance and carbon isotope techniques. Global Change Biology, 12, doi: 10.1111/j.1365-2486.2005.01103.x.

Priestley CHB and Taylor RJ. 1972. On the assessment of surface heat flux and evaporation using large-scale parameters. Monthly Weather Review, 100, 81-92.

Saigusa N, Oikawa T and Liu S. 1998. Seasonal variations in the exchange of $\mathrm{CO}_{2}$ and $\mathrm{H}_{2} \mathrm{O}$ between a grassland and the atmosphere: an experimental study. Agricultural and Forest Meteorology, 89, 131 - 139.

Shuttleworth WJ, Calder IR. 1979. Has the Priestley-Taylor equation any relevance to forest evaporation? Journal of Applied Meteorology, 18, 639-646.

Sims PL, Singh JS and Lauenroth WK. 1978. The structure and function of ten western North American grasslands. I. Abiotic and vegetational characteristics. Journal of Ecology, 66, $251-285$.

Stewart JB. 1988. Modelling surface conductance of Pine Forest. Agricultural and Forest Meteorology, 43, 19 - 35.

Stull R. 1997. An introduction to boundary layer meteorology. Kluwer Academic Publishers, Dordrecht, Netherlands, 670 pp.

Swanson DA, Barbour SL, Wilson GW, O'Kane M. 2003. Soil atmosphere modeling of an engineered soil cover for acid generating mine waste in a humid, alpine climate. Canadian Geotechnical Journal, 40, 276-292.

Tjoelker MG, Oleksyn J and Reich P. 2001. Modelling respiration of vegetation: evidence for a general temperature-dependent $\mathrm{Q}_{10}$. Global Change Biology, 7, 223 - 230 .

Tsialtas JT, Handley LL, Kassioumi MT, Veresoglou DS and Gagianas AA. 2001. Interspecific variation in potential water-use efficiency and its relation to plant species abundance in a water-limited grassland. Functional Ecology, 15, 605-614.

Twine TE, Kustas WP, Norman JM, Cook DR, Houser PR, Meyers TP, Prueger JH, Starks PJ and Wesely ML. 2000. Correcting eddy-covariance flux underestimates over a grassland. Agricultural and Forest Meteorology, 103, 279 - 300.

Vickers D, Mahrt L. 1997. Quality control and flux sampling problems for tower and aircraft data. Journal of Atmospheric and Oceanic Technology, 14(3), 512 - 526. 
Webb EK, Pearman GI, Leuning R. 1980. Correction of flux measurements for density effects due to heat and water vapour transfer. Quarterly Journal of the Royal Meteorological Society, 106, 85-100.

Wever LA, Flanagan LB and Carlson PJ. 2002. Seasonal and interannual variation in evapotranspiration, energy balance and surface conductance in a northern temperate grassland. Agricultural and Forest Meteorology, 112, 31 - 49.

Wikum DA and Shanholtzer GF. 1978. Application of the Braun-Blanquet CoverAbundance Scale for Vegetation Analysis in Land Development Studies. Environmental Management, 2, 323 - 329.

Wilczak JM, Oncley SP and Stage SA. 2001. Sonic anemometer tilt correction algorithms. Boundary-Layer Meteorology, 99, 127 - 150.

Wilson KB and Baldocchi DD. 2000. Seasonal and interannual variability of energy fluxes over a broadleaved temperate deciduous forest in North America. Agricultural and Forest Meteorology, 100, $1-18$.

Wilson GW, Fredlund DG, Barbour SL. 1997. The effect of soil suction on evaporative fluxes from soil surfaces. Canadian Geotechnical Journal, 34, 145-155.

Wyngaard JC and Coté OR. 1972. Cospectral similarity in the atmospheric surface layer. Quarterly Journal of the Royal Meteorological Society, 98, 590 - 603.

Yanful EK, Bell AV, Woyshner MR. 1993. Design of a composite soil cover for an experimental waste rock pile near Newcastle, New Brunswick, Canada. Canadian Geotechnical Journal, 30, 578-587. 